\author{
UNIVERSIDADE DE SÃO PAULO \\ FACULDADE DE MEDICINA DE RIBEIRÃO PRETO
}

\title{
HARIANE CÔco
}

Consequências da hiperhomocisteinemia sobre a resposta à endotelina-1 e fenilefrina em corpo cavernoso de ratos

Ribeirão Preto

2012 
Consequências da hiperhomocisteinemia sobre a resposta à endotelina-1 e fenilefrina em corpo cavernoso de ratos

\author{
Dissertação apresentada à \\ Faculdade de Medicina de Ribeirão \\ Preto da Universidade de São Paulo \\ para obtenção do título de Mestre \\ em Farmacologia.
}

Área de concentração:

Farmacologia

Orientadora: Profa Dra. Ana Maria de Oliveira

Ribeirão Preto

2012 
Autorizo a reprodução e divulgação total ou parcial deste trabalho, por qualquer meio convencional ou eletrônico, para fins de estudo e pesquisa, desde que citada a fonte.

Departamento Técnico do Sistema Integrado de Bibliotecas da USP Universidade de São Paulo

Côco, Hariane

Consequências da hiperhomocisteinemia sobre a resposta à endotelina-1 e fenilefrina em corpo cavernoso de ratos. Ribeirão Preto, 2012.

126 p. : il. ; $30 \mathrm{~cm}$

Dissertação de Mestrado, apresentada à Faculdade de Medicina de Ribeirão Preto/USP. Área de concentração: Farmacologia.

Orientadora: De Oliveira, Ana Maria.

1. Hiperhomocisteinemia. 2. Corpo cavernoso. 3. Endotelina-1. 4. Fenilefrina. 
Nome: CÔCO, Hariane.

Título: Consequências da hiperhomocisteinemia sobre a resposta à endotelina-1 e fenilefrina em corpo cavernoso de ratos.

Dissertação apresentada à Faculdade de Medicina de Ribeirão Preto da Universidade de São Paulo para obtenção do título de Mestre em Farmacologia.

Aprovada em:

Banca Examinadora

Prof. Dr.

Instituição:

Julgamento:

Assinatura:

Prof. Dr.

Instituição:

Julgamento:

Assinatura:

Prof. Dr.

Instituição:

Julgamento:

Assinatura: 
Aos mens pais, Wagner e Marcela, è à minha irmá Jéssica. Vocês foram $\sigma$ aticerce para que en conseguisse continuar minha caminhada. Sow imensamente grata por tudo. Amo muito vocês! 


\section{AGRADECIMENTOS}

À Deus por tudo que me permite alcançar a cada dia.

À profa. Dra Ana Maria de Oliveira pela orientação no desenvolvimento deste projeto, por todo apoio, confiança e amizade. Seus ensinamentos contribuiram imensamente para meu crescimento intelectual e pessoal.

Ao prof. Dr. Carlos Renato Tirapelli, membro da banca examinadora, pelo apoio, colaboração e valiosas sugestões durante o desenvolvimento deste projeto.

À profa. Dra. Luciana Venturini Rossoni do Instituto de Ciências Biomédicas - USP, pela disponibilidade para participar da banca examinadora e por contribuir muito na etapa final deste trabalho.

À profa. Dra. Leandra Naira Zambelli Ramalho pela colaboração com a preparação e análise do material histológico e imunohistoquímica.

Ao prof. Dr. José Eduardo Tanus dos Santos e ao técnico de seu laboratório Dr. Riccardo Lacchini pela disponibilidade e colaboração com os experimentos de PCR.

À profa. Dra. Evelin Cappelari Carnio da Escola Enfermagem de Ribeirão Preto USP e ao técnico de seu laboratório Marcelo Eduardo Batalhão pela disponibilidade e colaboração com as dosagens de nitrato.

Ao prof. Dr. Norberto Peporine Lopes e aos alunos de pós-graduação Michael Niehues e Dayana Rubio Gouvea, grupo NPPNS da Faculdade de Ciências Farmacêuticas de Ribeirão Preto - USP, pelas incansáveis tentativas na padronização do método de dosagem da homocisteina plasmática.

Ao prof. Dr. Roy Larson e à técnica do laboratório de microscopia confocal, Tatiane Ramos Santos, pela disponibilidade e apoio. 
À Faculdade de Medicina de Ribeirão Preto (FMRP) - USP pela oportunidade de realização do curso de mestrado.

À Faculdade de Ciências Farmacêuticas de Ribeirão Preto (FCFRP) - USP por colocar à disponibilidade a área experimental.

À Mayara Santos Gomes, técnica do laboratório de Farmacologia, pelo auxílio em todos os momentos durante $\mathrm{o}$ desenvolvimento deste projeto e por ser extremamente prestativa. Muito obrigada por estar sempre disponível, pela agradável convivência, amizade e por todo apoio técnico.

À Marlene Rodrigues da Silva, secretária da disciplina de Farmacologia da FCFRPUSP, por todo carinho, atenção e auxílio.

À Larissa Pernomian e Priscila Cristina Pereira, amigas do nosso grupo de pesquisa, pelo carinho, amizade e companheirismo. Obrigada por todo apoio experimental e discussões de resultados.

Às funcionárias do laboratório de Farmacologia, Miriam Cristina C. de Melo, Flávia F. Salata, Juliana Aparecida Vercesi, Aparecida Rosa da Silva (Dona Nina), Marcella Grando pela amizade e auxílio.

Aos docentes da disciplina de Farmacologia da FCFRP-USP, Prof. Dra. Glória Emília Petto de Souza, Prof. Dra. Lusiane Maria Bendhack, Profa. Dra. Sâmia Regina Lourenço Joca e Profa. Dra Sandra Y. Fukada Alves pelos ensinamentos e convivência.

Aos funcionários do Departamento de Farmacologia da FMRP-USP, Sonia Maria Stefanelli de Andrade, Fátima Helena Pentean e José Waldik Ramon e da seção de pós-graduação da FMRP-USP, por todo carinho e atenção.

Aos funcionários do biotério da FCFRP-USP, pelo cuidado com os animais utilizados em nossos estudos, especialmente ao Reinaldo Fernando Batista por todo apoio. 
Aos amigos da Farmacologia, Alejandro Ferraz de Prado, Alessandra Fedoce, Ariandra G. Sartim, Bruno Rodrigues da Silva, Cassiano Diniz, David, Débora Ramos, Dênis de M. Soares, Deidiane, Fernanda Aparecida de Andrade, Flávia Silva, Janaina Aparecida, Junior Ferreira, Laena Pernomian, Letícia Nogueira, Maria José Figueiredo (Zezé), Sara Hott, Tamy Midori Banin, Dra. Vânia de Rezende, Vinicius A. H. Sato, Vitor Silva Pereira, por toda amizade, incentivo e bons momentos.

À Laena Pernomian e Letícia Nogueira, um agradecimento mais que especial. La, obrigada por estar sempre presente e por tornar esta etapa mais alegre; tua amizade e companheirismo foram essenciais! Lê, tua amizade e colaboração foram preciosas, sem teu apoio com certeza tudo seria mais difícil!

À Sarah Blima, amiga e companheira de república, pela convivência, paciência e todo apoio nos momentos mais difíceis.

Aos amigos de Santa Rita do Passa Quatro, Daniela Leitão Delsin, Claudio Rozante, Micheli Furtado, Patricia Clapis e Carine Brito Penha por toda amizade e momentos alegres que passamos juntos, por poder sempre contar com vocês.

À minha família: meus pais, Marcela e Wagner, e minha irmã Jéssica, por apoiaremme em todas as minhas decisões e fornecerem suporte para a busca de meus sonhos e realizações, mesmo quando as condições eram bastante adversas; meus avós Roque e Pedrina, Frederico (in memorian) e Rosa, pela ajuda e carinho incondicionais; Dara, por trazer riso e alegria à minha vida. Vocês são preciosos!

Ao apoio financeiro da FAPESP (processo: 2010/03614-1), CNPq e CAPES. 
"Que os vossos esforços desafiem as impossibitidades, lembrai-vos de que as grandes coisas do homem foram conquistadas do que parecia impossivel." Charles Chaplin 


\section{RESUMO}

CÔCO, H. Consequências da hiperhomocisteinemia sobre a resposta à endotelina-1 e fenilefrina em corpo cavernoso de ratos. 2012. 126p. Dissertação (mestrado) - Faculdade de Medicina de Ribeirão Preto, Universidade de São Paulo, Ribeirão Preto, 2012.

A hiperhomocisteinemia (HHcy) tem sido associada à disfunção endotelial, em decorrência do aumento de ânion superóxido $\left(\mathrm{O}_{2}^{-}\right)$e redução da biodisponibilidade de óxido nítrico (NO), fatos estes que poderiam acarretar disfunção erétil. O objetivo deste trabalho foi estudar as consequências da HHcy sobre as respostas à endotelina-1 (ET-1) e fenilefrina (PhE) em corpos cavernosos de ratos, bem como os mecanismos envolvidos. Os animais foram divididos em dois grupos, os quais receberam água (controle) ou DL-homocisteina tiolactona (DL-HcyT, grupo HHcy), na dose de 1 g/Kg/dia, via oral por 15 dias. Análises morfológicas, de colágeno e expressão de a-actina não revelaram macroalterações na estrutura de corpos cavernosos de ratos HHcy, sugerindo que alterações na funcionalidade destes tecidos não decorrem de modificações estruturais. A HHcy acarretou aumento dos níveis de $\mathrm{O}_{2}{ }^{-}$em corpos cavernosos de ratos, avaliados por microscopia confocal. A reatividade vascular foi avaliada para $\mathrm{KCl}$, nitroprussiato de sódio (NPS), acetilcolina (ACh), ET-1, IRL-1620 e PhE. Não foram observadas alterações na reatividade vascular para $\mathrm{KCl}$ ou NPS. O relaxamento induzido por $\mathrm{ACh}$ foi reduzido em corpos cavernosos de ratos HHcy. A contração induzida por ET-1, via receptores $E T_{A}$, mostrou-se aumentada em corpos cavernosos de ratos HHcy, sugerindo possível envolvimento de $\mathrm{O}_{2}^{-}$basais em vias intracelulares, decorrentes da ativação de receptores $\mathrm{ET}_{\mathrm{A}}$. Observou-se prejuízo do relaxamento induzido por ET-1 e IRL-1620 em corpos cavernosos de ratos $\mathrm{HHcy}$, por ativação de receptores $\mathrm{ET}_{\mathrm{B}}$. O prejuízo do relaxamento induzido por $I R L-1620$ foi decorrente da produção e/ou biodisponibilidade reduzida de NO. A expressão de RNAm para pré-pró-ET-1, enzima conversora de $E T-1$ e receptores $E T_{A}$ e $E T_{B}$ não foram alteradas em decorrência da HHcy. O Emax da PhE foi aumentado em corpos cavernosos de ratos $\mathrm{HHcy}$, em decorrência de aumento nos níveis basais de $\mathrm{O}_{2}^{-}$e redução de 
fatores moduladores negativos da contração, tal como peróxido de hidrogênio $\left(\mathrm{H}_{2} \mathrm{O}_{2}\right)$, sugerindo possível prejuízo da enzima superóxido dismutase. A participação de metabólitos derivados da isoformas da enzima óxido nítrico sintase (NOS), eNOS, nNOS e iNOS que modulam negativamente a contração da PhE, mostraram-se importantes nesta resposta. $\mathrm{Na} \mathrm{HHcy,} \mathrm{os} \mathrm{metabólitos} \mathrm{derivados} \mathrm{principalmente} \mathrm{da}$ iNOS estão prejudicados, possivelmente por redução da atividade da NOS, processo de desacoplamento e/ou redução da biodisponibilidade de NO por interação com espécies reativas de oxigênio (ERO), formando peróxinitrito. A expressão de nitrotirosina, indicador da presença de peroxinitrito, não foi alterada em corpos cavernosos de ratos $\mathrm{HHcy}$. As dosagens plasmáticas de nitrato mostraram redução dos níveis de $\mathrm{NO}$ em ratos $\mathrm{HHcy}$, sendo sugestivo de redução de sua biodisponibilidade. A HHcy não alterou a expressão de RNAm para eNOS, nNOS e iNOS em corpos cavernosos de ratos. Os metabólitos da enzima cicloxigenase-1 (COX-1) e COX-2 participam modulando negativamente a contração da $\mathrm{PhE}$ e a HHcy não alterou esta modulação. Concluindo, a HHcy intermediária, por sua capacidade de aumentar os níveis basais de $\mathrm{O}_{2}^{-}$, pode afetar a função vasoativa, contração e relaxamento, do peptídeo ET-1, bem como aumentar a resposta de contração à $\mathrm{PhE}$ em decorrência de prejuízo de $\mathrm{H}_{2} \mathrm{O}_{2}$ e redução de metabólitos derivados da iNOS em corpos cavernosos de ratos.

Palavras chaves: hiperhomocisteinemia, corpo cavernoso, endotelina-1, fenilefrina. 


\section{ABSTRACT}

\section{CÔCO, H. Consequences of hyperhomocysteinemia on the response to}

endothelin-1 and phenylephrine in rats corpus cavernosum. 2012. 126p. Thesis (Master degree) - School of Medicine from Ribeirão Preto, University of São Paulo, Ribeirão Preto, 2012.

Hyperhomocysteinemia (HHcy) has been associated with endothelial dysfunction, due to the increase in superoxide anion $\left(\mathrm{O}_{2}{ }^{-}\right)$and reduced bioavailability of nitric oxide (NO), these facts could result in erectile dysfunction. The objective of this work was to study the consequences of HHcy on the responses to endothelin-1 (ET-1) and phenylephrine (PhE) in rat corpus cavernosum, as well as the mechanisms involved. The animals were divided into two groups, which received water (control) or DLhomocysteine thiolactone (DL-HcyT; HHcy group) at a dose of $1 \mathrm{~g} / \mathrm{kg} /$ day for 15 days orally. Morphological analysis and collagen and expression of $\alpha$-actin revealed no considerable alterations in the structure of the corpus cavernosum of HHcy rats, suggesting that alterations in the functionality of these tissues are not based on structural modifications. The HHcy resulted in increased levels of $\mathrm{O}_{2}^{-}$in corpus cavernosum of rats, assessed by confocal microscopy. Vascular reactivity was assessed for substances $\mathrm{KCl}$, sodium nitroprusside (SNP), acetylcholine (ACh), ET1, IRL-1620 and PhE. There were no changes in vascular reactivity to $\mathrm{KCl}$ or NPS. The relaxation induced by $\mathrm{ACh}$ was reduced in HHcy rat corpus cavernosum. The contraction induced by $\mathrm{ET}-1$, by $\mathrm{ET}_{\mathrm{A}}$ receptors, was increased in corpus cavernosum of $\mathrm{HHcy}$ rats, suggesting possible involvement of basal $\mathrm{O}_{2}^{-}$in intracellular pathways by activation of $E T_{A}$ receptors. There was prejudice to the relaxation to $E T-1$ and IRL1620 in HHcy rat corpus cavernosum by activation of $\mathrm{ET}_{\mathrm{B}}$ receptors. The decreased $\mathrm{IRL}-1620$-induced relaxation was due to the reduced production and/or bioavailability of NO.The expression of mRNA for pre-pro-ET-1, endothelin converting enzyme and $\mathrm{ET}_{\mathrm{A}}$ and $\mathrm{ET}_{\mathrm{B}}$ receptors were not altered in HHcy. The Emax of PhE was increased in $\mathrm{HHcy}$ rat corpus cavernosum, due to increase in basal levels of $\mathrm{O}_{2}^{-}$and reducing negative modulators factors of the contraction, such as hydrogen peroxide $\left(\mathrm{H}_{2} \mathrm{O}_{2}\right)$, suggesting possible loss of the enzyme superoxide dismutase (SOD). The 
participation of metabolites derived from eNOS, nNOS and iNOS, that modulate negatively PhE-induced contraction appear to be important in this response. In HHcy, these metabolites, derived primary from iNOS, are damaged, possibly by reducing the activity of NOS, the process of decoupling and/or reduced bioavailability of NO by interaction with reactive oxidative species (ROS) to form peroxynitrite. The expression of nitrotyrosine, inidicador the presence of peroxynitrite, was not altered in HHcy rat corpus cavernosum. Plasma levels of nitrate showed reduced levels of $\mathrm{NO}$ in HHcy rats, being suggestive of reduced bioavailability. The HHcy did not alter the expression of mRNA for eNOS, iNOS and nNOS in rat corpus cavernosum. The metabolites of the enzyme cyclooxygenase-1 (COX-1) and COX-2 participate negatively modulating the contraction of $\mathrm{PhE}$ and $\mathrm{HHcy}$ does not seem to change this modulation. In conclusion, intermediate HHcy, by its ability to increase basal levels of $\mathrm{O}_{2}{ }^{-}$, may affect the vasoactive function, contraction and relaxation of ET-1 peptide, as well as increase the contraction induced by $\mathrm{PhE}$ due to decrease of $\mathrm{H}_{2} \mathrm{O}_{2}$ and reduced of the metabolites derived from iNOS in rat corpus cavernosum.

Keywords: hyperhomocysteinemia, corpus cavernosum, endothelin-1, phenylephrine. 


\section{LISTA DE ABREVIATURAS, SIGLAS E SÍMBOLOS}

AARS enzima aminoacil-RNAt-sintetase

AC adenilato ciclase

ACh acetilcolina

ANOVA análise de variância

ATP adenosina trifosfato

BHMT betaína-homocisteina metiltransferase

Big-ET-1 big-endotelina-1

$\mathrm{CaCl}_{2} \quad$ cloreto de cálcio

C $\beta S$ enzima cistationina-beta-sintetase

cm centímetro

$\mathrm{CO}_{2}$ gás carbônico

COX enzima cicloxigenase

$\mathrm{Ct} \quad$ ciclo threshold

DAG diacilglicerol

DEPC dietil pirocarbonato

DHE sonda dihidroetidina

DL-HcyT DL-homocisteina tiolactona

DMSO dimetil sulfóxido

$\mathrm{EC}_{50}$ concentração de droga que produz $50 \%$ do efeito máximo

ECE enzima conversora de endotelina

Emax efeito máximo desencadeado pelo agonista

eNOS enzima óxido nítrico sintase endotelial

EPM erro padrão da média

ERK1/2 quinase regulada por sinal extracelular 1 e 2

ERO espécies reativas de oxigênio

ET-1 endotelina-1

g grama

GC guanilato ciclase

GMPc guanosina cíclica

GTP guanosina trifosfato

$\mathrm{HCl}$ ácido clorídrico

Hcy homocisteina

HHcy hiperhomocisteinemia

$\mathrm{H}_{2} \mathrm{O}_{2}$ peróxido de hidrogênio 


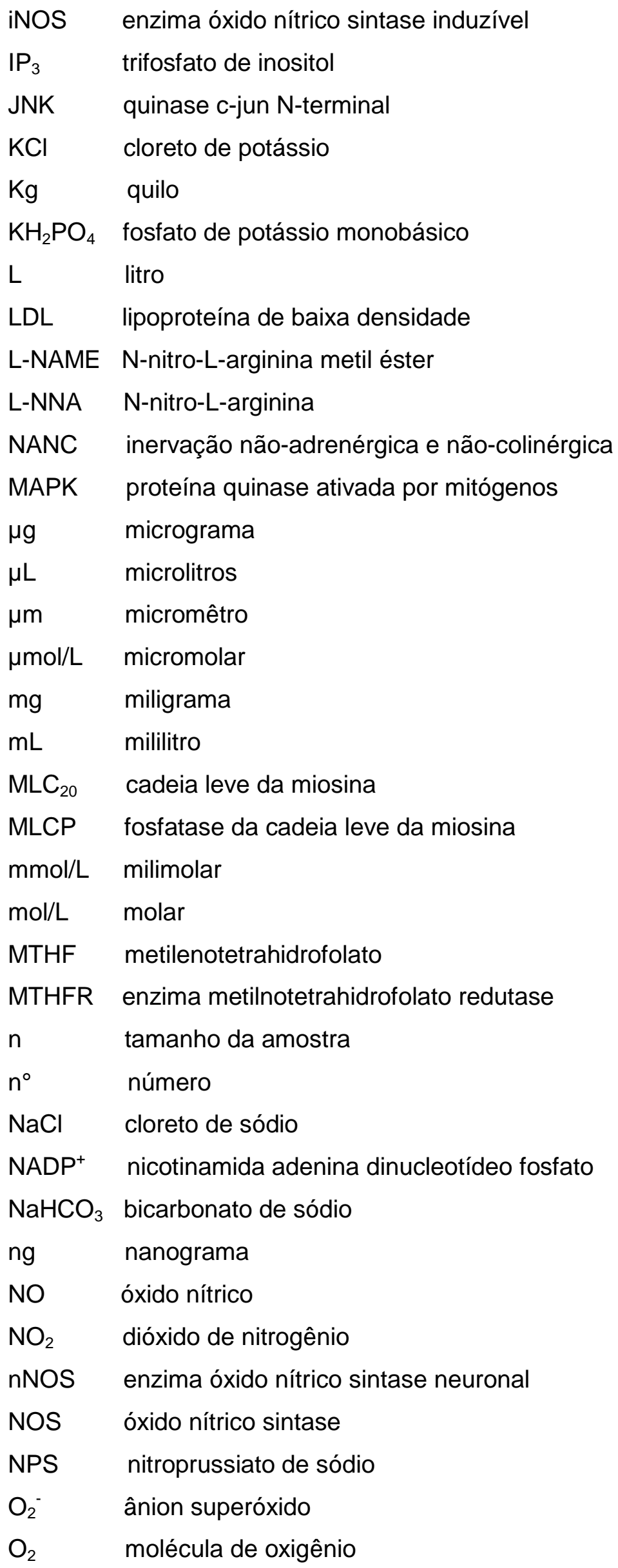


$\mathrm{O}_{3} \quad$ ozônio

$\mathrm{OH}^{-} \quad$ radical hidroxil

$P<0,05$ valor mínimo de probabilidade menor que 0,05 estatisticamente significativo

PBS tampão fosfato

PCR reação em cadeia da polimerase

$\mathrm{pD}_{2} \quad$ co-logaritmo da concentração de droga que produz $50 \%$ do efeito máximo

$\mathrm{PGD}_{2} \quad$ prostaglandina $\mathrm{D}_{2}$

$\mathrm{PGE}_{1} \quad$ prostaglandina $\mathrm{E}_{1}$

$\mathrm{PGE}_{2} \quad$ prostaglandina $\mathrm{E}_{2}$

$\mathrm{PGF}_{2 \alpha} \quad$ prostaglandina $\mathrm{F}_{2 \alpha}$

$\mathrm{PGH}_{2} \quad$ prostaglandina $\mathrm{H}_{2}$

$\mathrm{PGI}_{2} \quad$ prostaciclina

pH co-logaritmo da concentração de íons hidrogênio

$\mathrm{PhE} \quad$ fenilefrina

$\mathrm{PKC}$ proteina quinase $\mathrm{C}$

$\mathrm{PLA}_{2}$ fosfolipase $\mathrm{A}_{2}$

PLC fosfolipase $\mathrm{C}$

PPia peptidilprolil isomerase A

SAPK quinase ativada por estresse

SC-560 5-(4-clorofenil)-1-(4-metoxifenil)-3-(trifluorometil)-1H-pirazole

SOD enzima superóxido dismutase

TBE tampão tris-borato-EDTA

TBP tatabox binding protein

Tempol 4-hidroxitetrametil-L-piperidina-1-oxil

Tiron 4,5-dihidroxi-ácido-1,3-benzenodisulfonico dissódico monohidratado

$\mathrm{TXA}_{2} \quad$ tromboxana $\mathrm{A}_{2}$

UA unidade arbitrária

VOC canal para cálcio operado por voltagem

${ }^{\circ} \mathrm{C} \quad$ graus Celsius

1400W N-[3-(aminometil)benzil] acetamina

7-Ni 7-nitroindazol

40x quarenta vezes 


\section{SUMÁRIO}

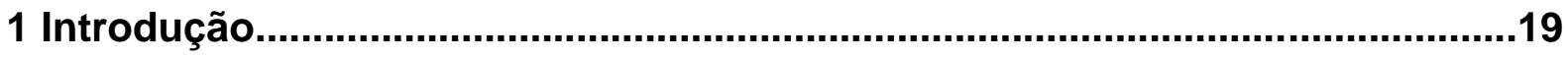

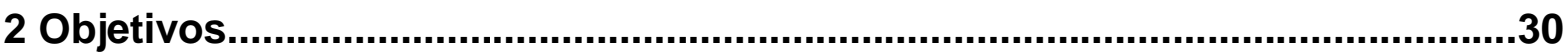

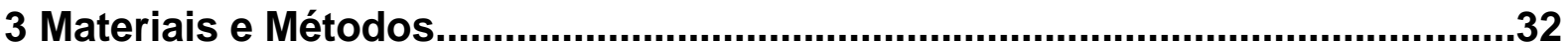

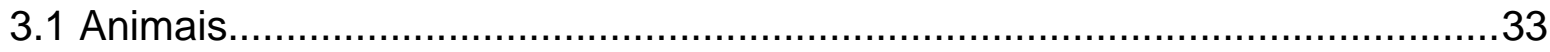

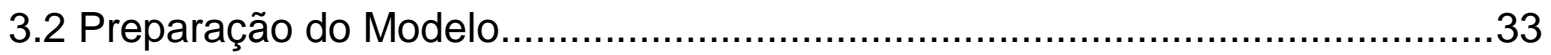

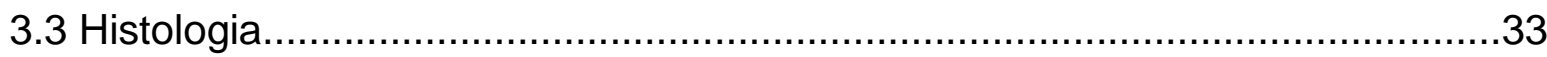

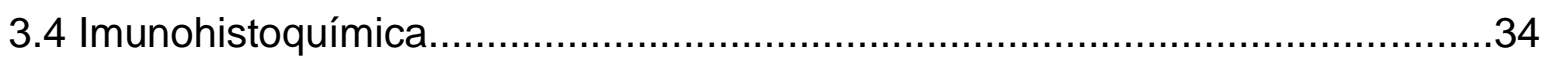

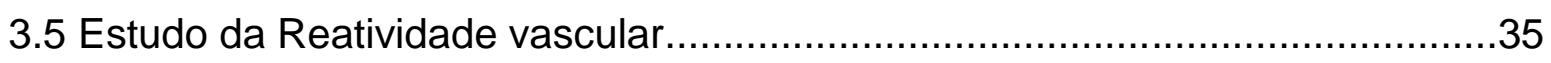

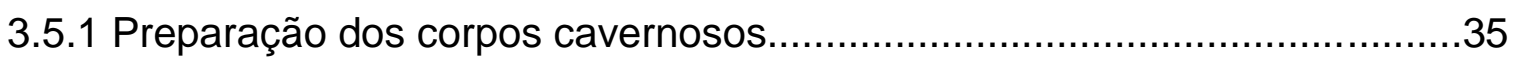

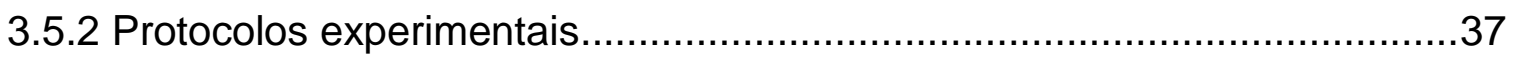

3.5.2.1 Efeito da HHcy sobre a contração induzida por ET-1 ............................37

3.5.2.2 Consequência da HHcy sobre a contração induzida por ET-1, em

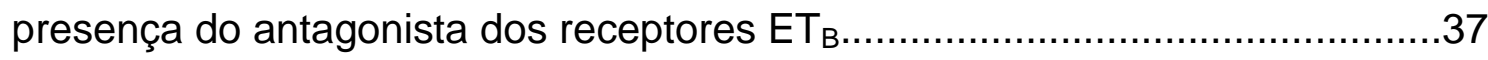

3.5.2.3 Consequência da HHcy sobre o relaxamento induzida por ET-1 ..........37

3.5.2.4 Consequência da HHcy sobre o relaxamento induzida por ET-1, em

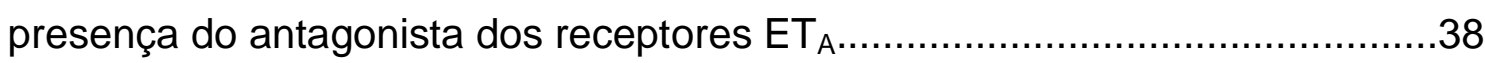

3.5.2.5 Consequência da HHcy sobre o relaxamento induzido por IRL-1620...38 3.5.2.6 Participação dos metabólitos da NOS sobre o relaxamento induzido por

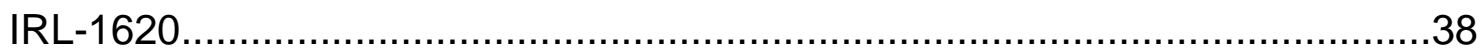

3.5.2.7 Consequência da HHcy sobre a contração induzida por $\mathrm{PhE} . . . \ldots \ldots \ldots . . . . .39$

3.5.2.8 Participação de ERO na contração desencadeada por $\mathrm{PhE}$..................39

3.5.2.9 Participação de metabólitos da NOS e de suas isoformas específicas na contração induzida por $\mathrm{PhE}$

3.5.2.10 Participação dos metabólitos da COX e de suas isoformas específicas

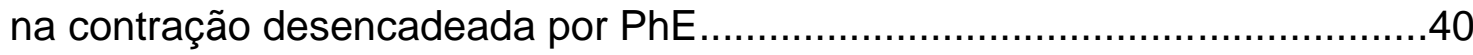

3.6 Produção de espécies reativas de oxigênio (ERO).......................................41

3.7 Reação em cadeia da polimerase em tempo real (Real Time-PCR)................41

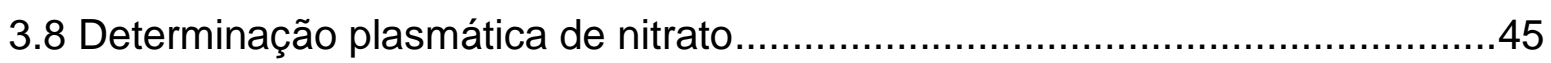

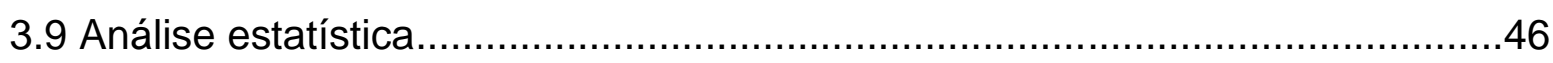

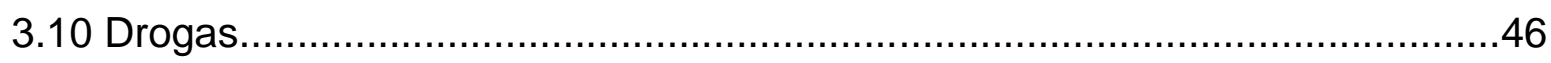


4.1 Consequência da HHcy sobre o peso dos animais......................................4

4.2 Consequência da HHcy sobre o peso seco de corpos cavernosos.................49

4.3 Efeito da HHcy sobre a morfologia de corpos cavernosos............................50

4.4 Efeito da HHcy sobre os depósitos de colágenos em corpos cavernosos.......51

4.5 Efeito da HHcy sobre a expressão de $\alpha$-actina.............................................52

4.6 Consequências da HHcy sobre as respostas induzida por $\mathrm{KCl}$, NPS e

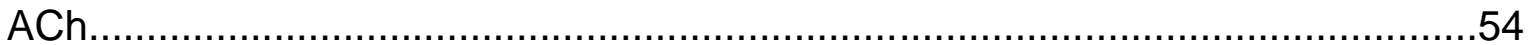

4.7 Efeito da HHcy sobre a contração induzida por ET-1 ....................................57

4.8 Consequência da HHcy sobre a contração induzida por ET-1, em presença do

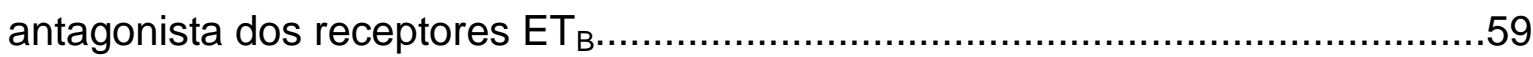

4.9 Consequência da HHcy sobre o relaxamento induzido por ET-1 ...................61

4.10 Consequência da HHcy sobre o relaxamento induzido por ET-1, em presença do antagonista dos receptores $\mathrm{ET}_{\mathrm{A}}$

4.11 Consequência da HHcy sobre o relaxamento induzido por IRL-1620_..........65

4.12 Participação dos metabólitos da NOS sobre o relaxamento induzido por IRL1620

4.13 Consequência da HHcy nos níveis basais de ERO e nos níveis produzidos por ET-1

4.14 Efeito da HHcy sobre a expressão do RNAm para pré-pró-ET, ECE e para os receptores $\mathrm{ET}_{\mathrm{A}}$ e $E \mathrm{~T}_{\mathrm{B}}$

4.15 Consequência da HHcy sobre a contração induzida por $\mathrm{PhE}$........................73

4.16 Participação de ERO na contração induzida por PhE...................................75

4.17 Consequência da HHcy nos níveis basais de ERO e nos níveis produzidos por $\mathrm{PhE}$

4.18 Participação de metabólitos da NOS e de suas isoformas específicas na contração induzida por $\mathrm{PhE}$

4.19 Efeito da HHcy sobre a expressão do RNAm para eNOS, nNOS e iNOS.....85

4.20 Efeito da HHcy sobre a expressão de nitrotirosina

4.21 Consequência da HHcy na concentração plasmática de nitrato

4.22 Participação de metabólitos da COX e de suas isoformas específicas na contração induzida por PhE. 


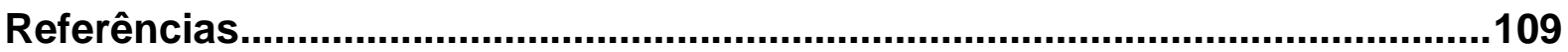

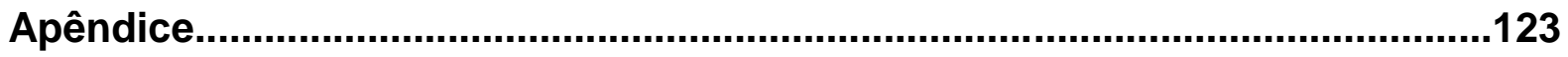

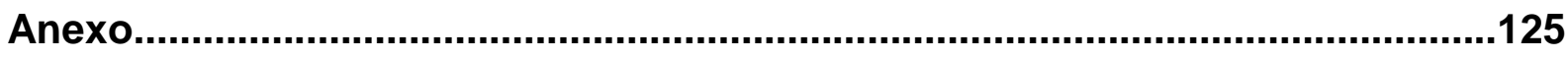


1 Introdução 
Em países ocidentais, pelo menos um em dez homens sofre de disfunção erétil. Esta disfunção é definida como a inabilidade para manter uma ereção suficiente que permita uma relação sexual satisfatória (NIH, 1993). No mundo, cerca de 150 milhões de homens sofrem dessa patologia e cerca de $52 \%$ destes estão entre os 40 e 70 anos de idade (LUE, 2000). No entanto, fatores sociais e culturais podem levar a diferentes percepções e relatos da patologia, tornando difícil a obtenção de estimativas precisas da incidência e prevalência real da disfunção erétil (MAAS et al., 2002).

O pênis é constituído por um par de estruturas eréteis situadas na porção dorsal, os corpos cavernosos, e por uma terceira estrutura que se localiza ventralmente, o corpo esponjoso, que rodeia e sustenta a uretra peniana. Ambos são envolvidos por uma cápsula de tecido conjuntivo denso, a túnica albugínea, cujas fibras se dispõem longitudinalmente na face externa e transversalmente na face interna, o que a torna mais espessa (LUE, 2003).

O interior de cada corpo cavernoso é constituído por pequenas cavidades vasculares, designadas sinusóides, lacunas ou espaços cavernosos, que são delimitados por endotélio, o que permite considerar o pênis um órgão essencialmente vascular. Os espaços sinusóides são sustentados por uma rede de trabéculas formadas por tecido muscular liso e conjuntivo, com fibras elásticas e de colágeno, onde existem numerosas arteríolas e terminações nervosas (LUE, 2003).

O controle do tônus do músculo liso cavernoso é um processo complexo que envolve três tipos de controle neurológico: adrenérgico, colinérgico e nãoadrenérgico e não-colinérgico (NANC) (SAENZ DE TEJADA et al., 1988).

As artérias e veias penianas, e o músculo liso cavernoso recebem uma rica inervação adrenérgica, e é geralmente aceito que o pênis se mantém em seu estado flácido principalmente via atividade tônica nestes nervos (ANDERSSON, 2001). O nervo simpático libera noradrenalina que induz a contração no músculo cavernoso (ANDERSSON, 2001), enquanto os nervos parassimpáticos medeiam o seu relaxamento (BURNETT et al., 1992).

A contração induzida por noradrenalina e fenilefrina $(\mathrm{PhE})$ em corpos cavernosos de humano é mediada por ativação dos receptores $\alpha_{1}$-adrenérgicos (CHRIST et al., 1990). Consequentemente, há redução do lúmen arteriolar e das cavidades sinusóides, restringindo o fluxo sanguíneo com a finalidade de manter 
uma baixa pressão intracavernosa e o pênis no estado flácido (BURNETT, 1995; ANDERSSON; STIEF, 1997; ANDERSSON, 2001).

A resposta erétil do pênis está associada ao músculo liso vascular na túnica média das artérias e arteríolas que carregam sangue dentro do corpo cavernoso, e também às células do músculo liso vascular que delineiam os sinusóides. 0 relaxamento destas células no início da resposta erétil permite aos sinusódes expandir e acomodar o aumento do influxo sanguíneo. Ao expandirem-se contra a túnica albugínea, os sinusóides comprimem as veias responsáveis pelo efluxo sanguíneo. A limitação do efluxo dependente da pressão constitui o processo venooclusivo. O resultante do aumento do influxo devido à dilatação arteriolar e a redução do efluxo resultante da veno-oclusão são a base da ereção peniana (MILLS et al., 1998).

O óxido nítrico (NO), sintetizado a partir do precursor L-arginina pela enzima óxido nítrico sintase (NOS), é um vasodilatador potente, fundamental para o relaxamento do músculo liso e do leito vascular do corpo cavernoso (RAJFER et al., 1992; BURNETT, 1995). O NO resultante da atividade da isoforma neuronal da NOS (nNOS) é considerado o principal fator responsável pelo relaxamento imediato do corpo cavernoso, enquanto que o produzido pela isoforma endotelial (eNOS) é essencial para a manutenção do relaxamento (ANDERSSON, 2003).

A liberação de NO, predominantemente pela ativação da enzima nNOS em nervos NANC e células endoteliais locais, estimula o relaxamento das células do músculo liso dos vasos e do corpo cavernoso (BURNETT, 1995; ANDERSSON; STIEF, 1997; ANDERSSON, 2001) pela ativação da enzima guanilato ciclase (GC) e consequente formação de guanosina cíclica (GMPc) (DEANFIELD et al., 2005).

Os prostanóides são originados da via metabólica do ácido araquidônico localizados no pênis. Foi evidenciado que as células musculares lisas do corpo cavernoso de humanos têm a habilidade de sintetizar vários prostanóides (ANDERSSON; WAGNER, 1995). Tomboxana (TX) $A_{2}$ e prostaglandina (PG) $F_{2 a}$ foram evidenciados como possíveis moduladores da contração do corpo cavernoso, por outro lado, $\mathrm{PGE}_{1}$ e $\mathrm{PGE}_{2}$ parecem modular o relaxamento desta estrutura (ANDERSSON, 2001).

O corpo cavernoso também possui vários peptídeos biologicamente ativos, como angiotensina II, angiotensina 1-7 e endotelina-1 (ET-1) (DE NICOLA et al., 1992; KIFOR et al., 1997; GRANCHI et al., 2002). A ET-1, um peptídeo composto 
por 21 resíduos de aminoácido, foi descrita como um potente vasoconstritor liberada pelo endotélio quando estimulado por fatores físicos e químicos (YANAGISAWA et al., 1988) e apresenta três isoformas isoladas, a ET-1, ET-2 e ET-3 (INOUE et al., 1989). A síntese da ET-1 ocorre a partir de diferentes pré-pró-ETs que são clivados por endopeptidases em pró-peptídeos, conhecidos como Big-endotelinas (Big-ET), que são convertidos em peptídeos pela ação da enzima conversora de ET, ECE (D'ORLÉANS-JUSTE et al., 2002).

As células endoteliais são a maior fonte de ET, com predominância da isoforma ET-1, no entanto, outros tecidos também podem sintetizá-la, incluindo células da musculatura lisa vascular, células não endoteliais do trato respiratório, gastrointestinal, renal e genito-urinário e algumas células nervosas (MASAKI et al., 1995).

A expressão de ambos os receptores do sistema $E T-1, E_{A}$ e $E T_{B}$, foi demonstrada em tecido cavernoso de humanos (GRANCHI et al., 2002) e diversas espécies animais como coelho (HOLMQUIST et al., 1992), rato (BELL et al., 1995; DAl et al., 2000) e bovinos (PARKKISENNIEMI \& KLINGE, 1996). A ET-1 induz vasoconstrição do tecido cavernoso in vivo predominantemente por meio da ativação de receptores $\mathrm{ET}_{\mathrm{A}}$ (DAl et al., 2000). No pênis, os efeitos biológicos da ET-1 envolvem a formação do trifosfato de inositol $\left(\mathrm{IP}_{3}\right)$, aumento da concentração intracelular de cálcio e a ativação da via de sinalização da Rho-A/Rho-quinase (MILLS et al., 2001). A Rho-A é uma pequena proteína G que é ativada pela ligação ao GTP e que pertence a uma família de genes homólogos da Ras (Rho), membro A (Rho-A). A ativação da Rho-A estimula efetores tais como a Rho-quinase ou ROCK. A Rho-quinase ativada induz a fosforilação da subunidade regulatória da fosfatase da cadeia leve da miosina (MLCP) e inibe a atividade desta, tendo como efeito final a inibição da defosforilação da cadeia leve da miosina $\left(\mathrm{MLC}_{20}\right)$ e favorecendo a contração do músculo liso e consequente flacidez do corpo cavernoso (LEITE et al., 2007). Além disso, a ativação da via Rho-A/Rho-quinase pela ET-1, via receptores $E_{\mathrm{A}}$, induz redução da expressão da eNOS em corpo cavernoso (CARNEIRO et al., 2008).

Outra via de sinalização ativada pela ET-1 no corpo cavernoso é a via das Proteínas Quinase Ativadas por Mitógenos (MAPKs - Mitogen-Activated Protein quinases) (CARNEIRO et al., 2008). Pelo menos três cascatas de MAPKs distintas e paralelas foram identificadas incluindo MAPKp42/44, que também são chamadas de 
quinases reguladas por sinal extracelular (ERK1/2 - extracellular signal-regulated kinases 1 and 2), MAPKp38 e quinase c-jun $\mathrm{N}$-terminal ou quinase ativada por estresse (JNK/SAPK - c-jun N-terminal kinase or stress activated protein kinase). As MAPKs fazem parte da cascata de sinalização intracelular que controla processos como diferenciação e proliferação celular, expressão de proteínas envolvidas na adesão de leucócitos e contração vascular (TOUYZ; SCHIFFRIN, 2000). A contração vascular mediada pelas MAPKs em resposta à ET-1 envolve a ativação de receptores $\mathrm{ET}_{\mathrm{A}}$ com consequente aumento da concentração de cálcio intracelular (ZUBKOV et al., 2004).

$A$ ativação dos receptores $\mathrm{ET}_{\mathrm{B}}$ no corpo cavernoso induz vasodilatação principalmente via liberação de NO (ARI et al., 1996). O NO pode influenciar a resposta erétil por ativação direta da via de relaxamento do músculo liso ou pela atenuação da ação vasoconstritora da ET-1 (MILLS et al., 2001a). Em ratos, a injeção intrapeniana de ET-1 induz um efeito bifásico dose-dependente. Doses mais baixas induzem um efeito vasodilatador, enquanto doses mais altas, um efeito vasoconstritor (ARI et al., 1996). Os autores sugerem que os efeitos deste peptídeo são dependentes do quanto e do local onde são liberados.

A administração oral de atrasentan, um antagonista dos receptores $\mathrm{ET}_{\mathrm{A}}$, preveniu, in vitro, o efeito de contração à ET-1 em corpo cavernoso de ratos hipertensos (CARNEIRO et al., 2008). Os autores também observaram que o agonista dos receptores $\mathrm{ET}_{\mathrm{B}}$, IRL-1620 produziu relaxamento das tiras de corpo cavernoso pré-contraídas com PhE. Este relaxamento foi prejudicado em corpos cavernosos de animais hipertensos. Carneiro et al. (2008) sugeriram que as alterações funcionais à ET-1 e ao IRL-1620 em corpos cavernosos de animais hipertensos estão associadas ao aumento da atividade de vias de sinalização da Rho-A/Rho-quinase e ERK 1/2 e redução da expressão da eNOS.

$\mathrm{Na}$ diabetes mellitus tipo I, as respostas contráteis para a ET-1 estão aumentadas no corpo cavernoso (CHANG et al., 2003). Esse aumento está associado à maior expressão de receptores $\mathrm{ET}_{\mathrm{A}}$ e ativação da via de sinalização da Rho-quinase. Isso acarreta aumento da atividade contrátil da ET-1 e redução da atividade dos mecanismos moleculares responsáveis pelo relaxamento do tecido cavernoso no diabetes (CHANG et al., 2003).

Dieta rica em lipídeos associada à obesidade causa alterações metabólicas que acarretam detumescência peniana em camundongos. Essas alterações são 
decorrentes de resposta de relaxamento reduzida via ativação de nervos NANC e aumento das respostas de contração desencadeadas por ativação de receptores $\alpha_{1}{ }^{-}$ adrenérgicos e receptores para ET-1 (TOQUE et al., 2010).

Os fatores de risco para a disfunção erétil estão associados à redução da biodisponibilidade de $\mathrm{NO}$ e aumento da formação de ânion superóxido $\left(\mathrm{O}_{2}{ }^{-}\right)$ (JEREMY et al., 2006; JONES et al., 2005), incluindo diabetes mellitus, hipertensão, dislipidemia e mais recentemente à hiperhomocisteinemia (HHcy). Assim, a disfunção endotelial pode ser um fator determinante na disfunção erétil (MAAS et al., 2002).

A homocisteina (Hcy, ácido 2-amino 4-mercaptobutírico) é um aminoácido sulfurado, não protéico (FINKELSTEIN, 1990), altamente reativo (HARKER et al., 1976) formado exclusivamente como um produto intermediário do metabolismo intracelular do aminoácido metionina ingerida na dieta (FINKELSTEIN, 1990). A Hcy é precursora de compostos vitais para a sobrevivência humana, tais como a metionina e cisteína, aminoácidos essenciais para a síntese de proteínas e enzimas (WALL et al., 1980).

O metabolismo intracelular da Hcy ocorre por meio de duas vias de remetilação, responsáveis pela conversão da Hcy em metionina, e uma via de transulfuração, que converte a Hcy em cisteína. Essas vias são dependentes das vitaminas $B_{6}, B_{12}$ e folato, que atuam como coenzimas ou cossubstratos (Figura 1). 


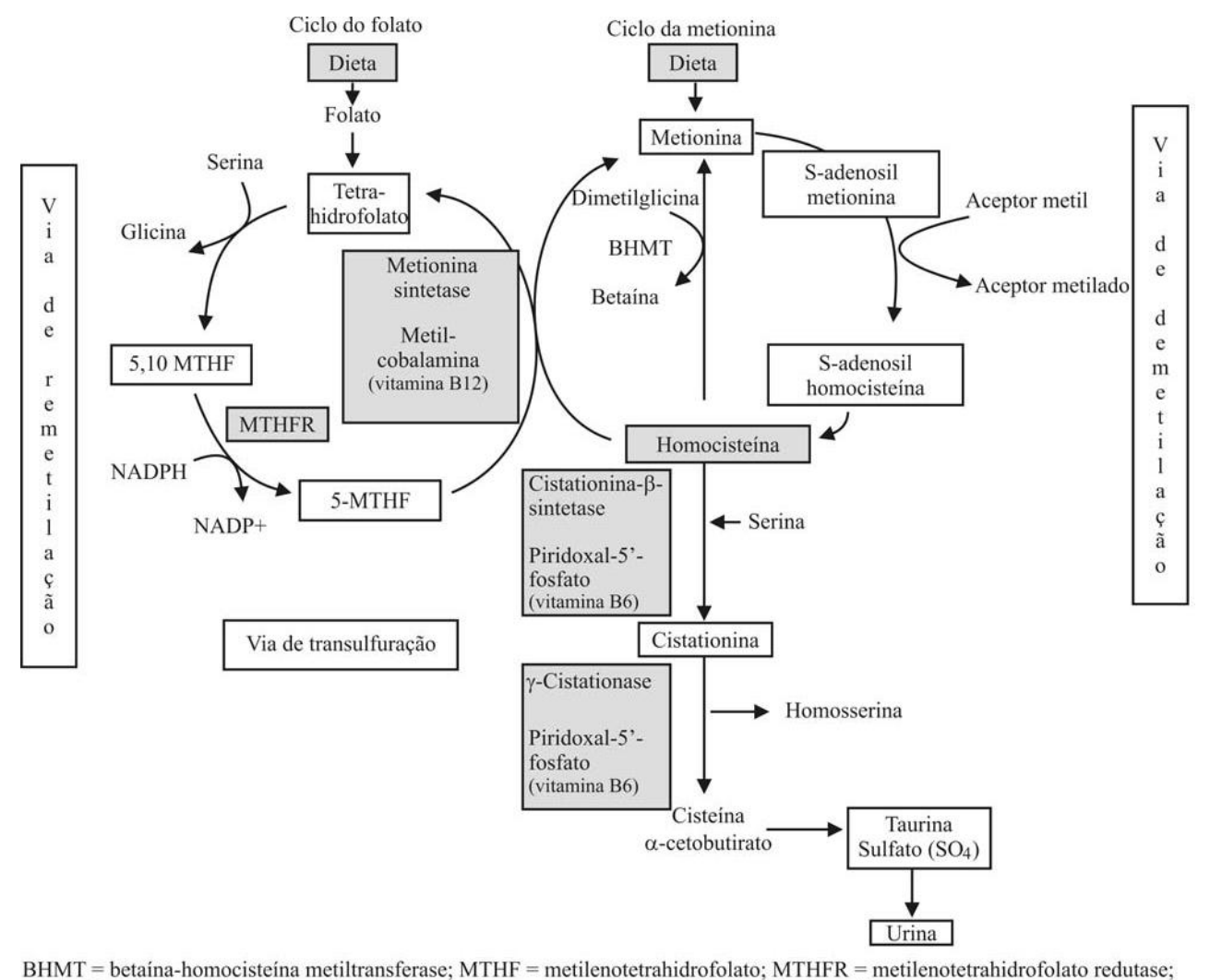

$\mathrm{NADPH}=$ nicotinamida adenina dinucleotideo fosfato na forma reduzida; NADP+ nicotinamida adenina dinucleotideo fosfato.

Figura 1: Representação esquemática das vias de metabolização da Hcy (RICHTER et al., 2000)

Em uma das vias de remetilação, o doador do grupo metil é 0 5metilenotetrahidrofolato (5-MTHF), forma principal do folato no plasma, produzido a partir da redução do 5,10-metilenotetrahidrofolato pela enzima metilenotetrahidrofolato redutase (MTHFR). A transferência do grupo metil para a Hcy é feita mediante ação da enzima metionina sintetase, que tem como cofator a metilcobalamina, uma coenzima derivada da cobalamina (vitamina $\mathrm{B}_{12}$ ). Subsequentemente, uma nova molécula de 5-MTHF é sintetizada pela transferência de um átomo de carbono (de uma fonte de carbono como serina) para uma molécula de tetrahidrofolato (SELHUB, 1999) (Figura 1).

$\mathrm{Na}$ outra via de remetilação (demetilação), que acontece principalmente no fígado, o doador do grupo metil para a conversão da Hcy em metionina é a betaína. Uma vez formada, a metionina é ativada pela adenosina trifosfato (ATP), formando S-adenosil-metionina, que funciona como doador de grupo metil para uma diversidade de receptores. O produto dessas reações de metilação é a S-adenosilhomocisteina, a qual é hidrolisada regenerando a Hcy, que se torna disponível para iniciar um novo ciclo de transferência de grupos metil (SELHUB; MILLER, 1992) (Figura 1). 
$\mathrm{Na}$ via de transulfuração, inicialmente a Hcy se condensa com uma molécula de serina para formar cistationina em reação irreversível que é catalisada pela enzima cistationina-beta-sintetase (CBS) e que tem como cofator o piridoxal-5'fosfato, um derivado da piridoxina ou vitamina $\mathrm{B}_{6}$. Posteriormente, a cistationina é hidrolisada em cisteína e ácido alfa-cetobutirato, reação esta que também requer vitamina $B_{6}$ e é catalisada pela enzima gama-cistationase. Desta forma, além da produção de cisteína, a via de transulfuração é responsável pelo catabolismo da Hcy tóxica, que não é necessária no ciclo de transferência de grupos metil. Portanto, essa via de metabolização visa à excreção renal da Hcy, diminuindo a concentração sérica desse aminoácido. Em condições metabólicas normais, a metabolização da Hcy é distribuída igualmente entre essas duas vias, que são coordenadas e competem pela utilização da Hcy disponível (SELHUB; MILLER, 1992) (Figura 1).

A concentração plasmática normal de Hcy quando analisada em jejum é de aproximadamente $10 \mu \mathrm{mol} / \mathrm{L}$ (SCHNYDER et al., 2002). Acima desses valores caracteriza-se a HHcy (UELAND et al., 1993). Kang et al. (1992) classificaram a HHcy nas formas grave, para concentrações maiores que $100 \mu \mathrm{mol} / \mathrm{L}$, intermediária, para concentrações entre 31 e $100 \mu \mathrm{mol} / \mathrm{L}$, e moderada, para concentrações entre 15 e $30 \mu \mathrm{mol} / \mathrm{L}$. As causas mais comuns de HHcy na população em geral estão relacionadas aos defeitos genéticos na codificação de enzimas ou à deficiência nutricional de vitaminas que estão envolvidas no metabolismo da Hcy. A concentração plasmática de Hcy está inversamente associada às concentrações sanguíneas de folato, vitamina $B_{6}$ e $B_{12}$ (SELHUD et al., 1993).

O aumento da concentração plasmática de Hcy promove prejuízo da função endotelial (CHAMBERS et al., 1999). Os mecanismos pelos quais a Hcy promove lesão endotelial e proliferação de células musculares envolvem a homocisteinilização de proteínas (JAKUBOWSKI, 2000, 2002) e a formação de espécies reativas de oxigênio $(E R O)$ decorrente do processo de auto-oxidação da Hcy (WANG et al., 2000).

No processo chamado de homocisteinilização, inicialmente ocorre conversão de Hcy para Hcy-tiolactona na célula por atividade da enzima aminocil-RNAtsintetase (AARS). A Hcy-tiolactona, formada na célula, interage com proteínas pelo mecanismo que envolve a homocisteinilização de resíduos de lisina das cadeias protéicas. Entre estas cadeias, pode-se destacar hemoglobina, albumina, gamaglobulina, transferrina, fibrinogênio, lipopoteína de baixa densidade (LDL), entre 
outros. Quanto maior a quantidade de resíduos de lisina, maior será o processo de homocisteinilização. As proteínas homocisteinilizadas tornam-se menos solúveis e tem sua atividade normal abolida ou diminuída. Além disso, o complexo Hcytiolactona-proteínas pode ser reconhecido por macrófagos desencadeando a fagocitose das células do endotélio, acarretando lesão endotelial (JAKUBOWSKI, 2002).

A HHcy pode exercer um papel importante na disfunção endotelial através de mecanismos oxidativos. O grupo sulfidrila (SH), presente na Hcy, é altamente reativo por ser doador de elétrons nos sistemas de oxidação, sendo oxidado rapidamente em dissulfeto (SS). A Hcy é prontamente oxidada quando chega ao plasma, principalmente em consequência de sua auto-oxidação, para formar SS, incluindo a homocistina, cisteinilhomocisteina e Hcy-tiolactona, sendo esta última a forma mais reativa da Hcy (BLOM, 2000).

$\mathrm{O}$ grupo $\mathrm{SH}$ reage com o oxigênio, produzindo o peróxido de hidrogênio $\left(\mathrm{H}_{2} \mathrm{O}_{2}\right)$ e o $\mathrm{O}_{2}^{-}$, os quais iniciam a peroxidação lipídica em superfície endotelial e nas lipoproteínas de baixa densidade (LDL) (BLOM, 2000). A auto-oxidação da Hcy no plasma favorece a redução na expressão e atividade da glutationa peroxidase e, assim, diminue o potencial antioxidante das células endoteliais (AUSTIN et al., 2004). Adicionalmente, foi mostrado que a Hcy reduz significativamente a concentração de cobre, e consequentemente, a atividade da enzima superóxido dismutase (SOD), uma vez que esse metal funciona como cofator dessa enzima (BROWN; STRAIN, 1990).

Os efeitos tóxicos da alta quantidade de Hcy em ratos são o comprometimento do crescimento, lesões teciduais específicas (coração, fígado e rins) e anormalidades hematológicas (BROWN; STRAIN, 1990). Chen et al. (2000) observaram que a $\mathrm{HHcy}$ apresenta efeito mitogênico sobre células musculares lisas e efeito citotóxico sobre as células endoteliais, diminuindo o crescimento do endotélio. A disfunção endotelial, consequente da lesão vascular acarreta liberação alterada de mediadores, como, o NO, citocinas, PGs e ET-1. Estas alterações na liberação de mediadores derivados do endotélio estão relacionadas a inúmeras doenças vasculares (BULT et al., 1999).

Os níveis de Hcy plasmática aumentados são acompanhados de um prejuízo na vasodilatação dependente do endotélio em voluntários que receberam dieta a base de metionina (CHAMBERS et al., 1999a). Na HHcy, o $\mathrm{O}_{2}^{-}$interage e 
causa redução da biodisponibilidade de NO, com consequente formação de peroxinitrito, limitando assim, o relaxamento dependente de endotélio (SHUKLA et al., 2002).

Em células endoteliais de artérias renais, a presença de Hcy causou redução das concentrações de $\mathrm{NO}$ e aumento dos níveis de $\mathrm{O}_{2}{ }^{-}$, sem alterações na atividade da NOS, sugerindo, que o estresse oxidativo induzido por Hcy em combinação com a redução de NO pode estar envolvido nos danos endoteliais causados pela HHcy (LI et al., 2002). A Hcy também pode reduzir a liberação de NO das células endoteliais pela oxidação dos grupamentos sulfidrilas das eNOS, reduzindo sua atividade e a consequente produção de NO (ZHANG et al., 2000).

A produção de $\mathrm{O}_{2}{ }^{-}$derivada do aumento da concentração da Hcy estimula a expressão de proteínas quimioatraentes para monócitos, linfócito T e neutrófilos em cultura de células endoteliais humanas (PODDAR et al., 2001). Estas células próinflamatórias são capazes de produzir citocinas e fatores de crescimento que contribuem para o desenvolvimento das lesões vasculares (AU-YEUNG et al., 2004; PODDAR et al., 2001).

A Hcy pode inibir especificamente a produção de $\mathrm{PGI}_{2}$ em culturas de células endoteliais (WANG et al., 1993). Foi mostrado ainda, que alguns compostos prostanóides análogos às $\mathrm{PGF}_{2 \alpha}$ são formados in vivo por reações não enzimáticas induzidas por peroxidação do ácido araquidônico (MORROW et al., 1990). Essa formação é aumentada em modelos animais de lesão oxidativa (BURK, 1983; MARNETT et al., 1985).

A HHcy também influencia o sistema endotelinérgico em artérias carótidas de ratos (de ANDRADE et al., 2009). A HHcy diminue a expressão de RNAm para pré-pró-ET-1 em células endoteliais, o que acarreta redução da produção de ET-1 e, consequentemente, da produção de $\mathrm{NO}$ e $\mathrm{PGl}_{2}$ (DEMUTH et al., 1999). Ungvari et al. (2000) sugeriram que, na HHcy, a redução da liberação endotelial de NO juntamente com a síntese aumentada de $\mathrm{TXA}_{2}$ em arteríolas de ratos pode interferir com a regulação endotelial do fluxo sanguíneo e provocar aumento na vasoconstrição deste leito, predispondo a alterações patogênicas.

Nosso grupo de pesquisa vem estudando as disfunções vasculares associadas à HHcy sobre os efeitos vasoativos dos peptídeos angiontensina e ET-1, bem como de PhE e acetilcolina (ACh). Bonaventura et al. (2004) estudaram o efeito da HHcy na reatividade à angiotensina II em carótida de ratos, demonstrando que o 
tratamento crônico com metionina eleva os níveis plasmáticos de Hcy e promove aumento da resposta contrátil induzida por angiotensina II devido, ao menos em parte, a alterações na produção e/ou liberação de prostanóides vasoconstritores. Em 2009, estes autores relataram que o consumo crônico de metionina prejudica o relaxamento induzido por bradicinina em carótidas isoladas de ratos devido à produção e/ou liberação de prostanóides vasoconstritores (como TXA ${ }_{2}$ ) (BONAVENTURA et al., 2009).

De Andrade et al. (2006) mostraram que o relaxamento induzido por receptores $\alpha_{1 D}$-adrenérgicos está prejudicado em carótida de ratos durante a disfunção endotelial provocada nos estágios iniciais da HHcy. Os autores observaram que a resposta contrátil acentuada para a PhE é devido, em parte, ao prejuízo dos mecanismos moduladores mediados por receptores $\alpha_{1 D}$-adrenérgicos de relaxamento em carótidas de ratos HHcy, causando redução da biodisponibilidade de $\mathrm{NO}$, assim como aumento de $\mathrm{O}_{2}{ }^{-}$.

De Andrade et al. (2009) foram os pioneiros em utilizar anéis de carótidas de ratos para investigar os mecanismos moleculares da disfunção vascular induzida por $\mathrm{ET}-1$ em ratos $\mathrm{HHcy}$ e relataram que os receptores $\mathrm{ET}_{\mathrm{A}}$ em artérias de ratos $\mathrm{HH}$ cy não apenas modulam a resposta contrátil a ET-1, como também aumentam a geração de potentes fatores constritores como $\mathrm{TXA}_{2}$ e o sistema Rho-quinase.

Celotto et al. (2009) mostraram que a HHcy crônica prejudica a função vascular em artérias carótidas de ratas ovariectomizadas. Os autores observaram que a HHcy pode diminuir a resposta contrátil adrenérgica indepentende de endotélio em artérias carótidas, efeito este revertido pelos inibidores da NOS, demonstrando a participação do NO na disfunção vascular decorrente da HHcy.

Os dados apresentados mostram que a HHcy afeta vários aspectos da função vascular, estando relacionada ao aumento do estresse oxidativo, redução da biodisponibilidade de $\mathrm{NO}$ e alteração da reatividade à $\mathrm{PhE}$. Os estudos revelam ainda, que a HHcy promove alteração nos mecanismos celulares da cascata do sistema endotelinérgico, fato este que se reflete em alteração no efeito vasorelaxante e vasocontrátil da ET-1. Fundamentado no conjunto de informações relativas à HHcy e ao fato de que o corpo cavernoso é considerado um órgão praticamente vascular, a hipótese do presente estudo é de que a HHcy pode acarretar alterações na reatividade e expressão de ET-1 e na reatividade à PhE em corpos cavernosos de ratos. 
2 Objetivos 


\section{Objetivo geral}

Estudar as consequências da HHcy sobre a reatividade à ET-1 e PhE, bem como os mecanismos envolvidos na modulação dessa resposta, em corpos cavernosos de ratos.

\section{Objetivos específicos}

- Estudar as alterações morfológicas e imunohistoquímicas decorrentes da HHcy em corpos cavernosos de ratos;

- Estudar as consequências da HHcy sobre a reatividade ao $\mathrm{KCl}, \mathrm{ACh}$ e nitroprussiato de sódio (NPS) em corpos cavernosos de ratos;

- Estudar as consequências da HHcy sobre a reatividade à ET-1 e ao IRL1620, bem como a participação da NOS em corpos cavernosos de ratos;

- Estudar as consequências da HHcy sobre a reatividade à $\mathrm{PhE}$ e a participação de ERO, NOS e cicloxigenases (COXs) em corpos cavernosos de ratos;

- Estudar as consequências da HHcy sobre os níveis de ERO por microscopia confocal;

- Estudar as consequências da HHcy sobre a concentração de metabólitos de NO;

- Estudar as consequências da HHcy sobre a expressão de RNAm de pré-pró-ET-1, ECE, receptores $\mathrm{ET}_{\mathrm{A}}$ e $\mathrm{ET}_{\mathrm{B}}$, nNOS, eNOS e iNOS. 
3 Materiais e Métodos 


\subsection{Animais}

Os experimentos foram realizados utilizando ratos Wistar, adultos, com idade média de 60 dias (360-400 g), provenientes do Biotério Central do Campus de Ribeirão Preto, da Universidade de São Paulo. Os animais foram mantidos com livre acesso à água e alimento, em ambiente com temperatura controlada de $22-26^{\circ} \mathrm{C}$ e em ciclo de luz de 12 horas (claro e escuro).

Os protocolos utilizados foram aprovados pela Comissão de Ética no Uso de Animais (CEUA) do Campus de Ribeirão Preto da Universidade de São Paulo ( $n^{\circ}$ 10.1.364.53.5, em anexo).

\subsection{Preparação do Modelo}

O estudo temporal realizado por de Andrade et al. (2009a) mostrou que aos 15 dias de tratamento com Hcy ocorriam as principais alterações funcionais em artéria carótida à ET-1 e PhE. A escolha deste tempo de tratamento norteou o delineamento experimental de nosso trabalho.

Os ratos, com idade média de 60 dias, foram submetidos ao tratamento com a substância DL-homocisteina-tiolactona (DL-HcyT) na dose de 1 $\mathrm{g} / \mathrm{kg} / \mathrm{dia}$ (de ANDRADE et al., 2006, 2009, 2009a) por 15 dias (grupo HHcy). A DL-HcyT foi diluída em água e acondicionada em bebedouros colocados em caixas contendo dois a três animais, de modo que se permitiu a ingestão diária de aproximadamente $35 \mathrm{~mL}$ de solução de DL-HcyT por animal. O grupo controle recebeu água.

\subsection{Histologia}

Para analisar as características morfológicas de corpos cavernosos, os ratos controle e HHcy foram anestesiados e perfundidos com tampão paraformaldeído $10 \%$. Os corpos cavernosos foram removidos e condicionados em tampão 
paraformaldeído 10\%, durante 24 horas. Os tecidos foram fixados, desidratados e incluídos em blocos de parafina. Cortes de $4 \mu \mathrm{m}$ de espessura foram dispostos em lâmina para microscopia. As lâminas foram analisadas quanto à morfologia pela coloração de Hematoxilina e Eosina e quanto aos depósitos de colágeno por meio da coloração de Tricrômico de Gomori.

Os corpos cavernosos foram fotografados em toda sua extensão utilizandose câmera digital (Nikon Coolpix 995, Roper Scientific, Japão), acoplada ao microscópio Nikon (Eclipse E400) e analisados em aumento de 40 vezes.

\subsection{Imunohistoquímica}

Com objetivo de estudar a consequência da HHcy sobre a imunorreatividade de a-actina e nitrotirosina em corpos cavernosos, os ratos controle e HHcy foram anestesiados e perfundidos com tampão paraformaldeído 10\%. As amostras de corpos cavernosos foram removidas e fixadas em tampão formaldeído 10\% por 24 horas e, após este período, lavadas em água corrente e deixadas em álcool 70\%. Posteriormente, os tecidos foram desidratados, emblocados em parafina, cortados em micrótomo ( 4 m de espessura) e dispostos em lâminas revestidas com poli-Llisina.

Os cortes foram desparafinizados, reidratados, imersos em $10 \mathrm{mmol} / \mathrm{L}$ de tampão de citrato, pH 6,0 e submetidos à recuperação do epítopo induzida por calor (HIER), utilizando vapor por 45 minutos. Em seguida as lâminas foram lavadas com tampão fosfato (PBS) e imersas em solução de $\mathrm{H}_{2} \mathrm{O}_{2} 3 \%$, diluído em metanol (30\%), por 20 minutos para o bloqueio da peroxidase endógena. As ligações protéicas inespecíficas foram bloqueadas por incubação com solução de soro normal (Vectastain Elite ABC Kit, Universal, Vector Laboratories Inc., Burlingame, CA, USA) por 30 minutos.

Posteriormente, as laminas foram incubadas com anticorpo primário monoclonal específico para a-actina do músculo liso (alpha-SMA; Santa Cruz Biotechnology, Santa Cruz, CA, USA, diluição 1:100) e nitrotirosina (clone HM11; Santa Cruz Biotechnology, Santa Cruz, CA, USA, diluição 1:100) por 2 horas em temperatura ambiente $\left(25^{\circ} \mathrm{C}\right)$ em câmara úmida. Após lavagens em PBS, os cortes 
foram incubados com anticorpo secundário biotinilado (Vectastain Elite ABC Kit, Universal, Vector Laboratories Inc.) por 30 minutos. Seguidamente, foram incubadas com o complexo avidina-biotina-peroxidase (Vectastain Elite ABC Kit, Universal, Vector Laboratories Inc.) por 30 minutos e reveladas com cromógeno vermelho (Kit Vector NovaRED; Vector Laboratories Inc.) por 5 minutos. A contra-coloração foi realizada com Hematoxilina de Harris.

Para a verificação da presença de imunorreatividade para nitrotirosina e $\alpha$ actina nas regiões de interesse para a quantificação, foi realizada uma análise qualitativa preliminar das lâminas utilizando-se microscópio Nikon (Eclipse E400) em aumento de 40 vezes. Os corpos cavernosos foram fotografados em toda sua extensão utilizando-se câmera digital (Nikon Coolpix995), acoplada ao microscópio e a quantificação foi realizada utilizando-se um analisador de imagens digitalizadas computadorizado (Image J, versão 1.33u, NIH, USA), em porcentagem de área marcada.

\subsection{Estudo da Reatividade vascular}

\subsubsection{Preparação dos corpos cavernosos}

Os animais foram anestesiados com isoflurano e mortos por decaptação, 15 dias após o início do tratamento com DL-HcyT ou água. O pênis foi isolado do animal, no nível de sua fixação ao osso ísquio, removeu-se a veia dorsal peniana e a uretra. Em seguida, os corpos cavernosos foram separados em dois fragmentos de um $\mathrm{cm}$. As extremidade de cada segmento foram amarradas com linha e colocadas em cubas de órgão isolado ( $5 \mathrm{~mL}$ ) contendo solução de Krebs cuja composição é (mmol/L): $\mathrm{NaCl} 118,0 ; \mathrm{KCl} 4,7 ; \mathrm{CaCl}_{2} 2 \mathrm{H}_{2} \mathrm{O}$ 2,5; $\mathrm{KH}_{2} \mathrm{PO}_{4} 1,2 ; \mathrm{MgSO}_{4} 7 \mathrm{H}_{2} \mathrm{O}$ 1,17; $\mathrm{NaHCO}_{3}$ 25,0; glicose 5,6; $\mathrm{pH}$ 7,4. Os tecidos foram mantidos a temperatura constante de $37^{\circ} \mathrm{C}$ e gaseificados com mistura carbogênica $\left(95 \% \mathrm{O}_{2}\right.$ e $\left.5 \% \mathrm{CO}_{2}\right)$ (FERMINO et al., 2009; CLAUDINO et al., 2004). Uma das extremidades da tira de corpo cavernoso foi conectada a um suporte fixo ajustável e a outra, a um transdutor para registro de tensão isométrica (Tri 201 - Letica, Espanha). Os resultados foram 
obtidos através de programa computadorizado (PROTO 5 - Letica, Espanha) em computador conectado ao transdutor.

Antes do início dos protocolos experimentais, as preparações permaneceram em repouso sob tensão de $0,25 \mathrm{~g}$, aproximadamente $80 \%$ da tensão máxima determinada por curvas de tensão (apêndice - A), durante 60 minutos para estabilização. Após o período de estabilização, a viabilidade das preparações foi testada com PhE $\left(5 \times 10^{-6} \mathrm{~mol} / \mathrm{L}\right)$.

Com o objetivo de verificar se o tratamento interfere com a capacidade contrátil dos corpos cavernosos e na mobilização de cálcio via canais de cálcio operados por voltagem (VOC), foram realizadas curvas concentração-efeito para $\mathrm{KCl}$ (10 a $90 \mathrm{mmol} / \mathrm{L})$. O relaxamento independente de endotélio em corpos cavernosos de ratos controle e HHcy, pré-contraídos com $\mathrm{PhE}\left(10^{-5} \mathrm{~mol} / \mathrm{L}\right)$, foi avaliado por curvas para NPS $\left(10^{-9}\right.$ a $\left.3 \times 10^{-4} \mathrm{~mol} / \mathrm{L}\right)$. Curvas cumulativas de relaxamento para ACh $\left(10^{-9}\right.$ a $\left.3 \times 10^{-4} \mathrm{~mol} / \mathrm{L}\right)$ foram realizadas em corpos cavernosos de ratos, précontraídos com $\mathrm{PhE}\left(10^{-5} \mathrm{~mol} / \mathrm{L}\right)$, com o objetivo de analisar o relaxamento dependente de endotélio. A concentração de PhE utilizada $\left(10^{-5} \mathrm{~mol} / \mathrm{L}\right)$ nos protocolos de relaxamento induziu o mesmo nível de pré-contração nas preparações dos dois grupos experimentais.

Após o término dos protocolos experimentais, os corpos cavernosos foram desidratados em estufa $\left(37^{\circ} \mathrm{C}\right)$ durante 24 horas e, posteriormente, pesados em balança analítica (Sartorius R-160P). As respostas contráteis foram expressas em gramas $(\mathrm{g})$ de contração/g de tecido seco, e as respostas de relaxamento foram expressas em \% de relaxamento relativa à pré-contração com $\mathrm{PhE}\left(10^{-5} \mathrm{~mol} / \mathrm{L}\right)$.

As determinações dos valores de Emax (efeito máximo) e $E_{50}$ (concentração do agonista que produz $50 \%$ do efeito máximo) foram realizadas utilizando o método de regressão não-linear dos mínimos quadrados através do programa GraphPad (GraphPad Software Corporation, versão 5.0, EUA). Para análise da potência do agonista foi utilizado o valor de $\mathrm{pD}_{2}$ (logaritmo negativo da concentração da droga que induz metade do efeito máximo). 


\subsubsection{Protocolos experimentais}

\subsubsection{Efeito da HHcy sobre a contração induzida por ET-1}

Para estudar o efeito da HHcy sobre a contração induzida por ET-1, realizaram-se curvas cumulativas concentração-efeito para ET-1 (10 $0^{-9}$ a $\left.10^{-5} \mathrm{~mol} / \mathrm{L}\right)$ em corpos cavernosos de ratos controle e HHcy.

\subsubsection{Consequência da HHcy sobre a contração induzida por ET-1, em presença do antagonista dos receptores $\mathrm{ET}_{\mathrm{B}}$}

Com o objetivo de estudar a contração induzida por ET-1, em ausência das respostas de relaxamento via receptores $\mathrm{ET}_{\mathrm{B}}$ que poderiam contrabalancear as respostas de contração via receptores $\mathrm{ET}_{\mathrm{A}}$, corpos cavernosos de ratos controle e HHcy foram pré-incubados por 30 minutos com antagonista dos receptores $E T_{B}$, $B Q$ $788\left(3 \times 10^{-6} \mathrm{~mol} / \mathrm{L}\right)$. Após o tempo de incubação, curvas concentração-efeito foram realizadas para $\mathrm{ET}-1\left(10^{-9}\right.$ a $\left.10^{-5} \mathrm{~mol} / \mathrm{L}\right)$.

\subsubsection{Consequência da HHcy sobre o relaxamento induzida por ET-1}

Para estudar a consequência da HHcy sobre o relaxamento induzida por ET1, curvas cumulativas concentração-efeito para ET-1 $\left(10^{-10}\right.$ a $\left.3 \times 10^{-8} \mathrm{~mol} / \mathrm{L}\right)$ foram realizadas em corpos cavernosos de ratos controle e HHcy. 
3.5.2.4 Consequência da HHcy sobre o relaxamento induzida por ET-1, em presença do antagonista dos receptores $\mathrm{ET}_{\mathrm{A}}$

Com o objetivo de estudar o relaxamento induzido por ET-1, em ausência das respostas de contração via receptores $\mathrm{ET}_{\mathrm{A}}$ que poderiam contrabalancear as respostas de relaxamento via receptores $\mathrm{ET}_{\mathrm{B}}$, foram realizadas curvas de relaxamento cumulativas concentração-efeito para ET-1 $\left(10^{-10}\right.$ a $\left.10^{-6} \mathrm{~mol} / \mathrm{L}\right)$, em presença de antagonista dos receptores $\mathrm{ET}_{\mathrm{A}}, \mathrm{BQ}-123\left(10^{-5} \mathrm{~mol} / \mathrm{L}\right)$, anteriormente incubados por 30 minutos, pré-contraídos com $\mathrm{PhE}\left(10^{-5} \mathrm{~mol} / \mathrm{L}\right)$.

\subsubsection{Consequência da HHcy sobre o relaxamento induzido por IRL-1620}

Para estudar a consequência da HHcy sobre o relaxamento induzido por IRL-1620 (10-10 a $\left.10^{-6} \mathrm{~mol} / \mathrm{L}\right)$, agonista seletivo dos receptores $E T_{\mathrm{B}}$, foram realizadas curva concentração-efeito para IRL-1620 em corpos cavernosos de ratos controle e HHcy, pré-contraídos com PhE $\left(10^{-5} \mathrm{~mol} / \mathrm{L}\right)$.

\subsubsection{Participação dos metabólitos da NOS sobre o relaxamento induzido por IRL-1620}

Com o objetivo de estudar a participação dos metabólicos derivados da enzima NOS no relaxamento induzido por IRL-1620, foram realizadas curvas concentração-efeito para IRL-1620 $\left(10^{-10}\right.$ a $\left.10^{-6} \mathrm{~mol} / \mathrm{L}\right)$, em corpos cavernosos de ratos controle e HHcy, pré-contraídos com $\mathrm{PhE}\left(10^{-5} \mathrm{~mol} / \mathrm{L}\right)$, em presença de inibidor não-seletivo da NOS, L-NAME $\left(10^{-4} \mathrm{~mol} / \mathrm{L}\right)$. 


\subsubsection{Consequência da HHcy sobre a contração induzida por PhE}

Com o objetivo de estudar a consequência da HHcy sobre a contração induzida por PhE $\left(10^{-7}\right.$ a $\left.3 \times 10^{-5} \mathrm{~mol} / \mathrm{L}\right)$, foram realizadas curvas concentração-efeito para este agonista em corpos cavernosos de ratos.

\subsubsection{Participação de ERO na contração desencadeada por PhE}

A participação de ERO na contração induzida por PhE foi estudada por realização de curva concentração-efeito para este agonista $\left(10^{-7}\right.$ a $\left.3 \times 10^{-5} \mathrm{~mol} / \mathrm{L}\right)$ em corpos cavernosos de ratos controle e HHcy, em presença do sequestrador de $\mathrm{O}_{2}^{-}$, tiron $\left(10^{-4} \mathrm{~mol} / \mathrm{L}\right)$, ou do mimético da enzima SOD, tempol $\left(10^{-3} \mathrm{~mol} / \mathrm{L}\right)$, pré-incubados durante 30 minutos.

$\mathrm{O}$ estudo do envolvimento de $\mathrm{H}_{2} \mathrm{O}_{2}$ na contração induzida por $\mathrm{PhE}$ em corpos cavernosos de ratos controle e HHcy, foi avaliado realizando-se curvas concentração-efeito para $\mathrm{PhE}\left(10^{-7}\right.$ a $\left.3 \times 10^{-5} \mathrm{~mol} / \mathrm{L}\right)$ em presença de peg-catalase (250 U/mL), enzima que decompõe o $\mathrm{H}_{2} \mathrm{O}_{2}$, sozinha ou em associação a tempol (10-3 $\mathrm{mol} / \mathrm{L})$, pré-incubados por 30 minutos.

Essas drogas atuam de diferentes modos na formação de ERO, conforme figura abaixo:

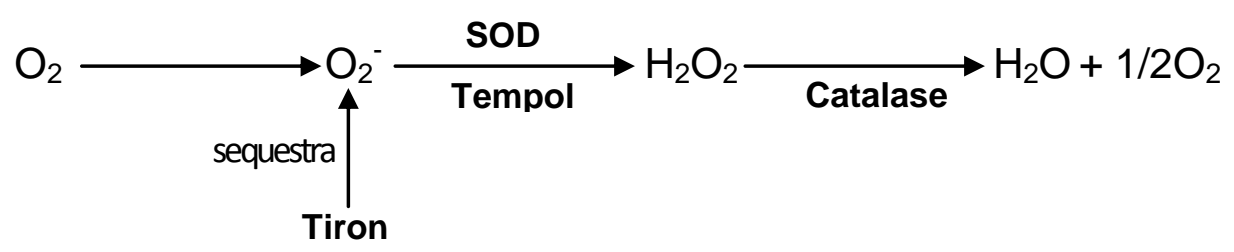

Figura 2: Esquema representativo da via de formação das ERO 


\subsubsection{Participação de metabólitos da NOS e de suas isoformas específicas na contração induzida por PhE}

Para estudar a participação dos metabólitos da enzima NOS na contração induzida por $\mathrm{PhE}$, foram realizadas curvas concentração-efeito para este agonista $\left(10^{-7}\right.$ a $\left.3 \times 10^{-5} \mathrm{~mol} / \mathrm{L}\right)$ em corpos cavernosos de ratos controle e HHcy, pré-incubadas por 30 minutos com inibidor não seletivo da NOS, L-NAME $\left(10^{-4} \mathrm{~mol} / \mathrm{L}\right)(\mathrm{VIGNOZZI} \mathrm{et}$ al., 2006).

O envolvimento de cada isoforma da enzima NOS foi estudado pela realização de curvas concentração-efeito para $\mathrm{PhE}$ em presença de inibidor seletivo da isoforma eNOS, L-NNA $\left(10^{-4} \mathrm{~mol} / \mathrm{L}\right)$, de inibidor seletivo para nNOS, 7Nitroindazol $\left(7-\mathrm{Ni}, 10^{-4} \mathrm{~mol} / \mathrm{L}\right)$ ou $1400 \mathrm{~W}$, inibidor seletivo para isoforma induzível da enzima (iNOS, $10^{-7} \mathrm{~mol} / \mathrm{L}$ ). Os inibidores foram pré-incubado por 30 minutos.

\subsubsection{Participação dos metabólitos da COX e de suas isoformas específicas na contração desencadeada por PhE}

A participação dos metabólitos da enzima COX na contração induzida por PhE foi avaliada por realização de curvas concentração-efeito para este agonista $\left(10^{-7}\right.$ a $\left.3 \times 10^{-5} \mathrm{~mol} / \mathrm{L}\right)$, em corpos cavernosos de ratos controle e HHcy, pré-incubados com indometacina, inibidor não-seletivo da $\operatorname{COX}\left(10^{-5} \mathrm{~mol} / \mathrm{L}\right)$ por 30 minutos.

Para determinar qual a isoforma da COX (COX-1 ou COX-2) está envolvida no processo, foram realizadas curvas concentração-efeito para PhE em corpos cavernosos de ratos controle e HHcy, em presença de SC-560 (inibidor seletivo de COX-1, $10^{-5} \mathrm{~mol} / \mathrm{L}$, pré-incubado por 30 minutos) ou SC-236 (inibidor seletivo de COX-2, $10^{-5} \mathrm{~mol} / \mathrm{L}$, pré-incubado por 30 minutos). 


\subsection{Produção de espécies reativas de oxigênio (ERO)}

Com o objetivo de estudar a consequência da HHcy nos níveis basais de ERO e produzidos por ET-1 e PhE em corpos cavernosos de ratos controle e HHcy, anéis destes tecidos foram colocados em lamínulas, cobertas por solução de poli-Llisina e incubados com dihidroetidina (DHE; $5 \times 10^{-5} \mathrm{~mol} / \mathrm{L}, 30$ minutos, a $37^{\circ} \mathrm{C}$ ), preparada em solução de hanks (composição em mmol/L: $\mathrm{CaCl}_{2}$ 1,6; $\mathrm{MgSO}_{4}$ 1,0; $\mathrm{NaCl} 145,0 ; \mathrm{KCl} 5,0 ; \mathrm{NaH}_{2} \mathrm{PO}_{4}$ 0,5; dextrose 10,0; hepes 10,0; $\mathrm{pH} 7,4$ ), em ausência ou presença do sequestrador de $\mathrm{O}_{2}^{-}$, tiron $\left(10^{-5} \mathrm{~mol} / \mathrm{L}\right)$.

As células são permeáveis a DHE, uma sonda fluorescente oxidativa e, em presença de ERO, esta sonda é oxidada ao fluorescente brometo de etídio, o qual reage com o DNA e produz fluorescência vermelha. Deste modo, a presença de fluorescência é sugestiva de ERO.

O nível de ERO nos tecidos foi analisado por microscópio confocal (Leica TSC SP5). DHE foi excitada com laser de argônio a $570 \mathrm{~nm}$ e a fluorescência emitida foi medida em $650 \mathrm{~nm}$. A fluorescência basal foi registrada em $t=0$ segundos, enquanto que a fluorescência após adição de ET-1 (10 $\left.0^{-5} \mathrm{~mol} / \mathrm{L}\right)$ ou PhE $\left(10^{-4} \mathrm{~mol} / \mathrm{L}\right) \quad$ (em $t=100$ segundos) foi registrada em $t=300$ segundos. $O$ software de análise temporal Leica Application Suite - Advanced Fluorescence Lite (LAS-AF Lite) foi utizado para capturar as imagens ao longo do tempo, e para quantificação de ERO. Para a quantificação, fixou-se uma determinada área e obteve-se a fluorescência média.

\subsection{Reação em cadeia da polimerase em tempo real (Real Time-PCR)}

Com o objetivo de estudar a consequência da HHcy sobre a expressão de RNAm para pré-pró-ET-1, ECE, receptores $\mathrm{ET}_{\mathrm{A}}$ e $\mathrm{ET}_{\mathrm{B}}, \mathrm{nNOS}$, eNOS e iNOS, foi realizada a técnica de Real Time-PCR em corpos cavernosos dos ratos. 


\section{Homogeneização do tecido}

Os corpos cavernosos de ratos controle e HHcy foram rapidamente isolados e congelados em nitrogênio líquido. Os tecidos congelados foram acrescidos de trizol (isotiocianato de guanidina em solução de fenol) e realizou-se a trituração em homogeneizador de tecido do tipo Polytron, em gelo.

\section{Extração do RNA}

Após a incubação do homogenato durante 5 minutos em temperatura ambiente, foi adicionado $200 \mu \mathrm{L}$ de clorofórmio para $1 \mathrm{~mL}$ de trizol. Os tubos foram agitados vigorosamente durante 15 segundos e incubados por 2 a 3 minutos em temperatura ambiente. As amostras foram centrifugadas $\left(11800 \mathrm{~g}, 15\right.$ minutos, $\left.4^{\circ} \mathrm{C}\right)$, e a fase aquosa (superior) foi transferida para outro tubo.

\section{Precipitação do RNA}

A fase aquosa anteriormente transferida para novo tubo foi acrescida de 10 $\mu \mathrm{L}$ de glicogênio gelado ( $20 \mathrm{mg} / \mathrm{mL}$ ) e $500 \mu \mathrm{L}$ de isopropanol, ambos gelados. Os tubos foram misturados por inversão e incubados em $-80^{\circ} \mathrm{C}$ por, no mínimo, 3 horas. Em seguida, as amostras foram centrifugadas $\left(11800 \mathrm{~g}, 15\right.$ minutos, $\left.4^{\circ} \mathrm{C}\right)$. $\mathrm{O}$ sobrenadante foi desprezado e adicionou-se $1 \mathrm{~mL}$ de etanol 75\% (em água DEPC, dietil pirocarbonato, inativa $0,01 \%$ ) ao pellet. As amostras foram agitadas em vortex e centrifugadas a $7500 \mathrm{~g}$, por 5 minutos a $4^{\circ} \mathrm{C}$. Verteu-se o sobrenadante, incubouse o pellet a temperatura ambiente por 5-10 minutos. O pellet foi ressuspendido em $16 \mu \mathrm{L}$ de água DEPC.

\section{Quantificação do RNA}

A quantificação foi realizada por espectrofotometria $(260 \mathrm{~nm})$ no aparelho NANODROP (Thermo Scientific, USA). O critério de pureza utilizado foi a razão

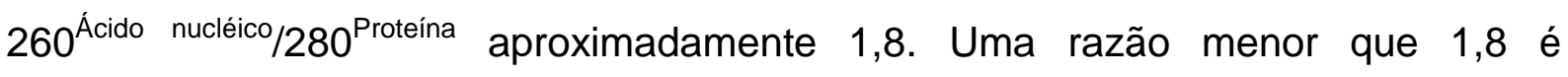
indicativo de contaminação por proteínas. A concentração foi fornecida em $n g / \mu \mathrm{L}$, e foram utilizados para leitura $2 \mu \mathrm{L}$ de amostra. 


\section{Gel de integridade do RNA}

A agarose $(1,2 \mathrm{~g})$ foi dissolvida em $100 \mathrm{~mL}$ de Tris-borato-EDTA (TBE) $1 \mathrm{x}$ por aquecimento. $\mathrm{O}$ gel foi resfriado sob água corrente e foram adicionados $2 \mu \mathrm{L}$ de brometo de etídio $(0,5 \mu \mathrm{g} / \mathrm{mL})$, em capela de exaustão. Após esse procedimento foi realizada eletroforese para verificar a integridade do RNA pela visualização das bandas $18 \mathrm{~S}$ e $28 \mathrm{~S}$.

Foi aplicado no gel, por poço, $5 \mu \mathrm{L}$ de cada amostra de RNA a $200 \mathrm{ng} / \mu \mathrm{L}$ (1 $\mu \mathrm{g}$ de RNA) ressuspendido em água DEPC. A eletroforese foi feita nas condições de 80 volts por 60 minutos. O gel foi observado em ultravioleta e fotografado com câmera digital Kodak Digital Science DC120 Zoom (Eastman Kodak Company, Rochester, USA).

\section{Reação de Transcriptase Reversa}

A reação de transcrição reversa é o processo pelo qual o RNA é usado como um molde para sintetizar cDNA. Para esta reação foi utilizado o Kit Multiscrib reverse transcription (Life Technologies). A reação foi preparada com $2 \mu \mathrm{L}$ de tampão (10x), $2 \mu \mathrm{L}$ de solução de primers randômicos (10x), 0,8 $\mu \mathrm{L}$ de solução de dNTPs (25x), $1 \mu \mathrm{L}$ de solução de enzima Multiscrib RT (50 U/ $\mu \mathrm{L}$ ), $1 \mu \mathrm{L}$ de inibidor de RNAase $(20 \mathrm{U} / \mu \mathrm{L}), 0,25 \mu \mathrm{L}$ de solução de primers oligo-dT $(0,5 \mu \mathrm{g} / \mu \mathrm{L}), 5 \mu \mathrm{L}$ de cada amostra de RNA (200 ng/ $\mu \mathrm{L})$, totalizando um volume de $20 \mu \mathrm{L}$.

As amostras foram incubadas a $25^{\circ} \mathrm{C}$ por 10 minutos, $37^{\circ} \mathrm{C}$ por 120 minutos e $85^{\circ} \mathrm{C}$ por 5 minutos. O cDNA obtido foi armazenado a $-20^{\circ} \mathrm{C}$ até as reações de Real Time-PCR.

\section{Real Time-PCR}

A expressão dos genes foram quantificadas pelo sistema TaqMan (Life Technologies). Este sistema utiliza sonda fluorescente para permitir a detecção de produto específico conforme este se acumula durante os ciclos de PCR. Uma sonda (oligonucleotídeo) é construída contendo um corante reporter fluorescente na extremidade 5' e um corante quencher (silenciador) na extremidade 3'. Enquanto a sonda está intacta, a proximidade do quencher reduz bastante a fluorescência 
emitida pelo corante reporter através da transferência de energia por ressonância de fluorescência (FRET) através do espaço. Se a sequência alvo estiver presente, a sonda se anela logo após um dos primers e é clivada pela atividade da nuclease 5' da Taq DNA polimerase enquanto o primer é estendido. Esta clivagem da sonda separa o corante reporter do corante quencher, aumentando o sinal do corante reporter, além de remover a sonda da fita alvo, permitindo que a extensão do primer continue até o final da fita molde.

A reação foi constituída de: $5 \mu \mathrm{L}$ de tampão TaqMan gene expression Mater Mix (2x) (Life Technologies), 0,5 $\mu \mathrm{L}$ de cada ensaio TaqMan (20x), $4 \mu \mathrm{L}$ de cDNA (diluído 1:15), totalizando um volume de $10 \mu \mathrm{L}$ com água Mili-Q. As amostras foram incubadas a $50^{\circ} \mathrm{C}$ por 2 minutos, em seguida a $95^{\circ} \mathrm{C}$ por 10 minutos, seguidos de 40 ciclos de $95^{\circ} \mathrm{C}$ por 15 segudos e $60^{\circ} \mathrm{C}$ por 1 minuto no aparelho Step One Plus (Life Technologies).

Foram analisados os seguintes genes (Life Technologies): pré-pró-ET-1 (Rn00561129_m1), ECE (Rn00585943_m1), receptor ET A (Rn00561137_m1),

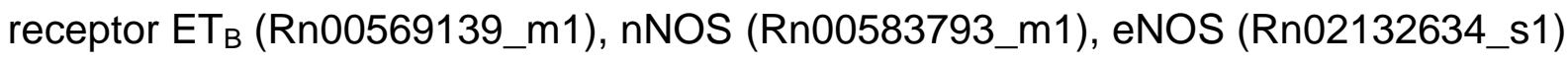
e iNOS (Rn00561646_m1).

Um experimento teste foi realizado utilizando-se endógenos diferentes (Life Technologies), incluindo: GAPDH (Rn01775763_g1), beta-actina (Rn00667869_m1), TBP (Tata box binding protein; Rn01455648_m1), beta-2-microglobulina (Rn00560865_m1), PPia (Peptidylprolyl isomerase A; Rn00690933_m1) e betaglucurosidade (Rn00566655_m1). Foi escolhido o gene beta-2-microglobulina por ser o que menos variou dentre os genes que não amplificaram contaminantes de DNA.

Foi fixado um valor de treshold para cada gene. O treshold é um nível de sinal reporter normalizado que é usado para determinação do Ct (ciclo treshold) em ensaios de Real Time. Ele deve ser ajustado acima do sinal fluorescente de fundo emitido durante os primeiros ciclos de PCR antes do instrumento de PCR em tempo real detectar a amplificação do produto de PCR (baseline). No entanto, deve ser suficientemente baixo para se encontrar dentro da região de crescimento exponencial de uma curva de amplificação.

O Ct é o número do ciclo no qual a fluorescência gerada dentro de uma reação cruza a linha threshold. Os valores de CT são logarítmicos e são usados para as análises quantitativas. 
A expressão gênica foi analisada pelo método de $2^{-\Delta \Delta C t}$. Calculou-se a média de Ct e desvio padrão das triplicatas. Se o desvio padrão foi maior que 0,2 ciclos, o valor da triplicata mais discrepante foi excluído e recalculou-se a média. Os valores de $2^{-\Delta \Delta C t}$ de cada amostra foram normalizados $\left(\log _{10}\right)$ e os grupos foram comparados por teste t de Studant.

\subsection{Determinação plasmática de nitrato}

Com o objetivo de estudar a consequência da HHcy sobre a biodisponibilidade de $\mathrm{NO}$, foram realizadas dosagens plasmáticas de nitrato. As amostras de sangue de ratos controle e HHcy foram coletadas em tubos contendo $500 \mu \mathrm{L}$ de heparina $(10 \mathrm{U} / \mathrm{mL})$ e centrifugadas (3000 g, 4ํㅡ, 20 minutos) para a obtenção do plasma. $\mathrm{O}$ plasma foi estocado à $-70^{\circ} \mathrm{C}$ até o momento das dosagens de nitrato.

Para as dosagens de NO plasmático, procedeu-se a desproteinização de alíquotas de $50 \mu \mathrm{L}$ das amostras por precipitação, utilizando $100 \mu \mathrm{L}$ etanol absoluto à $4^{\circ} \mathrm{C}$, seguido de agitação e mantidas por 30 minutos em freezer $\left(-20^{\circ} \mathrm{C}\right)$. Após isto, foram submetidas à centrifugação (10000 g, 25ํㅡ, 5 minutos).

A medida do NO foi realizada pela técnica de quimioluminescência NO/ozônio utilizando-se o analisador Sievers® Nitric Oxide Analyzer 280 (GE Analytical Instruments, Boulder, CO. USA). Das amostras desproteinizadas, utilizouse o volume de $5,0 \mu \mathrm{L}$, que foi injetado na câmara de reação do analisador, contendo um agente redutor ( $0,8 \%$ de cloreto de vanádio em $1 \mathrm{~N} \mathrm{de} \mathrm{HCl}$ à $\left.95^{\circ} \mathrm{C}\right)$ que converte o nitrato em NO, em quantidades equimolares. O NO é sugado para a câmara de quimioluminescência do analisador, que por sua vez, reage com o ozônio $\left(\mathrm{O}_{3}\right)$, formando dióxido de nitrogênio $\left(\mathrm{NO}_{2}^{-}\right)$. $\mathrm{O} \mathrm{NO}_{2}^{-}$apresenta-se numa forma instável e tem a capacidade de emitir fótons que se chocam contra uma superfície foto-sensível de uma célula fotomultiplicadora. O fóton emitido pela reação é detectado e convertido em sinal elétrico. A corrente de elétrons é captada, amplificada e processada por um transdutor analógico-digital, dando origem a um traçado gráfico, em que a área sob a curva gerada pela corrente elétrica corresponde à concentração de nitrato na amostra. 
A curva padrão foi preparada com nitrato de sódio nas concentrações 5,10 , 25, 50 e $100 \mu \mathrm{mol} / \mathrm{L}$. Os valores de nitrato foram expressos em $\mu \mathrm{mol} / \mathrm{L}$.

\subsection{Análise estatística}

A análise estatística utilizada para comparação entre os grupos foi a análise de variância (ANOVA) de uma via, seguido do pós-teste de Bonferroni; ou teste t de Student não pareado, utilizando o programa GraphPad Prism (versão 5.0 Prism, GraphPad, USA).

\subsection{Drogas}

ET-1, IRL-1620, BQ-788, BQ-123 (American Peptidase Company), DL-HcyT (Acros Organics), 7-Ni, $1400 \mathrm{~W}$ (Tocris), $\mathrm{NaCl}, \mathrm{KCl}, \mathrm{CaCl}_{2}, \mathrm{KH}_{2} \mathrm{PO}_{4}, \mathrm{MgSO}_{4}$, $\mathrm{NaHCO}_{3}, \mathrm{NaH}_{2} \mathrm{PO}_{4}$, glicose (Synth), Isoflurano (Baxter), anticorpos primário monoclonal para para a-actina e nitrotirosina (Santa Cruz), anticorpos secundário biotinilado (Vector), primers e sondas (Life Technologies), demais drogas e reagentes não especificados foram adquiridos da Sigma-Aldrich. Indometacina, SC560, SC-236 e BQ-788 foram dissolvidos em DMSO (dimetil sulfóxido). ET-1 foi dissolvida em ácido acético 5\%. Demais componentes não especificados foram dissolvidos em água deionizada. 
4 Resultados 


\subsection{Consequência da HHcy sobre o peso dos animais}

O desenvolvimento da idade acarretou aumento do peso dos ratos controle durante o período estudado. O tratamento com DL-HcyT por 15 dias não causou ganho significativo no peso dos animais (Figura 3).

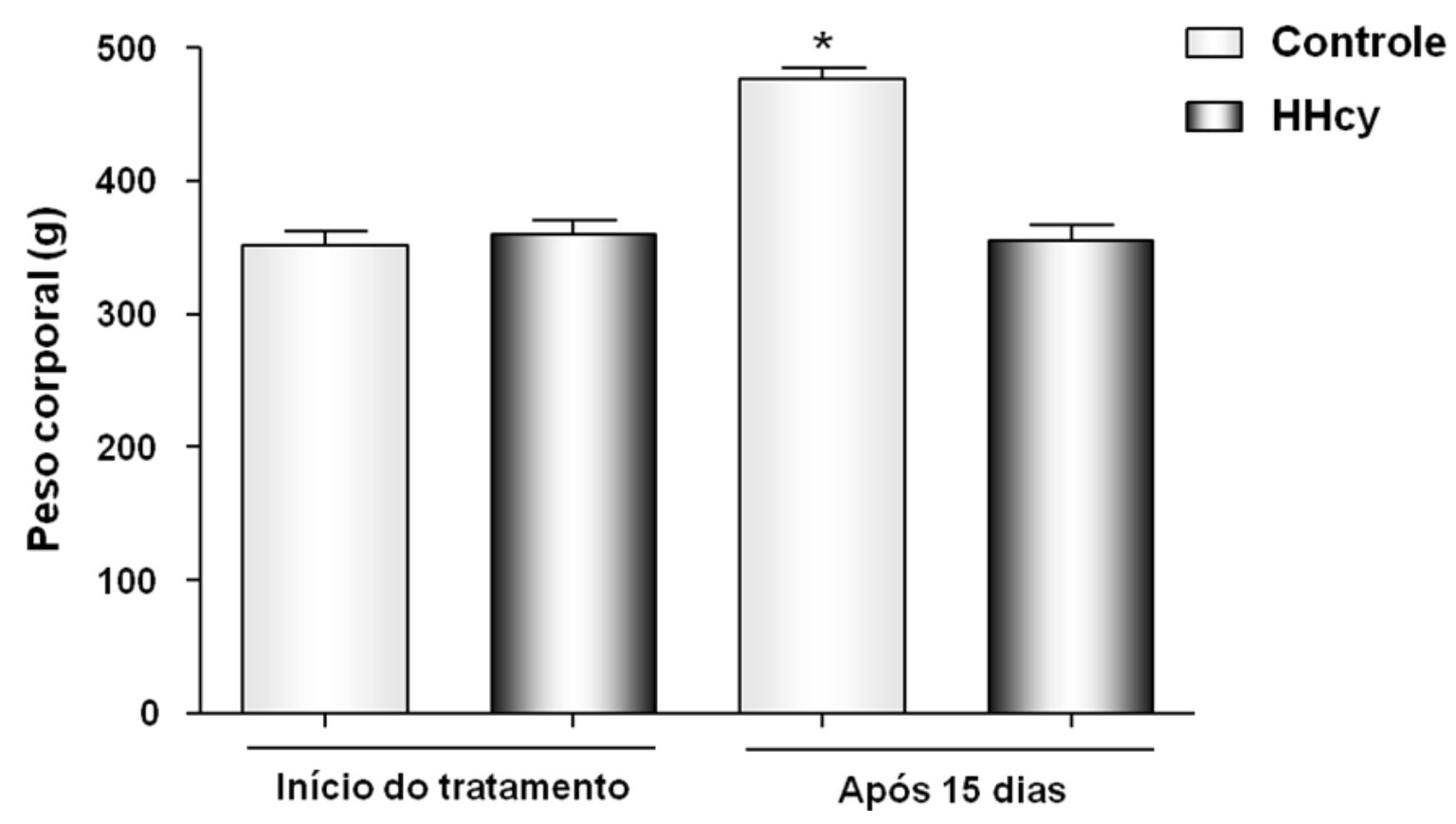

Figura 3: Consequência da HHcy sobre o peso dos animais. A figura mostra o peso corporal de ratos controle e HHcy. Os dados representam a média \pm E.P.M. ( $n=10$ para cada grupo). $\left(^{*}\right)$ significativamente diferente $(p<0,05)$ em relação ao controle no início do tratamento. ANOVA de uma via, pós-teste de Bonferroni. 


\subsection{Consequência da HHcy sobre o peso seco de corpos cavernosos}

Tiras de corpos cavernosos de ratos controle apresentaram peso seco médio de $0,0166 \pm 0,0003 \mathrm{~g}(\mathrm{n}=64)$. O tratamento com DL-HcyT reduziu o peso seco médio das tiras de corpos cavernosos de ratos provenientes deste grupo $(0,0146 \pm$ $0,0003 \mathrm{~g}, \mathrm{n}=64$ ) em relação ao grupo controle (Figura 4).

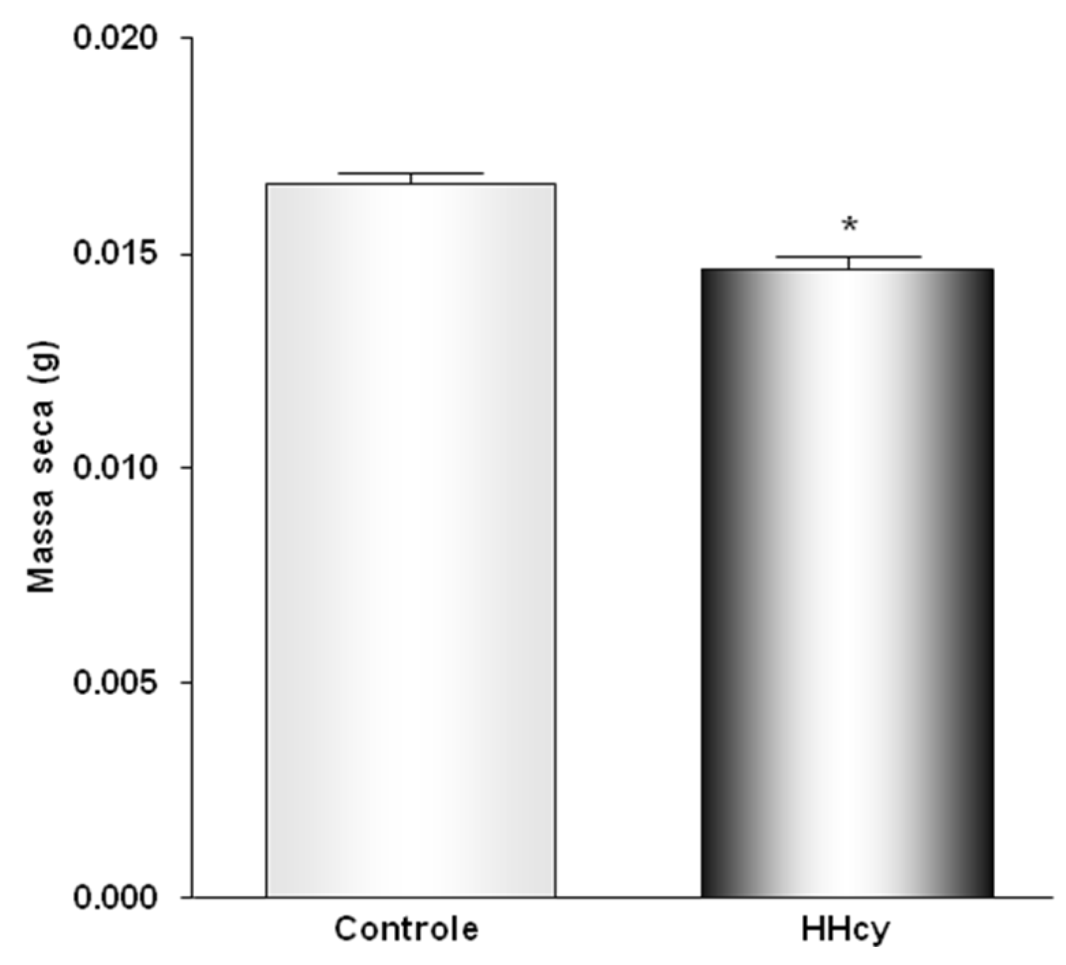

Figura 4: Consequência da HHcy sobre o peso seco de corpos cavernosos. A figura mostra a massa seca de tiras de corpos cavernosos de ratos controle e HHcy. Os dados representam a média \pm E.P.M. $(n=64$ para cada grupo). $\left(^{*}\right)$ significativamente diferente $(p<0,05)$ em relação ao controle. Teste t.

\section{Conclusão parcial}

- Em decorrência da diferença encontrada entre a massa seca de corpos cavernosos de ratos HHcy em relação a de ratos controle, fez-se necessária a correção dos resultados dos protocolos de contração para PhE e ET-1 em relação ao peso seco de cada preparação. 


\subsection{Efeito da HHcy sobre a morfologia de corpos cavernosos}

A análise morfológica de corpos cavernosos de ratos controle e HHcy foi realizada por meio de cortes histológicos e coloração específica, com o objetivo de estudar o efeito da HHcy sobre a morfologia nestes tecidos.

A coloração por Hematoxilina e Eosina evidencia, em roxo, estruturas celulares como núcleo, proteínas ácidas do citoplasma e proteoglicanas e, em rosa, filamentos protéicos do citoesqueleto, fibras colágenas e proteínas mitocondriais.

Em corpos cavernosos de ratos controle foram observadas as trabéculas e os espaços cavernosos, os quais são revestidos por endotélio. As análises morfológicas realizadas em corpos cavernosos de ratos HHcy mostraram que o tratamento não acarretou alterações morfológicas (Figura 5).
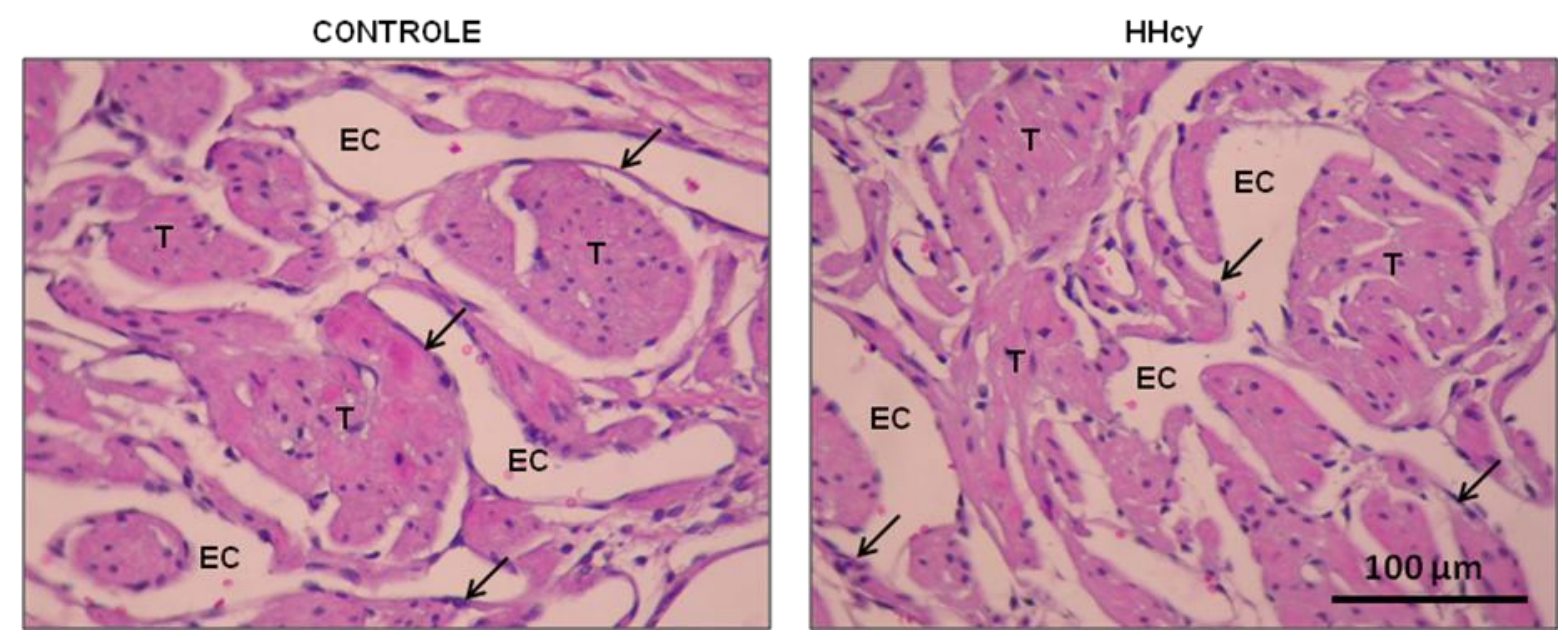

Figura 5: Efeito da HHcy sobre a morfologia de corpos cavernosos. Coloração com Hematoxilina e Eosina de corpos cavernosos de ratos controle e HHcy. Trabécula ( $T$ ), espaço cavernoso (EC), endotélio (seta). Aumento 40x. 


\subsection{Efeito da HHcy sobre os depósitos de colágenos em corpos cavernosos}

Com o objetivo de avaliar se a HHcy causou alterações nos depósitos de colágeno em corpos cavernosos de ratos, utilizou-se a coloração específica de Tricrômico de Gomori. Esta coloração permite identificar as fibras de colágeno em cor verde.

A análise microscópica em corpos cavernosos de ratos controle identificou a presença de fibras de colágeno nas trabéculas. A HHcy parece causar um discreto aumento no depósitos de colágeno nesta região, observado pela coloração verde levemente mais intensa (Figura 6).
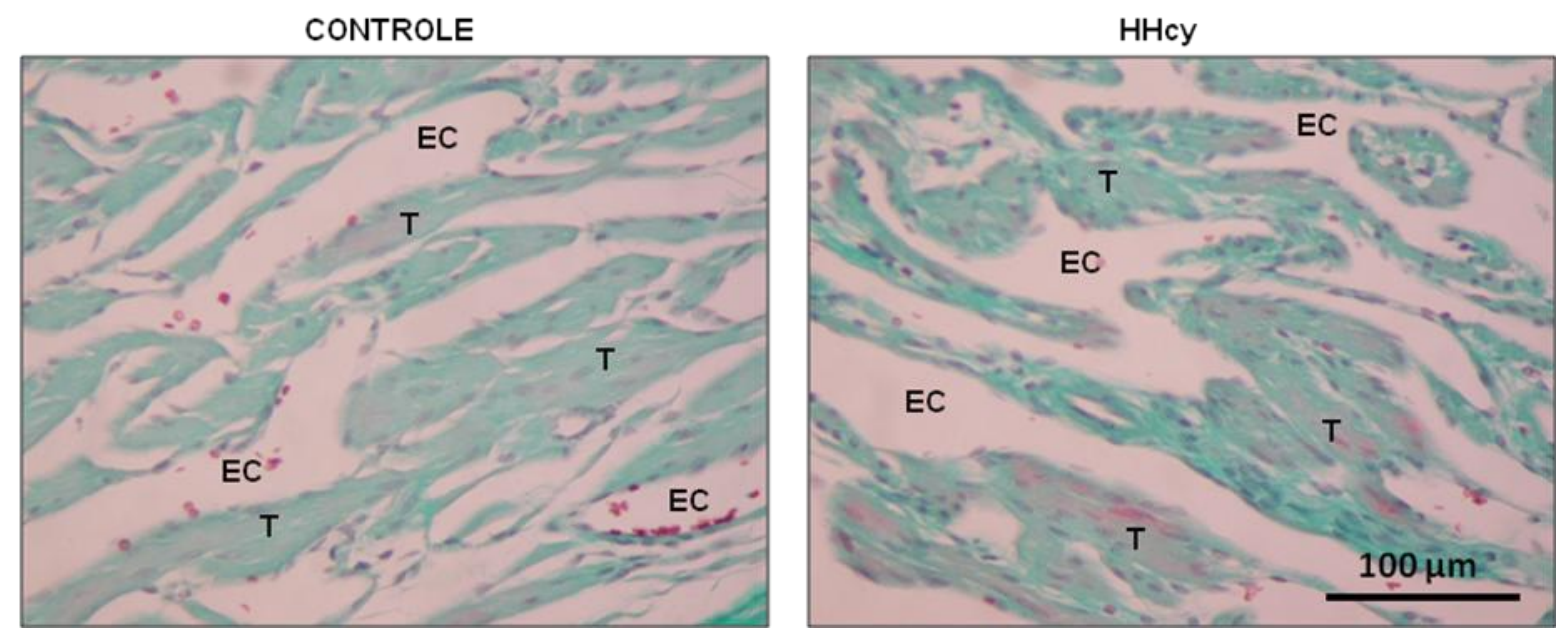

Figura 6: Efeito da HHcy sobre o depósito de colágeno em corpos cavernosos. Coloração com Tricrômico de Gomori de corpos cavernosos de ratos controle e HHcy. Trabécula (T), espaço cavernoso (EC). Aumento 40x. 


\subsection{Efeito da HHcy sobre a expressão de $\alpha$-actina}

O estudo da expressão da proteína a-actina tem por objetivo evidenciar se a HHcy causou hipertrofia ou hiperplasia em corpos cavernosos de ratos.

A imunorreatividade revelou expressão da proteína a-actina, pontos de coloração vermelho, em músculo liso das trabéculas de corpos cavernosos de ratos controle e HHcy (Figura 7).

No entanto, a porcentagem de área marcada não foi significativamente alterada em decorrência da HHcy em relação ao grupo controle (Figura 8).
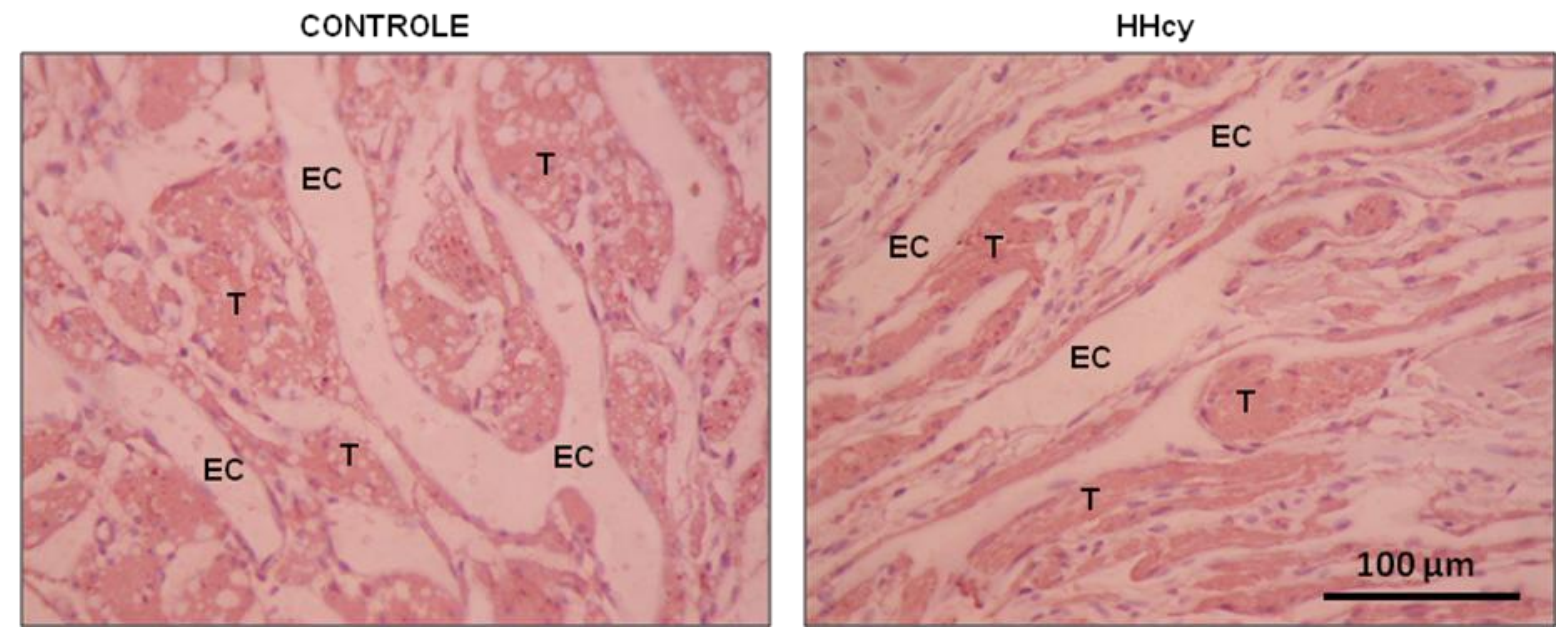

Figura 7: Efeito da HHcy sobre a expressão de $\alpha$-actina. Imunohistoquímica para expressão de $\alpha$-actina em corpos cavernosos de ratos controle e HHcy. Trabécula (T), espaço cavernoso (EC). Aumento 40x.

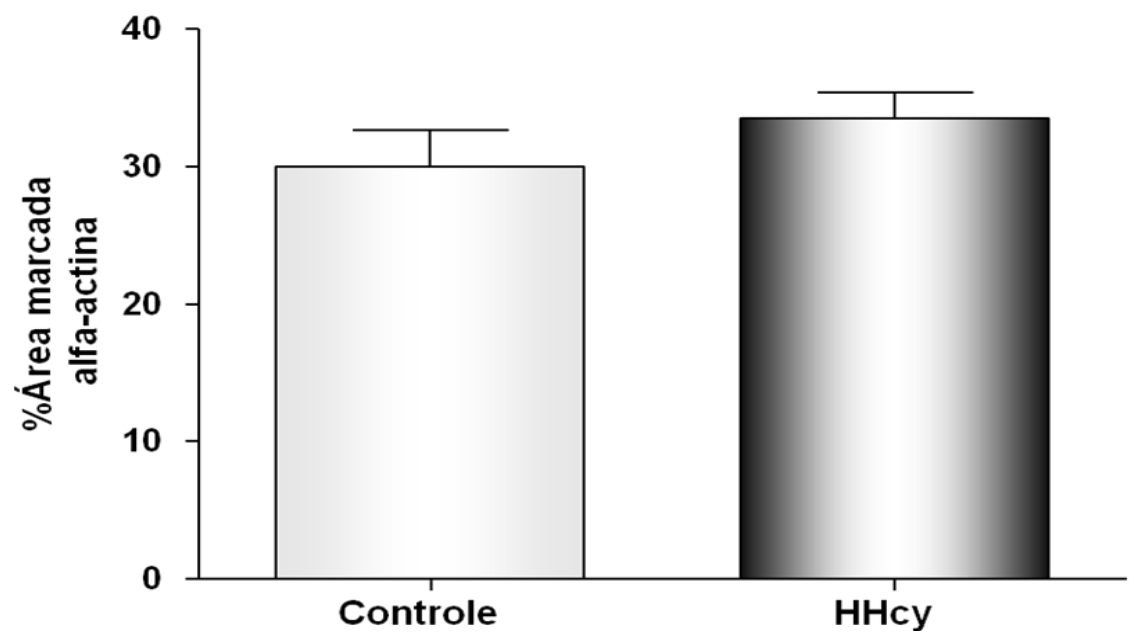

Figura 8: Efeito da HHcy sobre a expressão de $\alpha$-actina. Os valores em porcentagem de área marcada representam a expressão de $\alpha$-actina no músculo liso das trabéculas de corpos cavernosos de ratos controle e HHcy. Os dados representam a média \pm E.P.M. ( $n=5$ para cada grupo). Teste $t(p>0,05)$. 


\section{Conclusões parciais}

- O tratamento com DL-HcyT durante 15 dias não acarretou alterações morfológicas em corpos cavernosos de ratos.

- Foi observado discreto aumento nos depósitos de colágenos em corpos cavernosos de ratos HHcy, no entanto, não acarretou macroalterações que justificassem alterações na reatividade vascular.

- A formação de proteína a-actina, presente no músculo liso das trabéculas, não foi modificada em decorrência da HHcy, evidenciando que não ocorreu hiperplasia ou hipertrofia muscular. 


\subsection{Consequência da HHcy sobre as respostas induzidas por $\mathrm{KCl}$, NPS e ACh}

A consequência da HHcy sobre a contração induzida por $\mathrm{KCl}$ e sobre 0 relaxamento desencandeado por NPS e ACh foram estudadas pela realização de curva concentração-efeito para os respectivos agentes em corpos cavernosos de ratos controle e HHcy.

O KCl (10 a $90 \mathrm{mmol} / \mathrm{L})$ produziu contração dependente da concentração em corpos cavernosos de ratos controle. Em corpos cavernosos de ratos HHcy, a resposta de contração induzida por $\mathrm{KCl}$ não foi modificada em relação ao grupo controle (Figuras 9A; Tabela 1).

O NPS $\left(10^{-9}\right.$ a $\left.3.10^{-4} \mathrm{~mol} / \mathrm{L}\right)$ produziu uma resposta de relaxamento dependente da concentração em corpos cavernosos de ratos controle. $O$ relaxamento induzido por NPS, em corpos cavernosos de ratos HHcy, não foi alterado em relação ao grupo controle (Figuras 9B; Tabela 1).

A ACh $\left(10^{-9}\right.$ a $\left.3.10^{-4} \mathrm{~mol} / \mathrm{L}\right)$ produziu uma resposta de relaxamento dependente da concentração, em corpos cavernosos de ratos controle. A HHcy acarretou redução no Emax de relaxamento da ACh, em corpos cavernosos de ratos deste grupo, em relação ao controle. $O$ valor de $\mathrm{pD}_{2}$ da $A C h$ apresentou-se diminuído (Figura 9C; Tabela 1). 
A
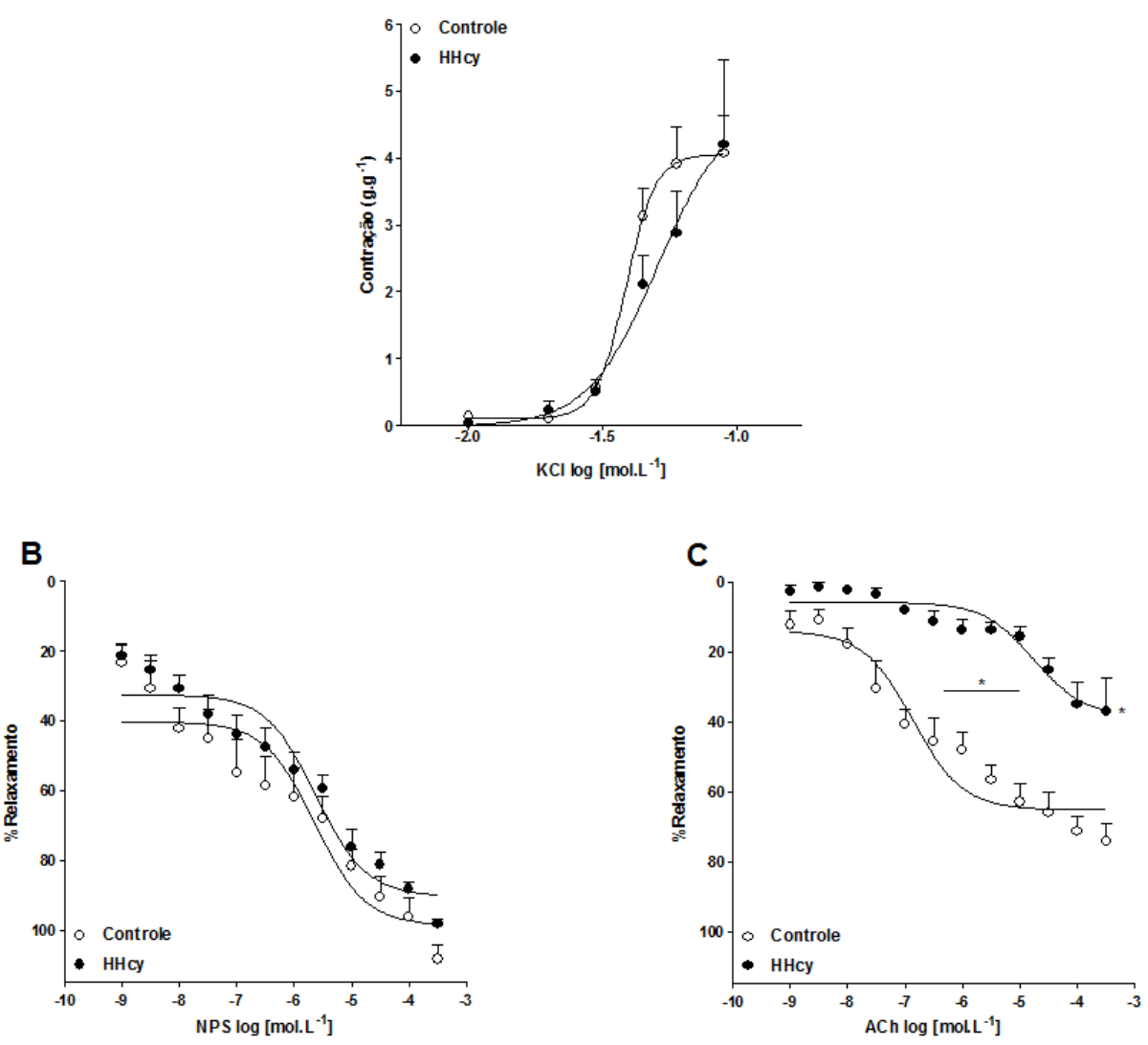

Figura 9: Consequências da HHcy sobre as respostas induzidas por $\mathrm{KCl}$, NPS e ACh. A figura mostra curvas concentração-efeito para $\mathrm{KCl}(\mathrm{n}=8$ para grupo controle e $n=7$ para grupo $\mathrm{HHcy})(A), N P S(n=5$ para cada grupo) (B) e ACh ( $n=5$ para cada grupo) (C) em corpos cavernosos de ratos controle e HHcy. Os dados representam a média \pm E.P.M. $\left(^{*}\right)$ significativamente diferente $(p<0,05)$ em relação ao grupo controle. Teste t.

Tabela 1 - Valores de Emax e $\mathrm{pD}_{2}$ dos respectivos agentes em corpos cavernosos de ratos controle e HHcy.

\begin{tabular}{c|c|c|cc}
\hline \multirow{2}{*}{ Agentes } & \multicolumn{2}{|c|}{ Emax } & \multicolumn{2}{c}{ pD $_{2}$} \\
\cline { 2 - 5 } & Controle & HHcy & Controle & HHcy \\
\hline \multirow{2}{*}{ KCI } & $4,1 \pm 0,6$ & $4,2 \pm 1,3$ & $1,41 \pm 0,03$ & $1,33 \pm 0,05$ \\
NPS & $98,6 \pm 4,6$ & $90,3 \pm 3,1$ & $5,63 \pm 0,20$ & $5,62 \pm 0,13$ \\
ACh & $64,1 \pm 2,3$ & $37,9 \pm 3,6^{*}$ & $7,07 \pm 0,15$ & $4,82 \pm 0,20^{*}$ \\
\hline
\end{tabular}

Os dados representam a média \pm E.P.M. $\left(^{*}\right)$ significativamente diferente $(p<0,05)$ em relação ao grupo controle. Teste t. 


\section{Conclusões parciais}

- A HHcy não alterou a resposta de contração induzida por $\mathrm{KCl}$, sugerindo que o tratamento não altera a função contrátil do corpo cavernoso de ratos, bem como a mobilização de cálcio via canais para cálcio operado por voltagem (VOC).

- Não foi observada modificação no relaxamento induzido por NPS na HHcy, o que sugere que o sistema de transdução de sinal via NO-GMPc não foi afetado pelo tratamento.

- Em corpos cavernosos de ratos HHcy, o relaxamento induzido por ACh apresentou-se reduzido em relação ao grupo controle, evidenciando que houve prejuízo no mecanismo de relaxamento dependente do endotélio. 


\subsection{Efeito da HHcy sobre a contração induzida por ET-1}

Com o objetivo de estudar o efeito da HHcy sobre a contração induzida por ET-1, foram realizadas curvas concentração-efeito para este agonista em corpos cavernosos de ratos controle e HHcy.

A ET-1 $\left(10^{-9}\right.$ a $\left.10^{-5} \mathrm{~mol} / \mathrm{L}\right)$ produziu contração dependente da concentração em corpos cavernosos de ratos controle (Figuras 10 e 11; Tabela 2).

Os resultados mostram que em corpos cavernosos de ratos HHcy, o Emax da ET-1 não apresentou alteração significativa em relação ao grupo controle. Observou-se ainda, que não houve alteração do valor de $\mathrm{pD}_{2}$ (Figuras 10 e 11; Tabela 2).

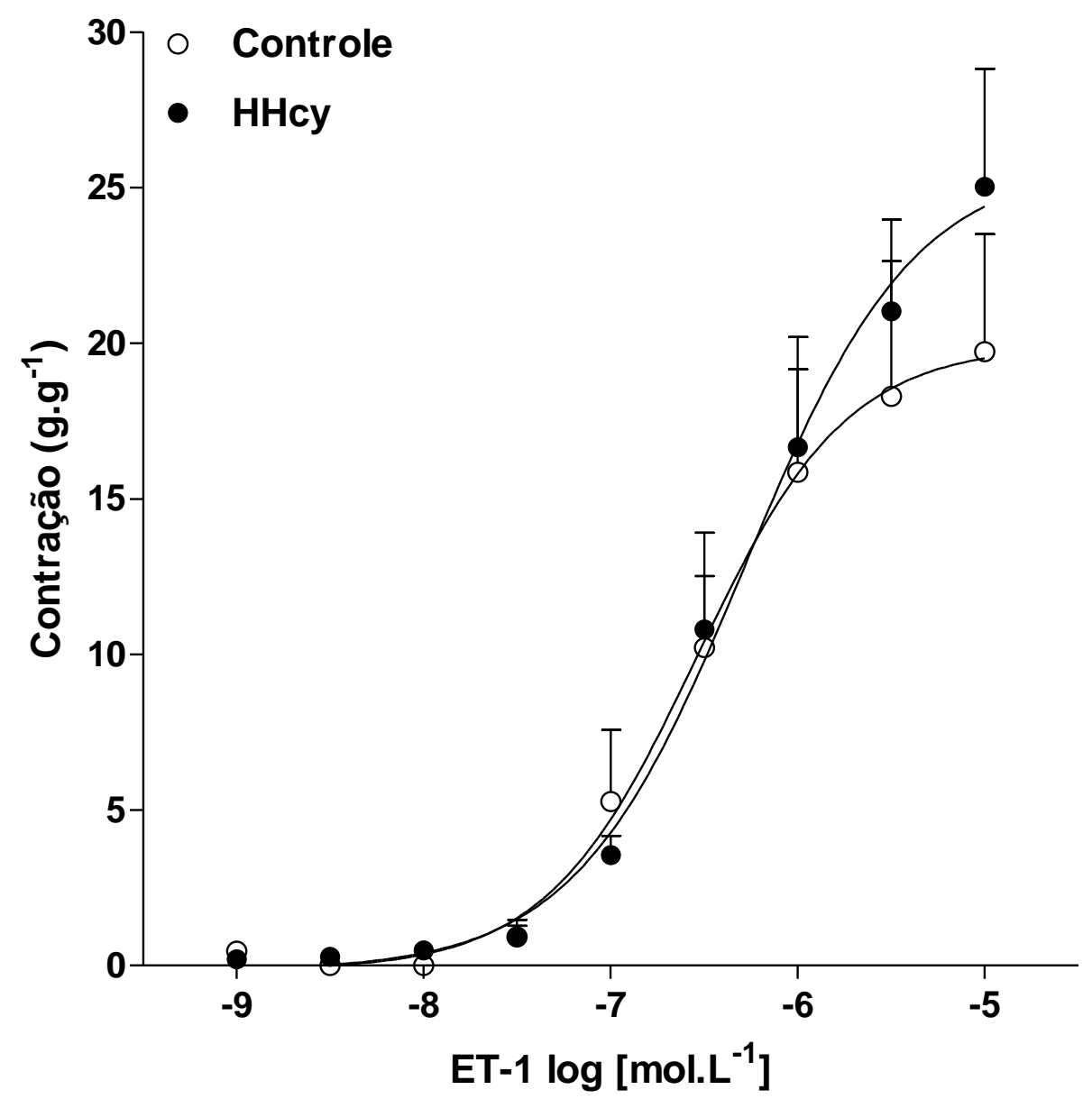

Figura 10: Efeito da HHcy na contração induzida por ET-1. A figura mostra curvas concentração-efeito para ET-1 em corpos cavernosos de ratos controle e HHcy. Os dados representam a média \pm E.P.M. $(n=5$ para cada grupo). Teste t $(p>0,05)$. 


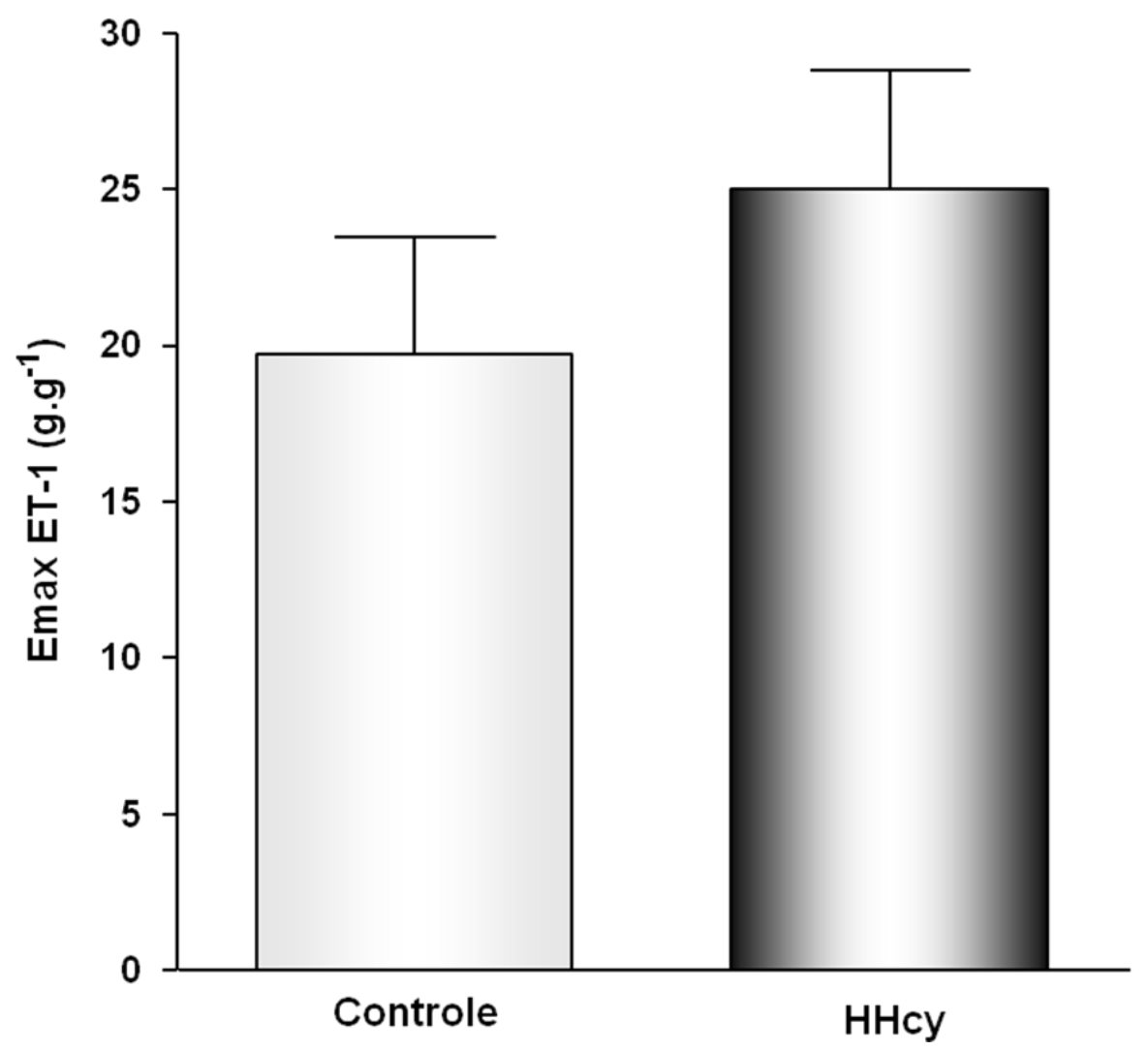

Figura 11: Efeito da HHcy sobre o Emax da ET-1. A figura mostra os valores de Emax da ET-1 em corpos cavernosos de ratos controle e HHcy. Os dados representam a média \pm E.P.M. ( $n=5$ para cada grupo). Teste $t$ ( $p$ $>0,05)$.

Tabela 2 - Valores de Emax e $\mathrm{pD}_{2}$ de ET-1 em corpos cavernosos de ratos controle e HHcy.

\begin{tabular}{c|c|c}
\hline Grupos & Emax $\left(\mathbf{g} \cdot \mathbf{g}^{-1}\right)$ & $\mathbf{p D}_{\mathbf{2}}$ \\
\hline Controle & $19,7 \pm 3,8$ & $6,55 \pm 0,15$ \\
HHcy & $25,0 \pm 3,8$ & $6,32 \pm 0,09$ \\
\hline
\end{tabular}

Os dados representam a média \pm E.P.M. ( $n=5$ para cada grupo). Teste $t(p>0,05)$. 


\subsection{Consequência da HHcy sobre a contração induzida por ET-1, em presença do antagonista dos receptores $\mathrm{ET}_{\mathrm{B}}$}

Com o objetivo de estudar a contração induzida por ET-1, em ausência das respostas de relaxamento via receptores $\mathrm{ET}_{\mathrm{B}}$ que poderiam contrabalancear as respostas de contração via receptores $\mathrm{ET}_{\mathrm{A}}$, foram realizadas curva concentraçãoefeito para ET-1 em corpos cavernosos de ratos controle e HHcy em presença do antagonista dos receptores $\mathrm{ET}_{\mathrm{B}}, \mathrm{BQ}-788$.

Em corpos cavernosos de ratos controle, em presença de BQ-788, a ET-1 $\left(10^{-9}\right.$ a $\left.10^{-5} \mathrm{~mol} / \mathrm{L}\right)$ produziu contração dependente da concentração (Figuras 12 e 13; Tabela 3).

A HHcy acarretou aumento no Emax da ET-1, em relação ao grupo controle, sem alteração do valor de $\mathrm{pD}_{2}$ (Figuras 12 e 13; Tabela 3).

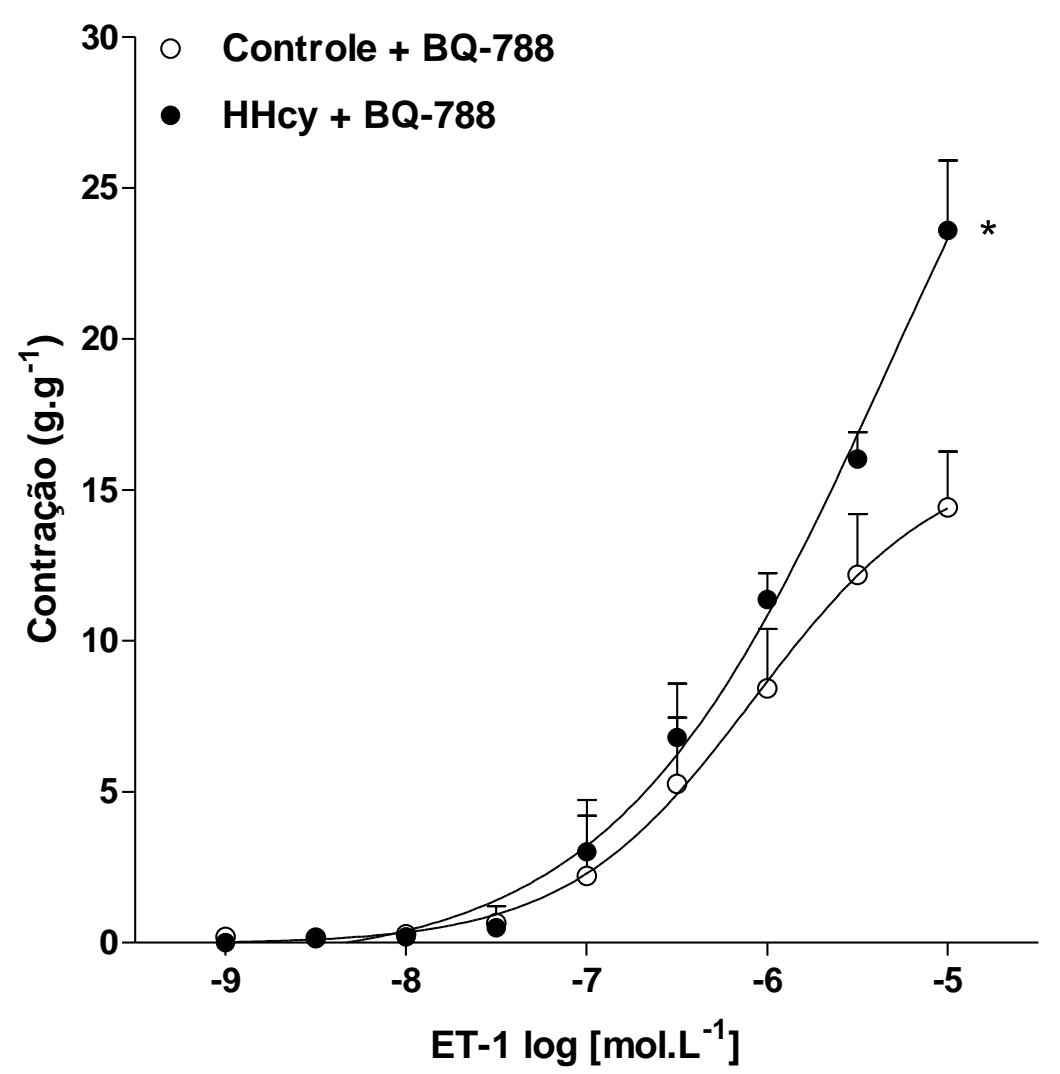

Figura 12: Consequência da HHcy na contração induzida por ET-1, em presença do antagonista dos receptores $\mathrm{ET}_{\mathrm{B}}$. A figura mostra curvas concentração-efeito para $\mathrm{ET}-1$, em presença de $\mathrm{BQ}-788$, em corpos cavernosos de ratos controle e HHcy. Os dados representam média \pm E.P.M. ( $n=5$ para cada grupo). ( $\left.{ }^{*}\right)$ significativamente diferente $(p<0,05)$ em relação ao grupo controle. Teste t. 


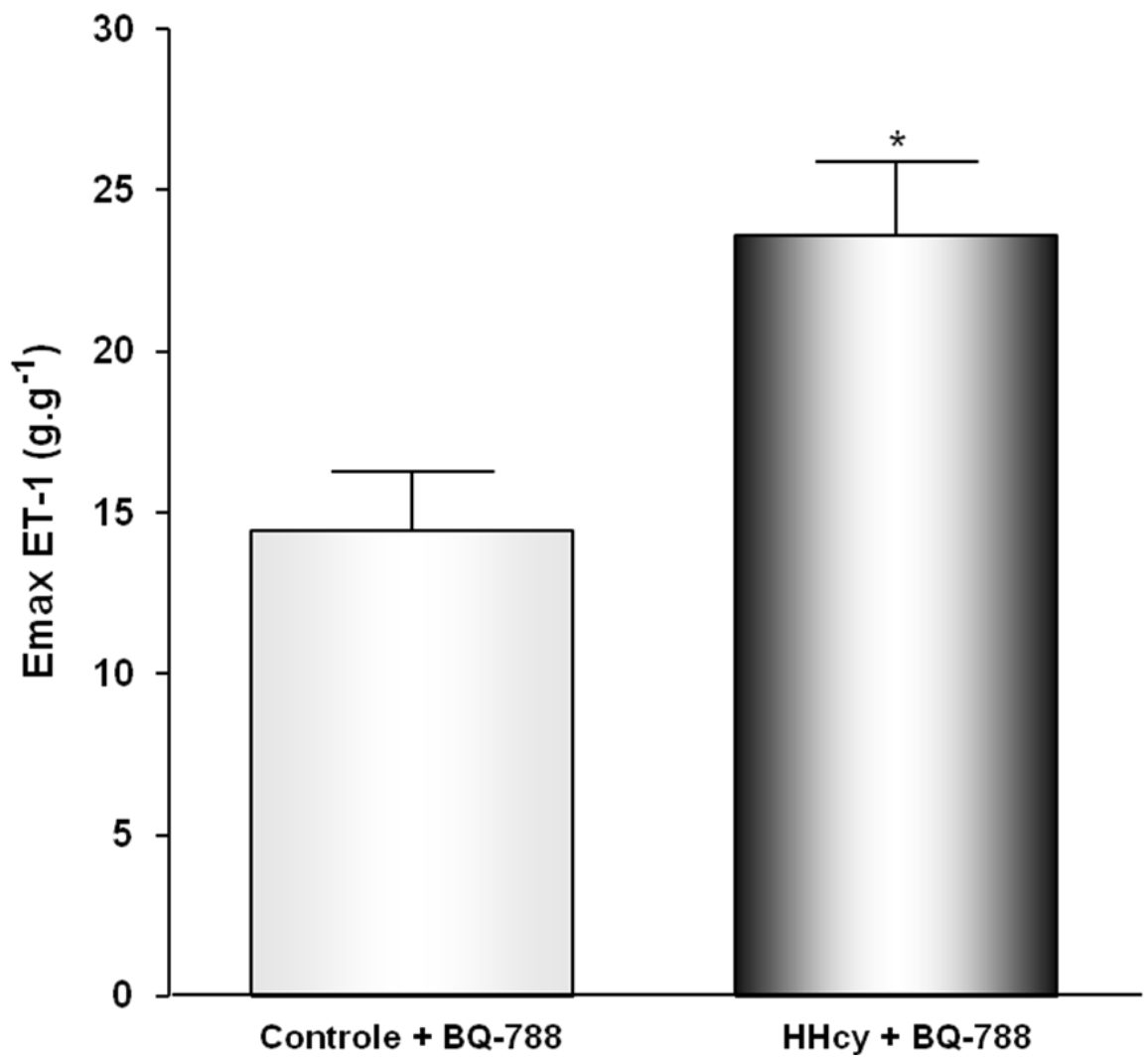

Figura 13: Consequência da HHcy sobre o Emax da ET-1, em presença do antagonista dos receptores

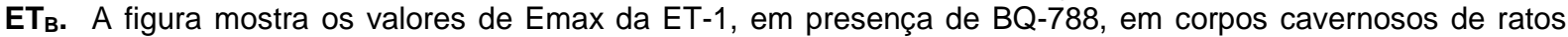
controle e HHcy. Os dados representam a média \pm E.P.M. ( $n=5$ para cada grupo). ( $\left.{ }^{*}\right)$ significativamente diferente $(p<0,05)$ em relação ao grupo controle. Teste t.

Tabela 3 - Valores de Emax e $\mathrm{pD}_{2}$ de ET-1, em presença de BQ-788, em corpos cavernosos de ratos controle e HHcy.

\begin{tabular}{c|c|c}
\hline Grupos & Emax $\left(\mathbf{g} \cdot \mathbf{g}^{-1}\right)$ & $\mathbf{p D}_{\mathbf{2}}$ \\
\hline Controle + BQ-788 & $14,4 \pm 1,8$ & $6,21 \pm 0,12$ \\
HHcy + BQ-788 & $23,6 \pm 2,3^{*}$ & $6,00 \pm 0,07$ \\
\hline
\end{tabular}

Os dados representam a média \pm E.P.M. ( $n=5$ para cada grupo). $\left(^{*}\right)$ significativamente diferente $(p<0,05)$ em relação ao grupo controle. Teste t. 


\subsection{Consequência da HHcy sobre o relaxamento induzido por ET-1}

A consequência da HHcy sobre o relaxamento induzido por ET-1 foi estudada pela realização de curva concentração-efeito para ET-1 em corpos cavernosos de ratos controle e HHcy, pré-contraídos com PhE.

Em corpos cavernosos de ratos controle, a ET-1 $\left(10^{-10}\right.$ a $\left.3.10^{-8} \mathrm{~mol} / \mathrm{L}\right)$ produziu relaxamento dependente da concentração (Figuras 14 e 15; Tabela 4).

A HHcy acarretou redução do relaxamento máximo induzido por ET-1 em relação ao grupo controle, sem alteração no valor de $\mathrm{pD}_{2}$ (Figuras 14 e 15; Tabela 4).

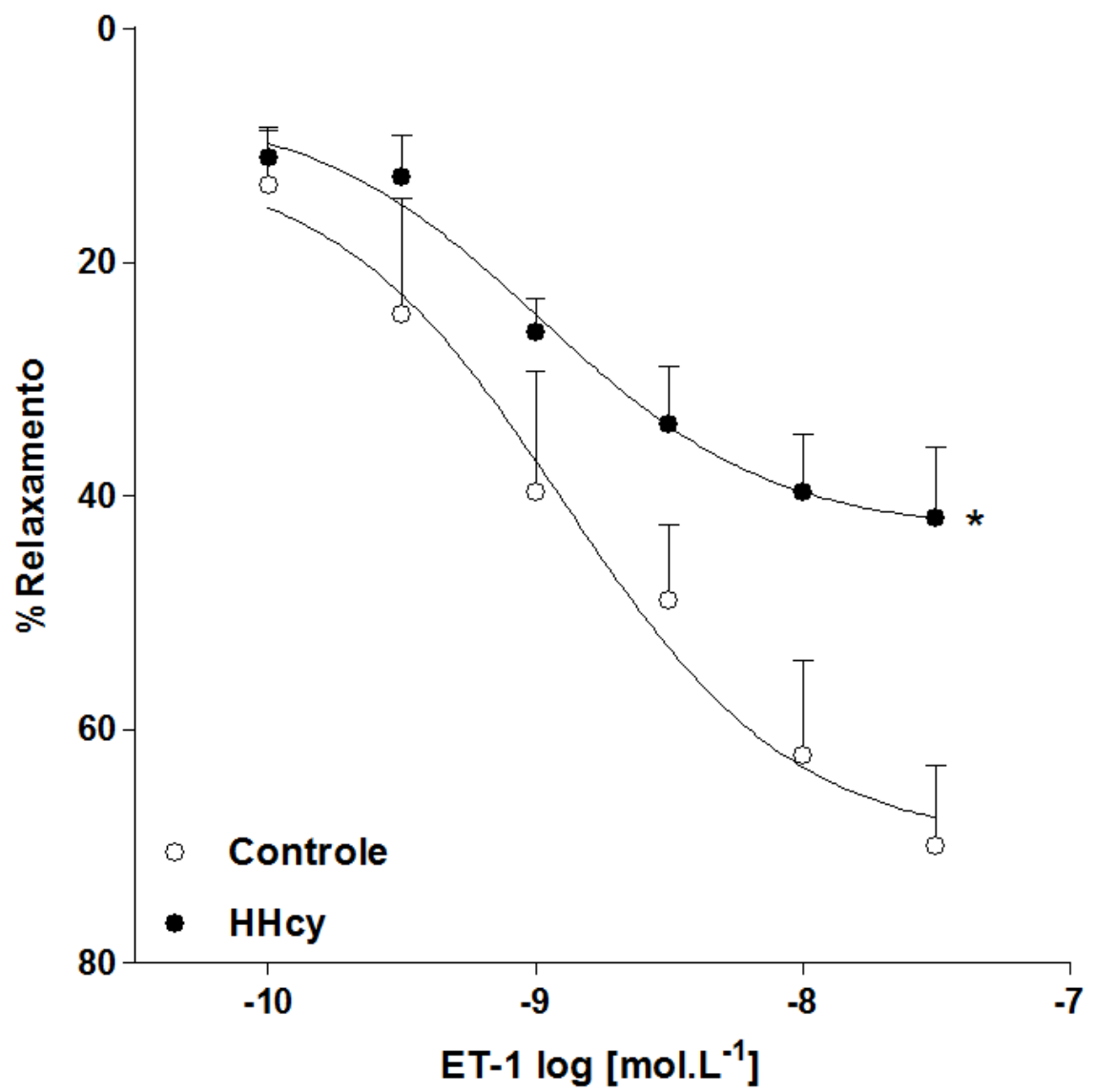

Figura 14: Consequência da HHcy sobre o relaxamento induzido por ET-1. A figura mostra curvas concentrações-efeito para ET-1 em corpos cavernosos de ratos controle e HHcy. Os dados representam a média \pm E.P.M. ( $n=5$ para cada grupo). $\left(^{*}\right)$ significativamente diferente $(p<0,05)$ em relação ao grupo controle. Teste $t$ 


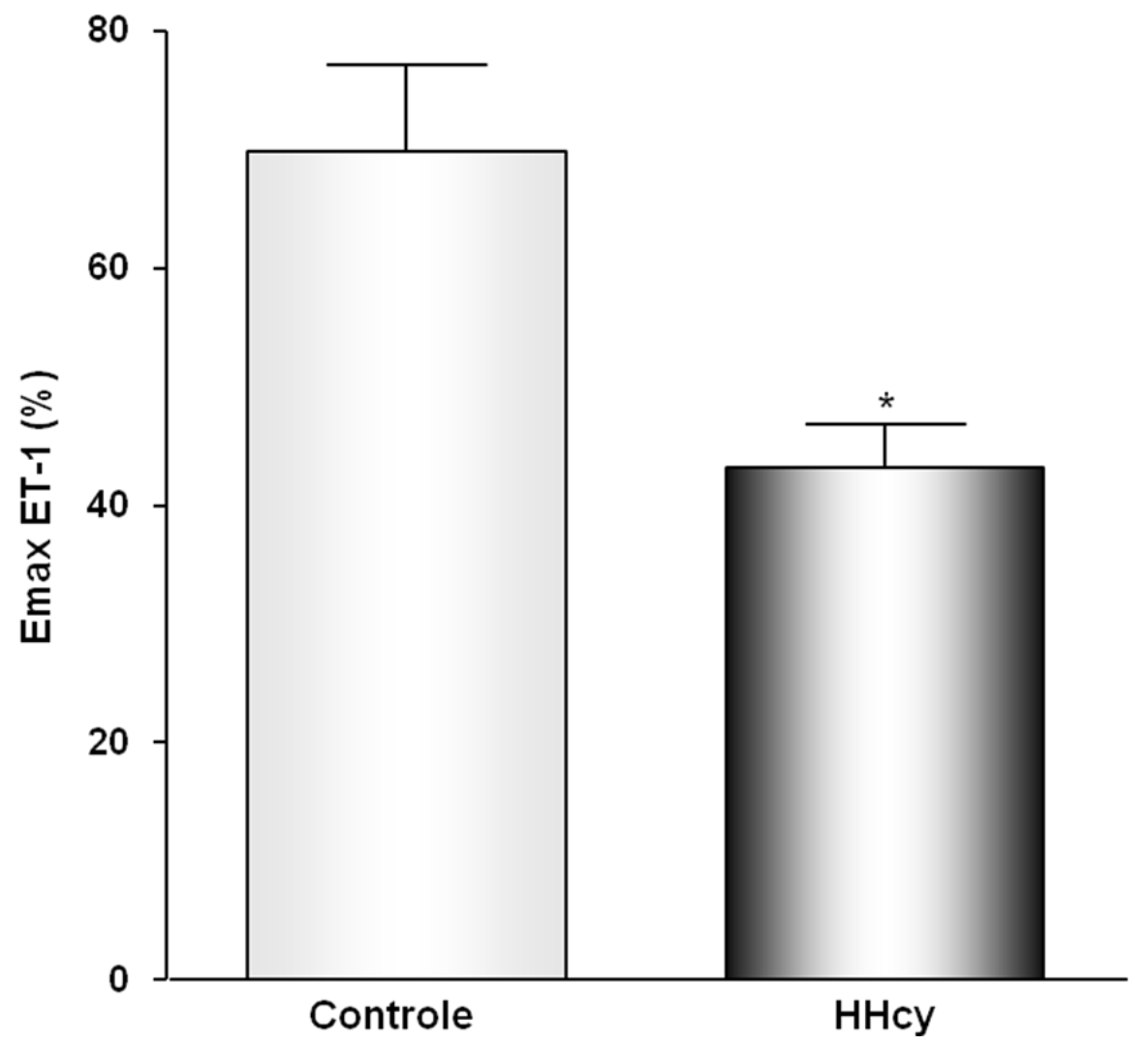

Figura 15: Consequência da HHcy sobre o Emax da ET-1. A figura mostra os valores de Emax da ET-1 em corpos cavernosos de ratos controle e HHcy. Os dados representam a média \pm E.P.M. ( $n=5$ para cada grupo). ( $\left.{ }^{*}\right)$ significativamente diferente $(p<0,05)$ em relação ao grupo controle. Teste t.

Tabela 4 - Valores de Emax e $\mathrm{pD}_{2}$ de $\mathrm{ET}-1$ em corpos cavernosos de ratos controle e HHcy.

\begin{tabular}{l|c|c}
\hline Grupos & Emax (\%) & $\mathbf{p D}_{\mathbf{2}}$ \\
\hline Controle & $69,9 \pm 7,3$ & $8,90 \pm 0,32$ \\
HHcy & $43,1 \pm 3,7^{*}$ & $8,89 \pm 0,28$ \\
\hline
\end{tabular}

Os dados representam a média \pm E.P.M. $\left(n=5\right.$ para cada grupo). $\left(^{*}\right)$ significativamente diferente $(p<0,05)$ em relação ao grupo controle. Teste t. 


\subsection{Consequência da HHcy sobre o relaxamento induzido por ET-1, em presença do antagonista dos receptores $\mathrm{ET}_{\mathrm{A}}$}

O relaxamento induzido por ET-1, em ausência das respostas de contração via receptores $\mathrm{ET}_{\mathrm{A}}$ contrabalanceando as respostas de relaxamento via receptores $E T_{B}$, foi estudado pela realização de curva concentração-efeito para ET-1 em corpos cavernosos de ratos controle e HHcy, em presença do antagonista dos receptores $\mathrm{ET}_{\mathrm{A}}, \mathrm{BQ}-123$, pré-contraídos com PhE.

Em corpos cavernosos de ratos controle, em presença de BQ-123, a ET-1 $\left(10^{-10}\right.$ a $\left.10^{-6} \mathrm{~mol} / \mathrm{L}\right)$ produziu relaxamento dependente da concentração (Figuras $16 \mathrm{e}$ 17; Tabela 5).

A HHcy acarretou redução do relaxamento máximo induzido por ET-1 em relação ao grupo controle, sem alteração no valor de $\mathrm{pD}_{2}$, em presença de $\mathrm{BQ}-123$ (Figuras 16 e 17; Tabela 5).

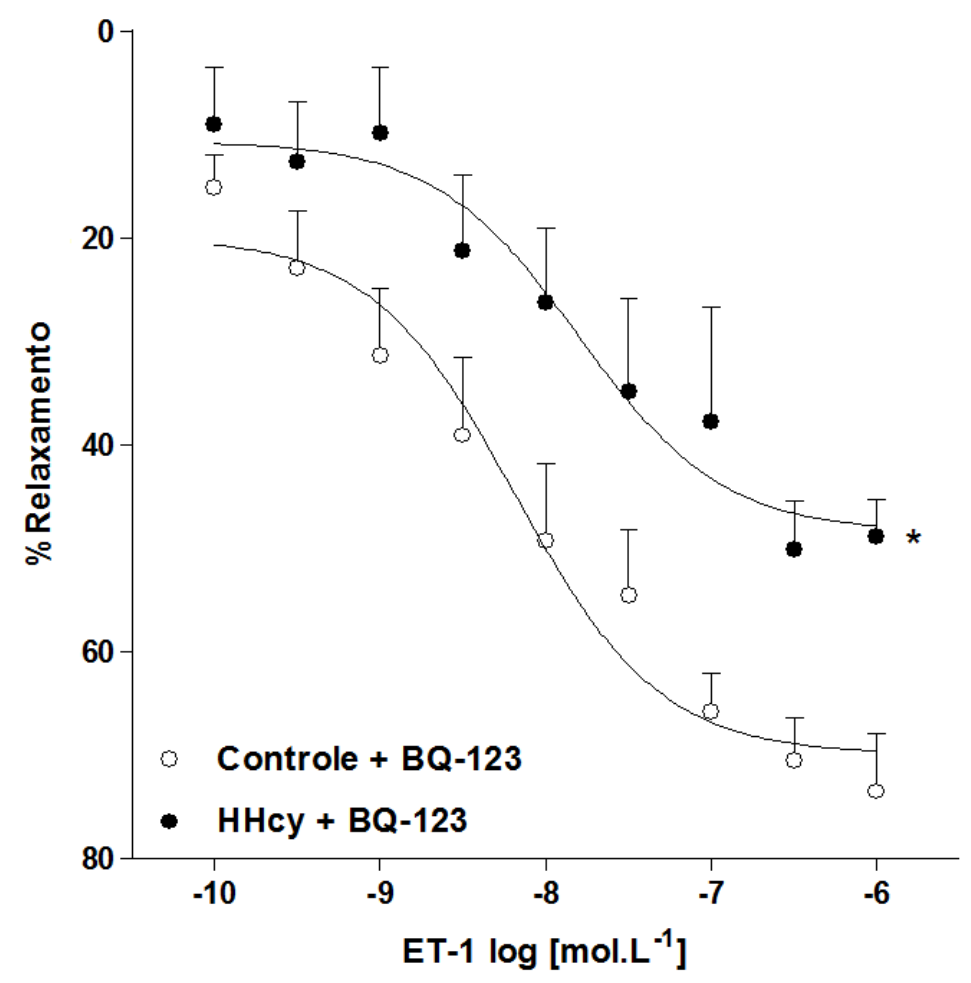

Figura 16: Consequência da HHcy sobre o relaxamento induzido por ET-1, em presença do antagonista dos receptores $\mathbf{E T}_{\mathbf{A}}$. A figura mostra curvas concentração-efeito para ET-1, em presença de BQ-123, em corpos cavernosos de ratos controle e HHcy. Os dados representam a média \pm E.P.M. ( $n=5$ para cada grupo). ( $\left.{ }^{*}\right)$ significativamente diferente $(p<0,05)$ em relação ao grupo controle. Teste t. 


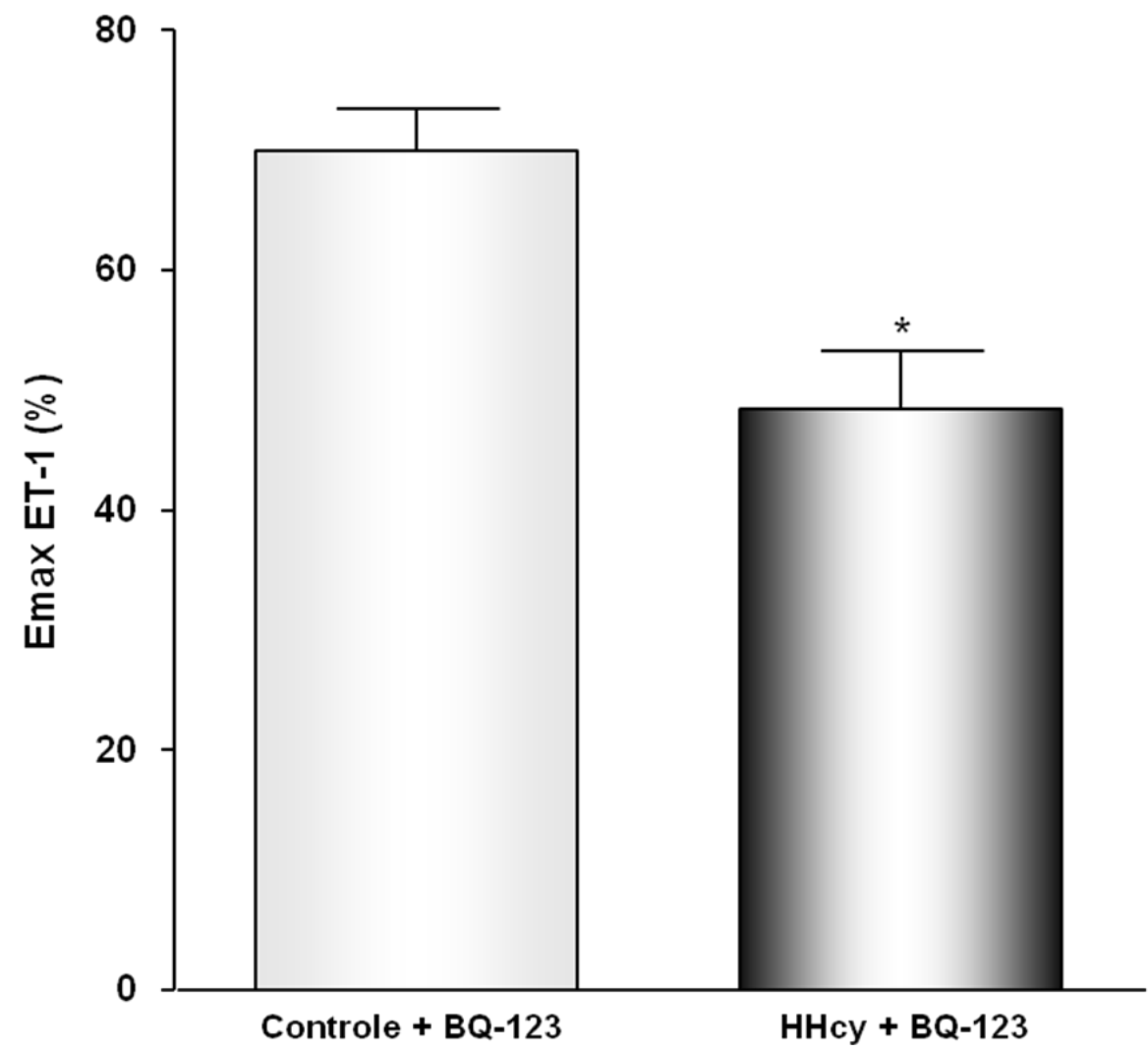

Figura 17: Consequência da HHcy sobre o Emax da ET-1, em presença de antagonista dos receptores $\mathrm{ET}_{\mathrm{A}}$. A figura mostra os valores de Emax da ET-1, em presença de BQ-123, em corpos cavernosos de ratos controle e HHcy. Os dados representam a média \pm E.P.M. ( $n=5$ para cada grupo). ( $\left.{ }^{\star}\right)$ significativamente diferente $(p<0,05)$ em relação ao grupo controle. Teste t.

Tabela 5 - Valores de Emax e $\mathrm{pD}_{2}$ de ET-1, em presença de BQ-123, em corpos cavernosos de ratos controle e HHcy.

\begin{tabular}{c|c|c}
\hline Grupos & Emax (\%) & $\mathbf{p D}_{\mathbf{2}}$ \\
\hline Controle + BQ-123 & $69,9 \pm 3,5$ & $8,18 \pm 0,20$ \\
HHcy + BQ-123 & $48,4 \pm 4,8^{*}$ & $7,80 \pm 0,31$ \\
\hline
\end{tabular}

Os dados representam a média \pm E.P.M. $\left(n=5\right.$ para cada grupo). $\left({ }^{*}\right)$ significativamente diferente $(p<0,05)$ em relação ao grupo controle. Teste t. 


\subsection{Consequência da HHcy sobre o relaxamento induzido por IRL-1620}

A consequência da HHcy sobre o relaxamento induzido por IRL-1620, agonista dos receptores $\mathrm{ET}_{\mathrm{B}}$, foi estudada pela realização de curva concentraçãoefeito para IRL-1620 em corpos cavernosos de ratos controle e HHcy, pré-contraídos com PhE.

Em corpos cavernosos de ratos controle, o IRL-1620 produziu relaxamento dependente da concentração (Figuras 18 e 19; Tabela 6).

A HHcy acarretou redução do relaxamento máximo induzido por IRL-1620 em relação ao grupo controle, sem alteração no valor de $\mathrm{pD}_{2}$ (Figuras 18 e 19; Tabela 6).

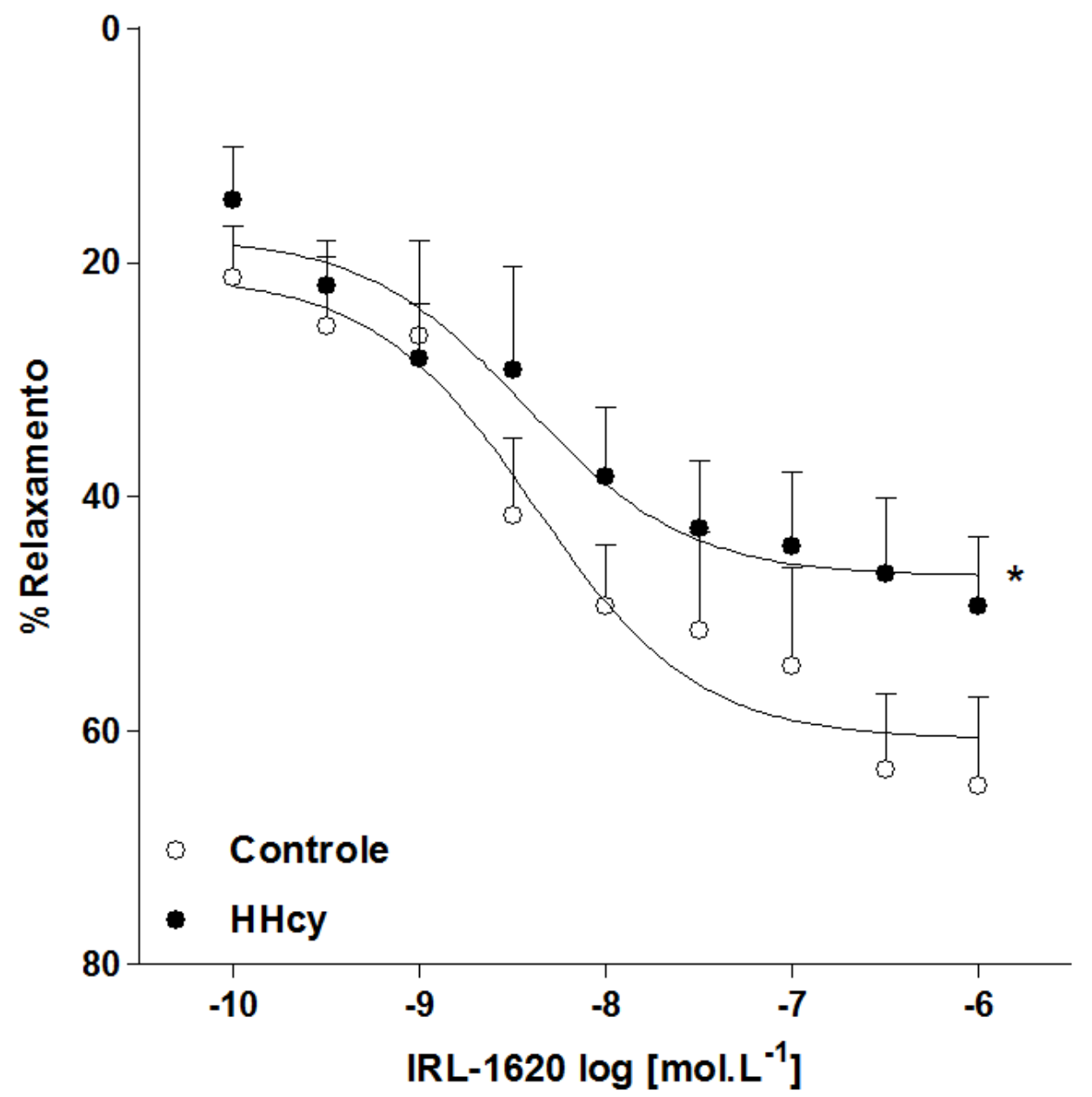

Figura 18: Consequência da HHcy sobre o relaxamento induzido por IRL-1620. A figura mostra curvas concentração-efeito para IRL-1620 em corpos cavernosos de ratos controle e HHcy. Os dados representam a média \pm E.P.M. ( $n=5$ para cada grupo). $\left(^{*}\right)$ significativamente diferente $(p<0,05)$ em relação ao grupo controle. Teste t. 


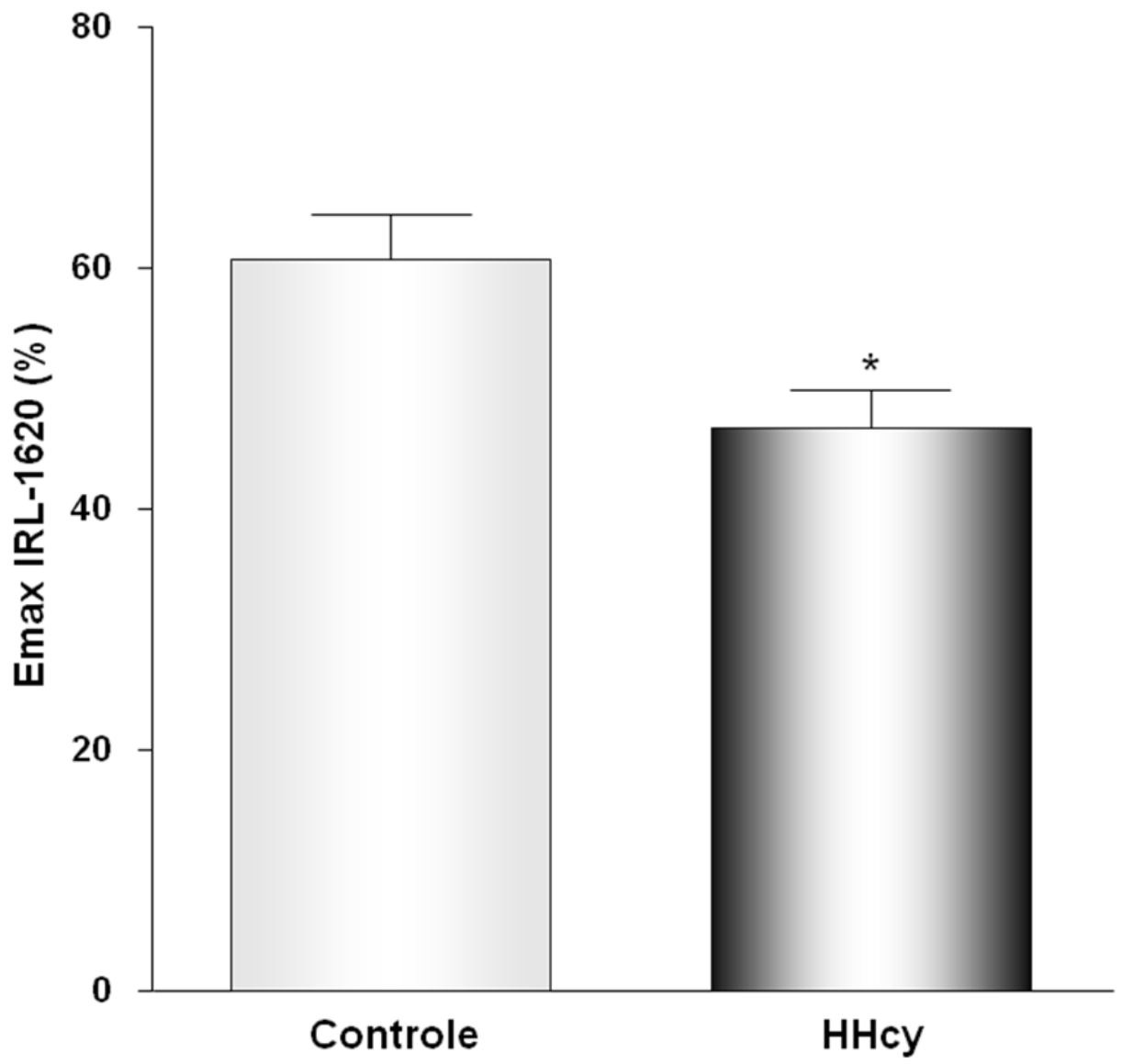

Figura 19: Consequência da HHcy sobre o Emax do IRL-1620. A figura mostra os valores de Emax para IRL1620 em corpos cavernosos de ratos controle e HHcy. Os dados representam a média \pm E.P.M. $(n=5$ para cada grupo). $\left({ }^{*}\right)$ significativamente diferente $(p<0,05)$ em relação ao grupo controle. Teste t.

Tabela 6 - Valores de Emax e $\mathrm{pD}_{2}$ de IRL-1620 em corpos cavernosos de ratos controle e HHcy.

\begin{tabular}{c|c|c}
\hline Grupos & Emax (\%) & $\mathbf{p D}_{\mathbf{2}}$ \\
\hline Controle & $60,7 \pm 3,8$ & $8,38 \pm 0,29$ \\
HHcy & $46,8 \pm 3,1^{*}$ & $8,43 \pm 0,34$ \\
\hline
\end{tabular}

Os dados representam a média \pm E.P.M. $\left(n=5\right.$ para cada grupo). $\left({ }^{*}\right)$ significativamente diferente $(p<0,05)$ em relação ao grupo controle. Teste t. 


\subsection{Participação dos metabólitos da NOS sobre o relaxamento induzido por IRL-1620}

Com o objetivo de estudar a participação dos metabólicos derivados da enzima NOS no relaxamento induzido por IRL-1620, agonista dos receptores $\mathrm{ET}_{\mathrm{B}}$, foram realizadas curvas concentração-efeito para IRL-1620, em corpos cavernosos de ratos controle e HHcy, em presença ou ausência de inibidor não-seletivo da NOS, L-NAME.

Em corpos cavernosos de ratos controle, o relaxamento máximo induzido por IRL-1620 foi reduzido pela adição de L-NAME, em relação ao respectivo grupo em ausência deste. Não se observaram diferenças no valor de $p D_{2}$ do IRL-1620 entre os grupos (Figuras 20A e 21; Tabela 7).

A presença de L-NAME não alterou o relaxamento máximo induzido por IRL1620 em corpos cavernosos de ratos HHcy, em relação ao respectivo grupo em ausência deste inibidor, assim como o valor de $\mathrm{pD}_{2}$ (Figuras 20B e 21; tabela 7).
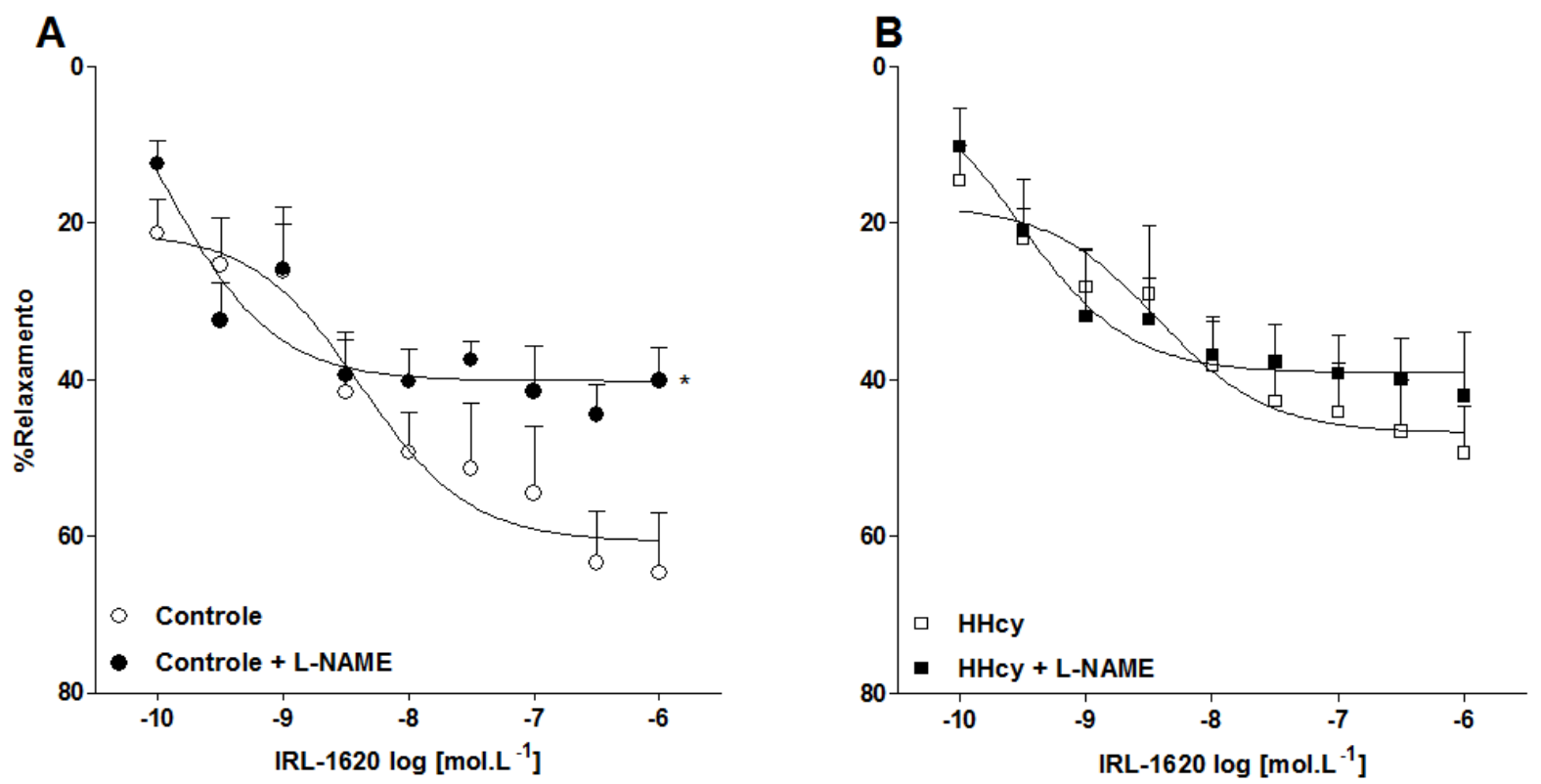

Figura 20: Participação dos metabólitos da NOS no relaxamento induzido por IRL-1620. A figura mostra curvas concentração-efeito para IRL-1620 em corpos cavernosos de ratos controle $(A)$ e HHcy (B), em presença ou ausência de L-NAME. Os dados representam a média \pm E.P.M. ( $n=5$ para cada grupo). ( ${ }^{*}$ ) significativamente diferente $(p<0,05)$ em relação ao respectivo grupo em ausência de L-NAME. ANOVA de uma via, pós-teste de Bonferroni. 


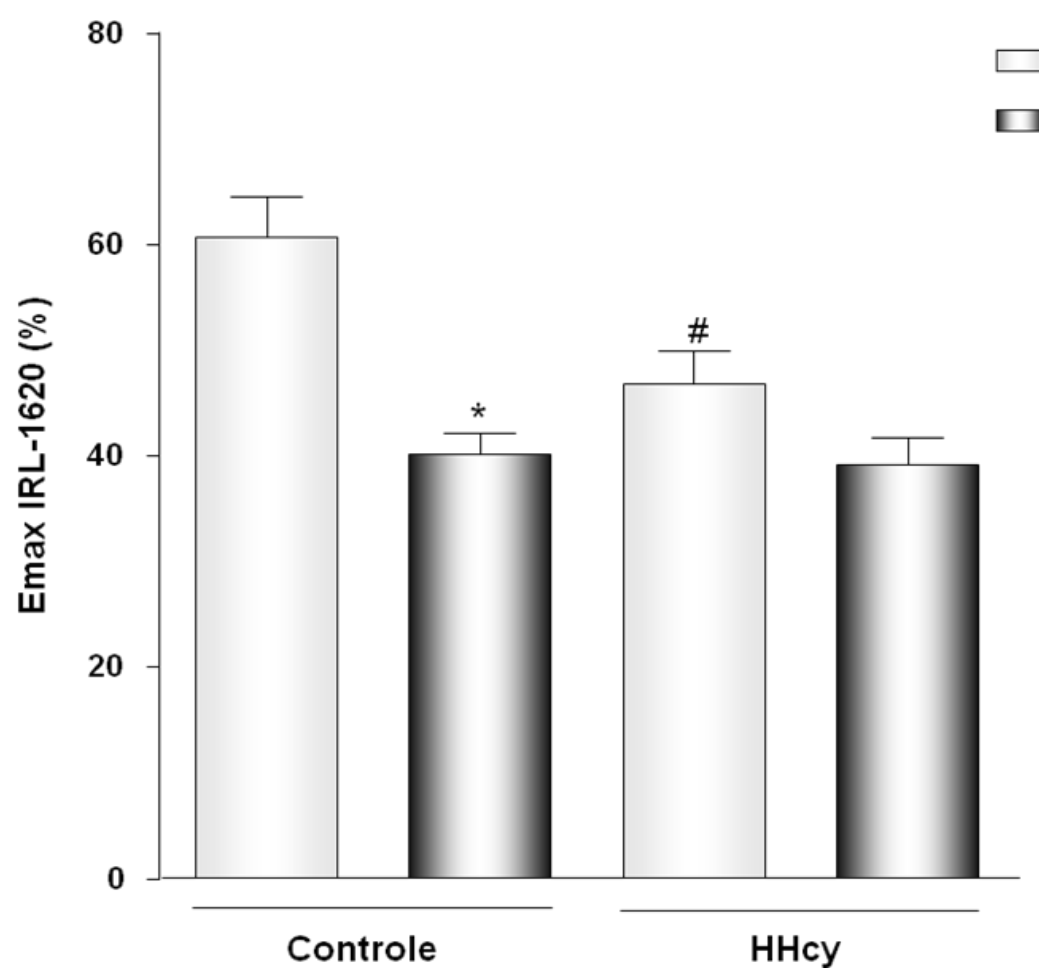

Figura 21: Participação dos metabólitos da NOS no Emax do IRL-1620. A figura mostra os valores de Emax do IRL-1620, em presença ou ausência de L-NAME, em corpos cavernosos de ratos controle e HHcy. Os dados representam a média \pm E.P.M. ( $n=5$ para cada grupo). $\left.{ }^{*}\right)$ significativamente diferente $(p<0,05)$ em relação ao respectivo grupo em ausência de L-NAME. (\#) significativamente diferente $(p<0,05)$ em relação ao respectivo controle em ausência ou presença de L-NAME. ANOVA de uma via, pós-teste de Bonferroni.

Tabela 7 - Valores de Emax e $\mathrm{pD}_{2}$ de IRL-1620, em presença ou ausência de LNAME, em corpos cavernosos de ratos controle e HHcy.

\begin{tabular}{l|cc|cc}
\hline \multirow{2}{*}{ Grupos } & \multicolumn{2}{|c|}{ Emax (\%) } & \multicolumn{2}{c}{$\mathbf{p D}_{2}$} \\
\cline { 2 - 5 } & Controle & HHcy & Controle & HHcy \\
\hline \multirow{2}{*}{ Ausência } & $60,7 \pm 3,8$ & $46,8 \pm 3,1^{\#}$ & $8,4 \pm 0,3$ & $8,4 \pm 0,3$ \\
& $40,2 \pm 1,9^{*}$ & $39,1 \pm 2,5$ & $9,9 \pm 0,6$ & $9,5 \pm 0,5$ \\
\hline
\end{tabular}

Os dados representam a média \pm E.P.M. $\left(n=5\right.$ para cada grupo). $\left({ }^{\star}\right)$ significativamente diferente $(p<0,05)$ em relação ao respectivo grupo na ausência de L-NAME. (\#) significativamente diferente $(p<0,05)$ em relação ao respectivo grupo controle em ausência ou presença de L-NAME. ANOVA de uma via, pós-teste de Bonferroni. 


\subsection{Consequência da HHcy nos níveis basais de ERO e nos níveis produzidos por ET-1}

Com o objetivo de medir os níveis basais de ERO e os níveis produzidos por ET-1, realizou-se a medida de fluorescência por microscopia confocal.

A HHcy aumentou a fluorescência basal em corpos cavernosos deste ratos em relação aos do grupo controle (Figuras 22 e 23).

A adição de ET-1 não alterou a fluorescência basal em corpos cavernosos de ratos controle ou HHcy (Figuras 22 e 23).

Em presença do seqüestrador seletivo para $\mathrm{O}_{2}{ }^{-}$, tiron, observou-se redução da intensidade de fluorescência basal e após estímulo com ET-1 em corpos cavernosos de ratos controle (Figura 22 e 23).

Em corpos cavernosos de ratos HHcy, o sequestrador tiron reduziu a intensidade de fluorescência basal e após adição de ET-1 (Figura 22 e 23).

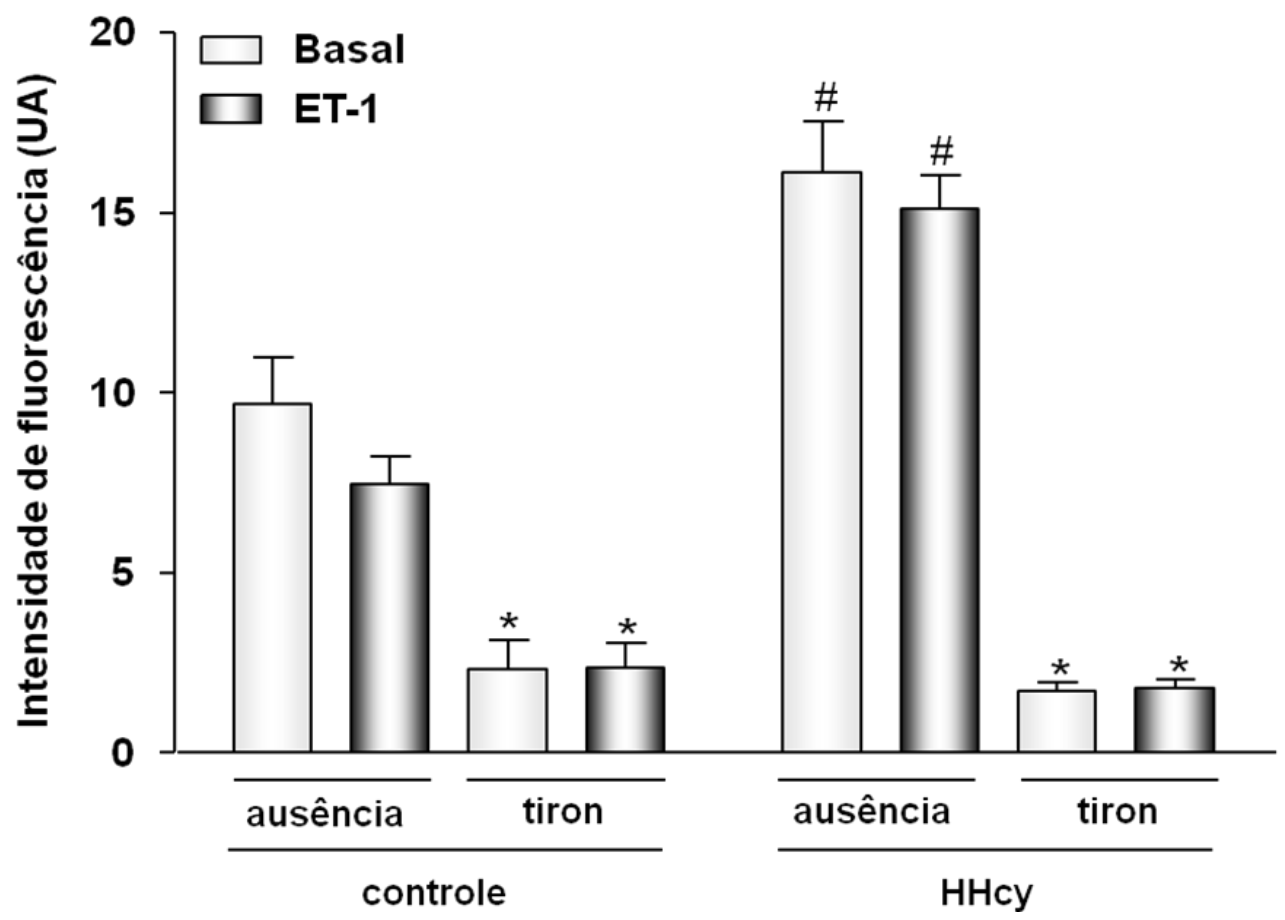

Figura 22: Consequência da HHcy na intensidade de fluorescência basal e após estímulo com ET-1, em presença ou ausência de tiron. A figura mostra a intensidade de fluorescência basal emitida por corpos cavernosos de ratos controle e HHcy e a produzida por ET-1, em presença ou ausência do pré-tratamento com tiron. Os dados representam a média \pm E.P.M. $\left(n=5\right.$ para cada grupo). $\left({ }^{*}\right)$ significativamente diferente $(p<0,05)$ em relação à fluorescência emitida por corpos cavernosos de ratos dos respectivos grupos em ausência de tiron. (\#) significativamente diferente $(p<0,05)$ em relação à fluorescência, basal ou após estímulo com ET-1, do grupo controle em ausência de tiron. ANOVA de uma via, pós-teste de Bonferroni. 


\section{A. Controle}
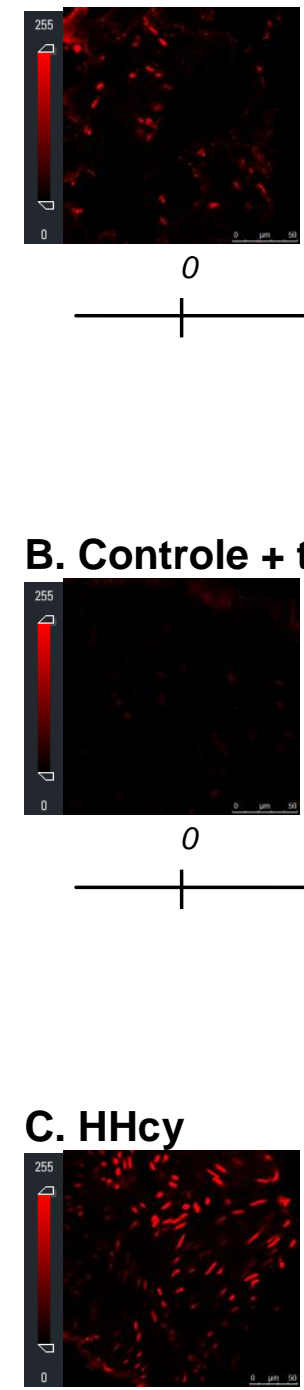

0

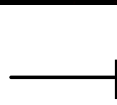

\section{HHcy}

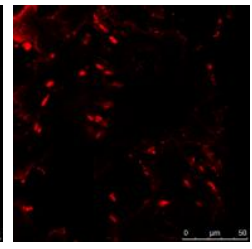

100
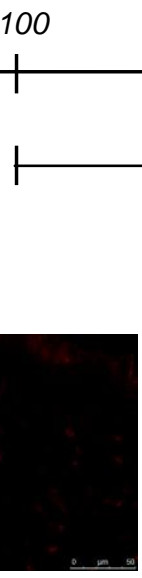

100

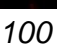

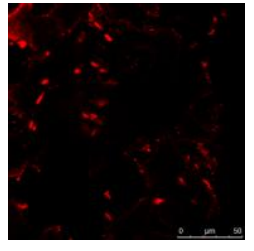

150

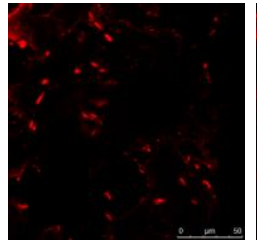

200
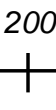

$E T-1$
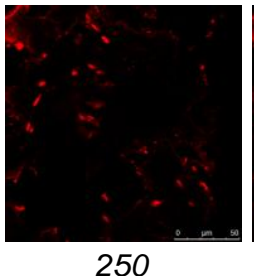

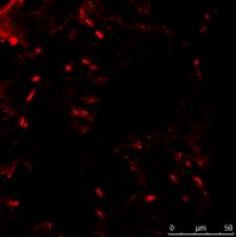

300

Tempo (s)

\section{B. Controle + tiron}

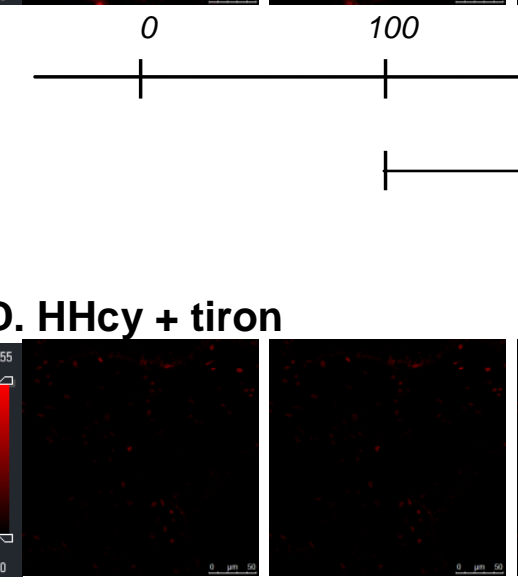

100

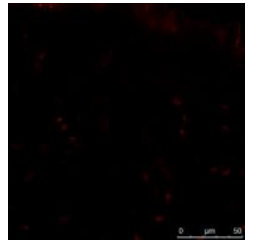

150

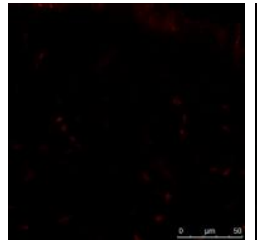

200

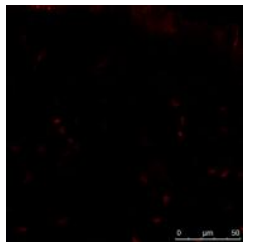

250

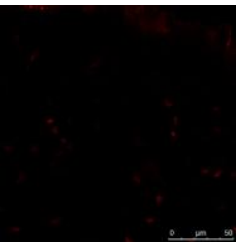

300

Tempo (s)

ET-1

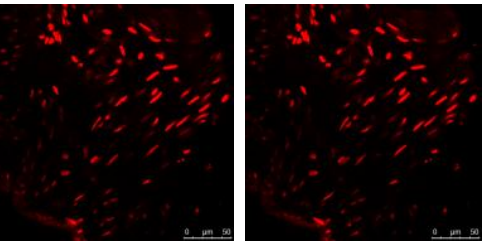

150

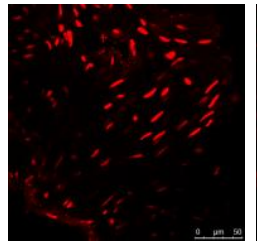

200

ET-1

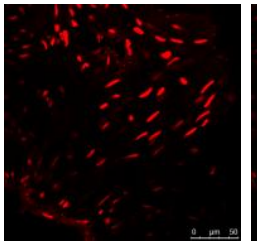

250

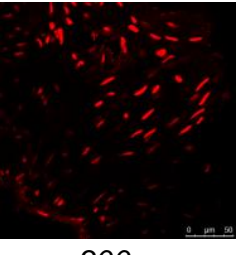

300

Tempo (s)
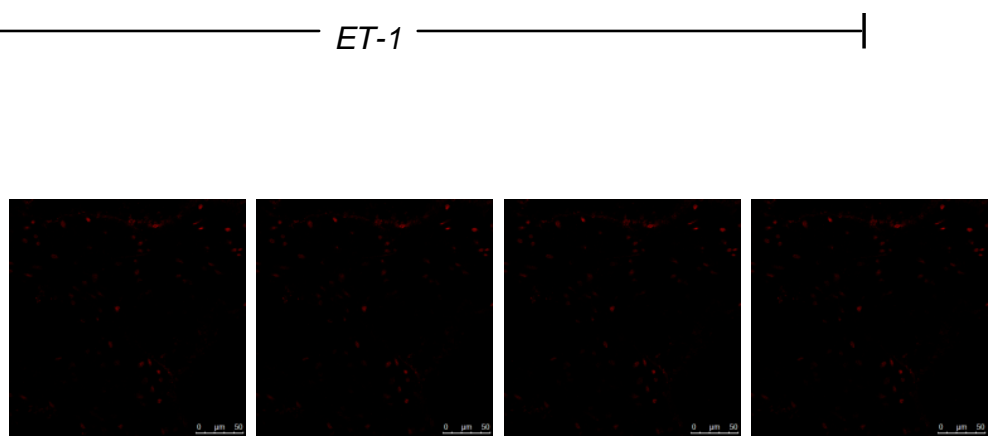

300

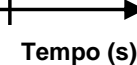

1

Figura 23: Imagens representativas da fluorescência em corpos cavernosos marcados com brometo de etídio. A figura mostra a marcação com brometo de etídio, antes ( $t=0 \mathrm{~s})$ e após $(\mathrm{t}=100 \mathrm{~s})$ a estimulação com ET-1 em corpos cavernosos de ratos controle em ausência (A) ou em presença de tiron (B) e em corpos cavernosos de ratos HHcy em ausência (C) ou presença de tiron (D). 


\subsection{Efeito da HHcy sobre a expressão do RNAm para pré-pró-ET, ECE e para} os receptores $\mathrm{ET}_{\mathrm{A}}$ e $\mathrm{ET}_{\mathrm{B}}$.

A expressão do RNAm para pré-pró-ET-1, ECE e para os receptores $E_{\mathrm{A}} \mathrm{e}$ $\mathrm{ET}_{\mathrm{B}}$ foi analisada pela técnica de Real Time-PCR. A HHcy não acarretou alterações significativas na expressão de RNAm para pré-pré-ET-1, ECE e para os receptores $\mathrm{ET}_{\mathrm{A}}$ e $\mathrm{ET}_{\mathrm{B}}$ em relação ao grupo controle (Figura 24).
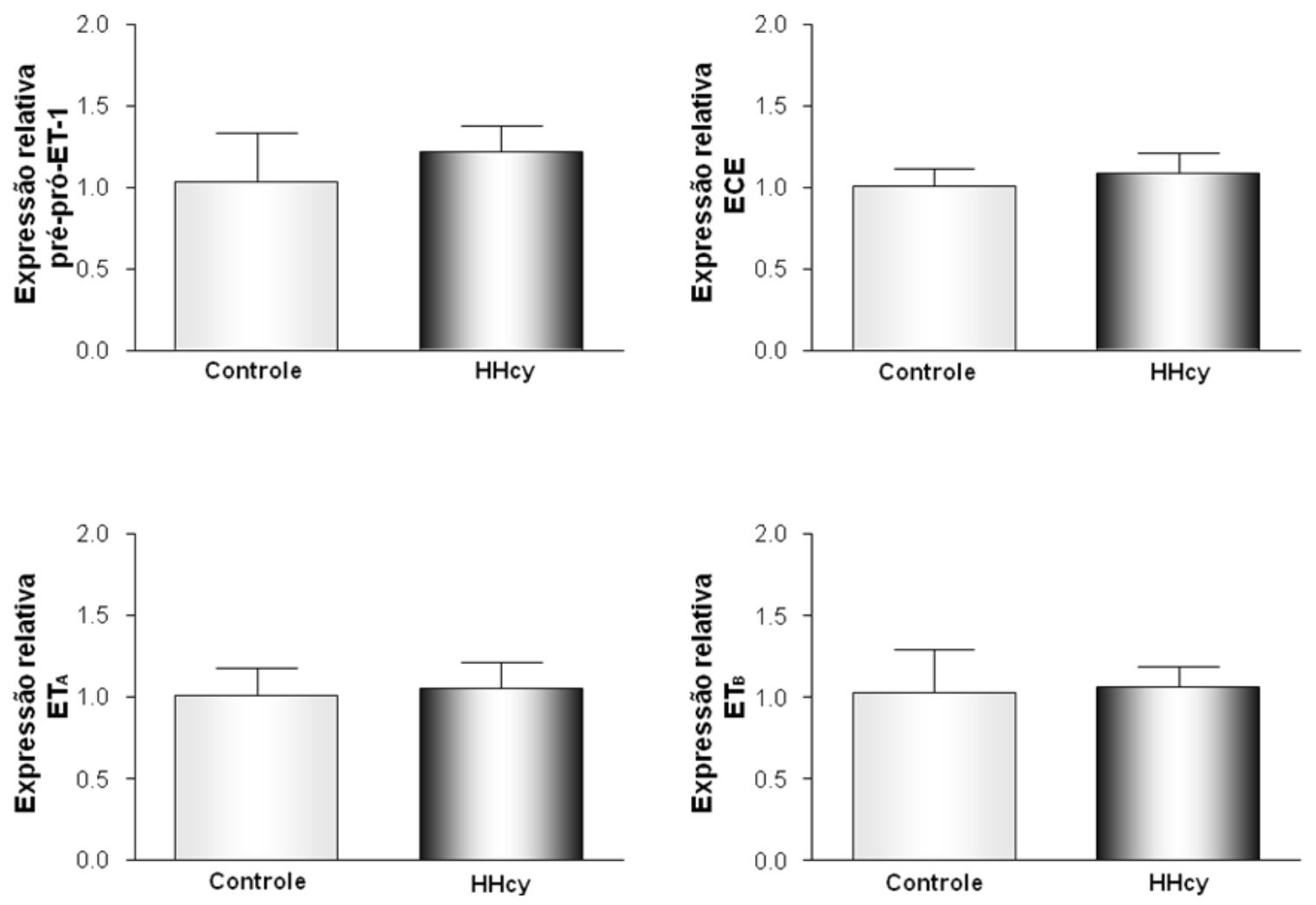

Figura 24: Efeito da HHcy sobre a expressão de RNAm para pré-pró-ET-1, ECE e para receptores $E_{A}$ e $\mathrm{ET}_{\mathrm{B}}$. A figura mostra os valores de $2^{-\Delta \Delta C}$ para a pré-pró-ET-1, ECE, receptores $\mathrm{ET}_{\mathrm{A}}$ e $E T_{\mathrm{B}}$ em corpos cavernosos de ratos controle e HHcy. Os valores foram normalizados pelo produto correspondente da reação de Real TimePCR para beta-2-microglobulina. Os dados representam a média \pm E.P.M. ( $n=10$ para cada grupo). Teste $t(p>$ 0,05). 


\section{Conclusões Parciais}

- A HHcy eleva os níveis basais de ERO em corpos cavernosos de ratos, por mecanismos independente da via da ET-1, uma vez que a presença de ET-1 não foi capaz de induzir produção de ERO.

- Em corpos cavernosos de ratos HHcy, o aumento no Emax da ET-1, em presença de antagonista dos receptores $E T_{B}$, em relação ao grupo controle, sugere que o tratamento acarreta aumento de fatores que modulam positivamente este parâmetro ou redução de fatores que modulam negativamente esta resposta, com possível envolvimento de ERO.

- O prejuízo do relaxamento induzido por ET-1 e IRL-1620 na HHcy envolve aumento de fatores com efeito contráteis e/ou redução de fatores relacionados a essa resposta de relaxamento.

- Em corpos cavernosos de ratos controle, a presença de L-NAME reduziu o Emax do IRL-1620, sugerindo a participação de metabólitos derivados da NOS nesta resposta.

- Na HHcy, o Emax do IRL-1620, em presença de L-NAME, não sofreu alteração, sugerindo prejuízo da produção e/ou biodisponibilidade dos metabólitos derivados da NOS envolvidos nesta resposta de relaxamento.

- A HHcy não causou alteração nos fatores pré-transcricionais da expressão de RNAm para pré-pró-ET-1, ECE e receptores $E T_{A}$ e $E T_{B}$. 


\subsection{Consequência da HHcy sobre a contração induzida por PhE}

A consequência da HHcy sobre a contração induzida por PhE $\left(10^{-7}\right.$ a $3.10^{-5}$ $\mathrm{mol} / \mathrm{L})$ foi estudada pela obtenção de curvas concentração-efeito desencadeadas por este agonista em corpos cavernosos de ratos.

Em corpos cavernosos de ratos controle, a $\operatorname{PhE}\left(10^{-7}\right.$ a $\left.3.10^{-5} \mathrm{~mol} / \mathrm{L}\right)$ produziu uma resposta de contração dependente da concentração (Figuras 25 e 26; Tabela 8).

O Emax da PhE foi aumentado em corpos cavernosos de ratos HHcy, em relação aos de ratos controle. A HHcy não alterou o valor de $\mathrm{pD}_{2}$ da $\mathrm{PhE}$ em corpos cavernosos de ratos deste grupo em relação ao controle (Figuras 25 e 26; Tabela 8).

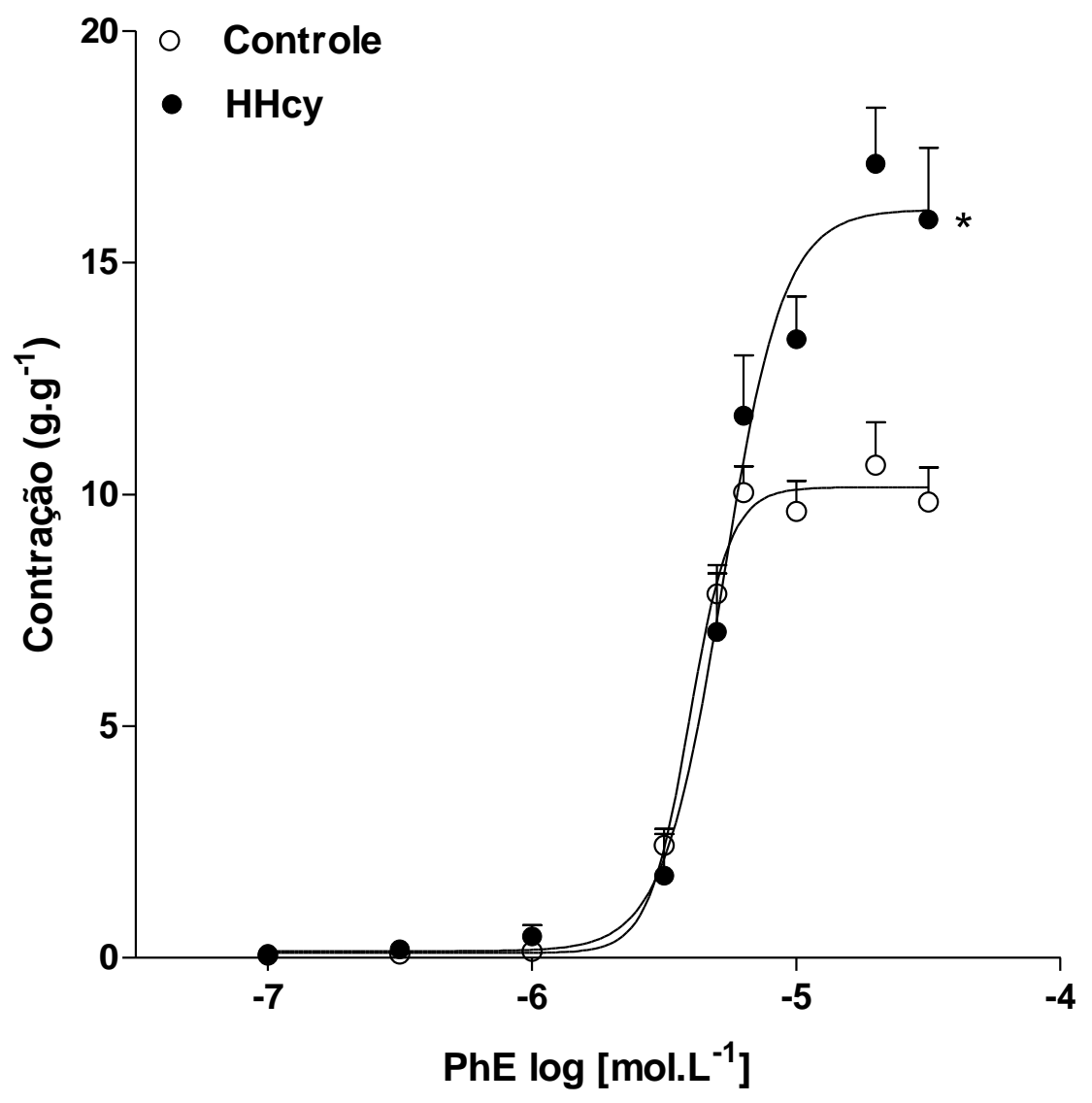

Figura 25: Consequência da HHcy sobre a contração induzida por PhE. A figura mostra curvas concentração-efeito para $\mathrm{PhE}$ em corpos cavernosos de ratos controle e HHcy. Os dados representam a média \pm E.P.M. ( $n=5$ para cada grupo). $\left(^{\star}\right)$ significativamente diferente $(p<0,05)$ em relação ao grupo controle. Teste t. 


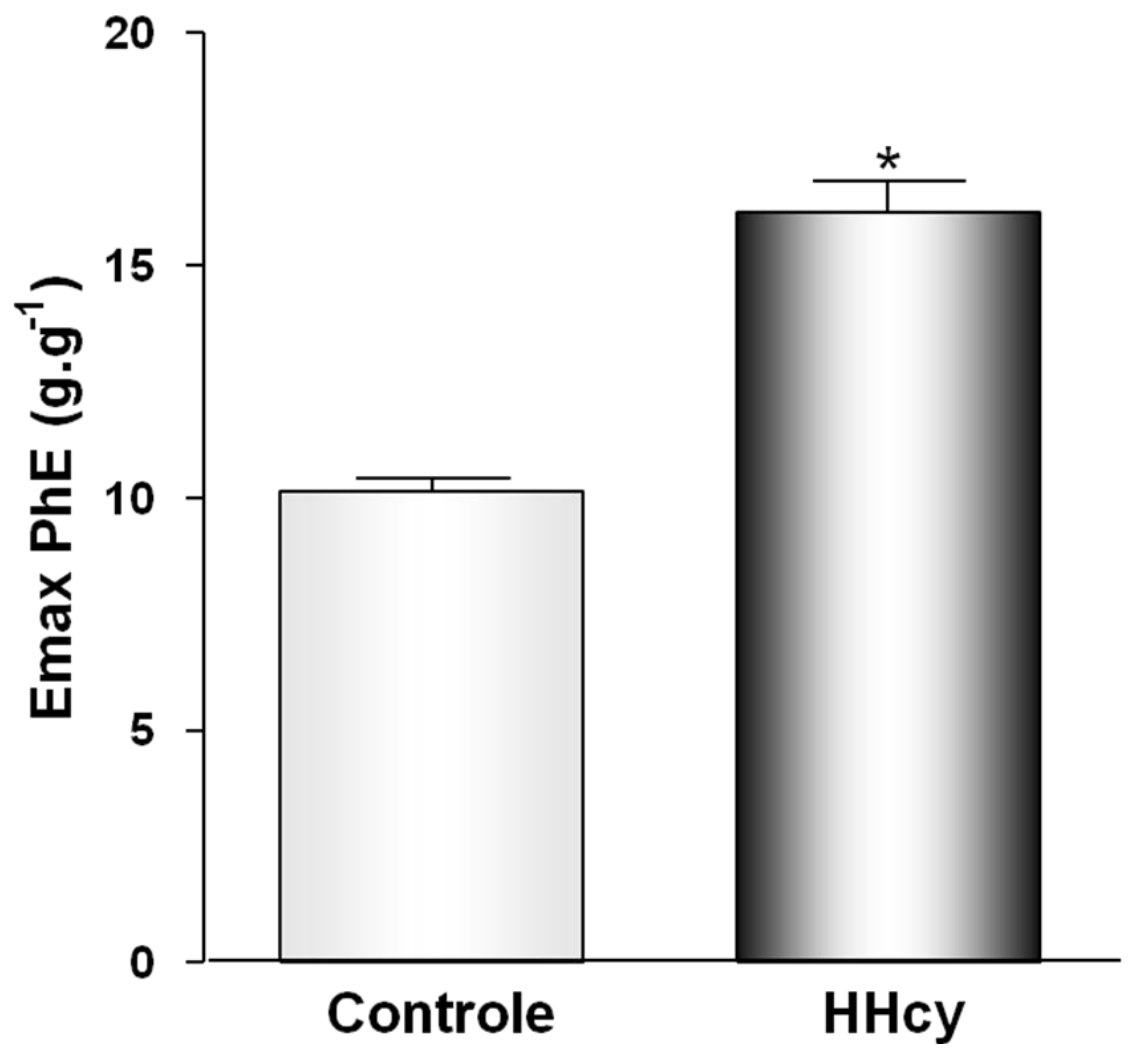

Figura 26: Consequência da HHcy sobre o Emax da PhE. A figura mostra os valores de Emax da PhE em corpos cavernosos de ratos controle e HHcy. Os dados representam a média \pm E.P.M. ( $n=5$ para cada grupo). $\left(^{*}\right)$ significativamente diferente $(p<0,05)$ em relação ao grupo controle. Teste t.

Tabela 8 - Valores de Emax e $\mathrm{pD}_{2}$ de PhE em corpos cavernosos de ratos controle e HHcy.

\begin{tabular}{l|c|c}
\hline Grupos & Emax $\left(\mathbf{g} \cdot \mathbf{g}^{-1}\right)$ & $\mathbf{p D}_{\mathbf{2}}$ \\
\hline Controle & $10,1 \pm 0,3$ & $5,41 \pm 0,02$ \\
HHcy & $16,1 \pm 0,7^{*}$ & $5,28 \pm 0,02$ \\
\hline
\end{tabular}

Os dados representam a média \pm E.P.M. $\left(n=5\right.$ para cada grupo). $\left({ }^{*}\right)$ significativamente diferente $(p<0,05)$ em relação ao grupo controle. Teste t. 


\subsection{Participação de ERO na contração induzida por PhE}

A participação de $\mathrm{O}_{2}{ }^{-}$e $\mathrm{H}_{2} \mathrm{O}_{2}$ na contração induzida por PhE foi estudada por realização de curva concentração-efeito para PhE em corpos cavernosos de ratos controle e HHcy, em presença ou ausência do sequestrador seletivo de $\mathrm{O}_{2}^{-}$, tiron, ou da enzima que decompõe $\mathrm{O}_{2} \mathrm{O}_{2}$, peg-catalase, ou do mimético da SOD, tempol, ou da associação tempol e peg-catalase $\left(\mathrm{O}_{2} \longrightarrow \mathrm{O}_{2}{ }^{-} \stackrel{\text { tempol }}{\longrightarrow} \mathrm{H}_{2} \mathrm{O}_{2} \stackrel{\text { catalase }}{\longrightarrow} \mathrm{H}_{2} \mathrm{O}+1 / 2 \mathrm{O}_{2}\right)$.

Em corpos cavernosos de ratos controle, a adição de tiron induziu aumento no Emax da PhE, em relação ao respectivo grupo na ausência do sequestrador. $O$ valor de $\mathrm{pD}_{2}$ da $\mathrm{PhE}$ não foi alterado pela presença de tiron (Figuras 27A e 28; Tabela 9). A HHcy não causou alteração no Emax da PhE, em presença de tiron, comparado ao respectivo grupo na ausência deste sequestrador. Não houve modificação no valor de $\mathrm{pD}_{2}$ da PhE pela adição de tiron (Figuras 27B e 28; Tabela 9).

A peg-catalase provocou aumento no Emax da PhE em corpos cavernosos de ratos controle, em relação ao respectivo grupo na ausência da enzima. Não se observou modificação no valor de $\mathrm{pD}_{2}$ pela adição de peg-catalase (Figuras 27C e 28; Tabela 9). Em corpos cavernosos de ratos HHcy, o Emax da PhE não sofreu alteração em presença de peg-catalase, assim como o valor de $\mathrm{pD}_{2}$, comparado com o respectivo grupo em ausência de peg-catalase (Figuras 27D e 28; Tabela 9).

A presença de tempol resultou em aumento no Emax da PhE em corpos cavernosos de ratos controle, em relação ao respectivo grupo na ausência desta droga. $\mathrm{O}$ valor de $\mathrm{pD}_{2}$ da $\mathrm{PhE}$ não foi alterado pela presença de tempol (Figuras 27E e 28; Tabela 9). O Emax da PhE foi reduzido pela adição de tempol em corpos cavernosos de ratos HHcy, em relação ao respectivo grupo na ausência da droga. Não foram observadas alterações no valor de $\mathrm{pD}_{2}$ (Figuras 27F e 28; Tabela 9).

A presença de peg-catalase juntamente com tempol não alterou o Emax da PhE em corpos cavernosos de ratos controle, em relação ao respectivo grupo na ausência destes. Não houve alteração no valor de $\mathrm{pD}_{2}$ da $\mathrm{PhE}$ (Figuras 27G e 28; Tabela 9). Em corpos cavernosos de ratos HHcy, a presença de peg-catalase associada ao tempol não alterou o Emax da $\mathrm{PhE}$ e causou redução no valor de $\mathrm{pD}_{2}$ da PhE em relação ao respectivo grupo na ausência das substâncias (Figuras $27 \mathrm{H} \mathrm{e}$ 28; Tabela 9). 

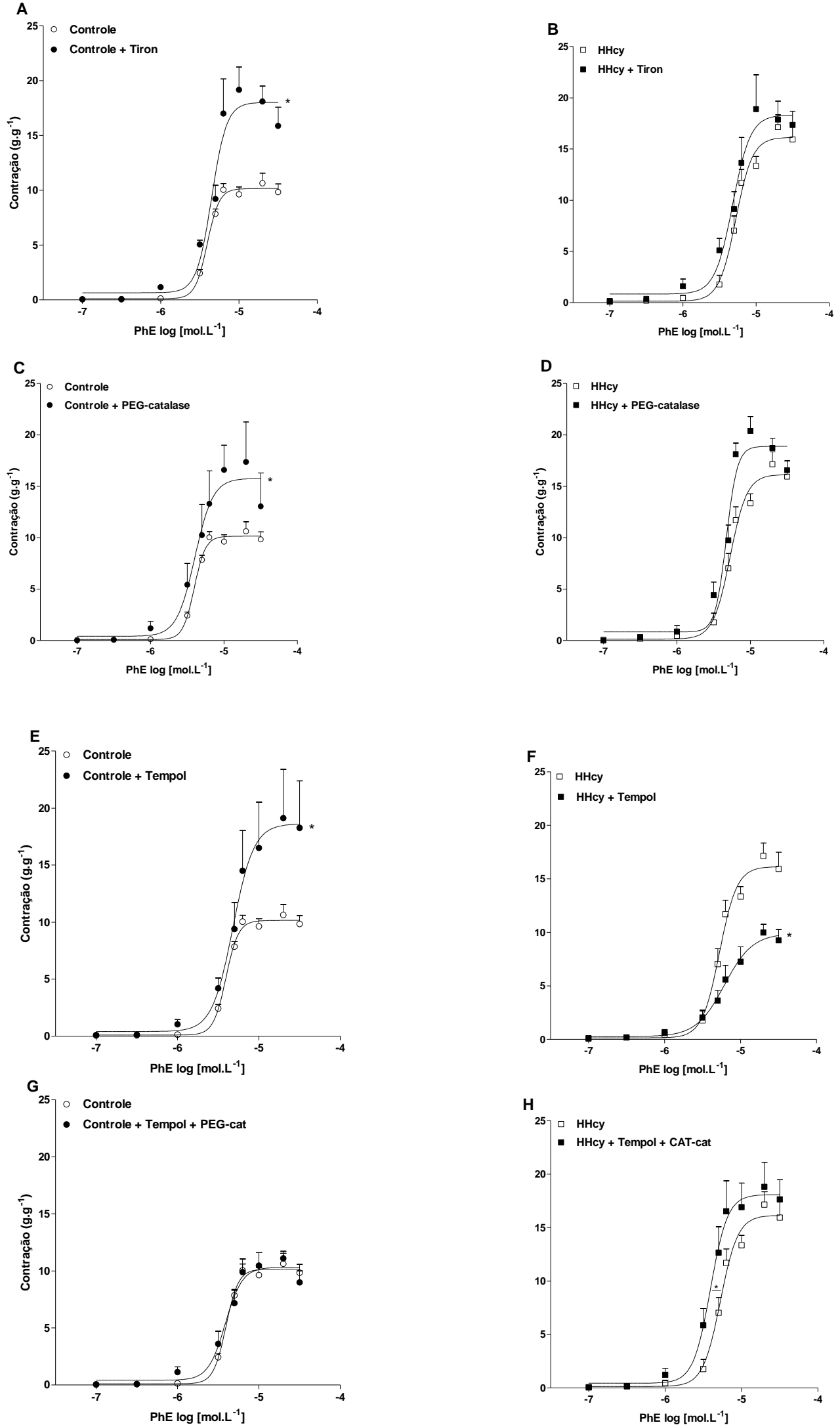

Figura 27: Participação de ERO na contração induzida por PhE. A figura mostra curvas concentração-efeito para PhE em corpos cavernosos de ratos controle $(A, C, E, G)$ e HHcy $(B, D, F, H)$, em presença ou ausência de diferentes inibidores. Os dados representam a média \pm E.P.M. $\left(n=5\right.$ para cada grupo). $\left(^{*}\right)$ significativamente diferente $(p<0,05)$ em relação ao respectivo grupo na ausência de inibidor. ANOVA de uma via, pós-teste de Bonferroni. 


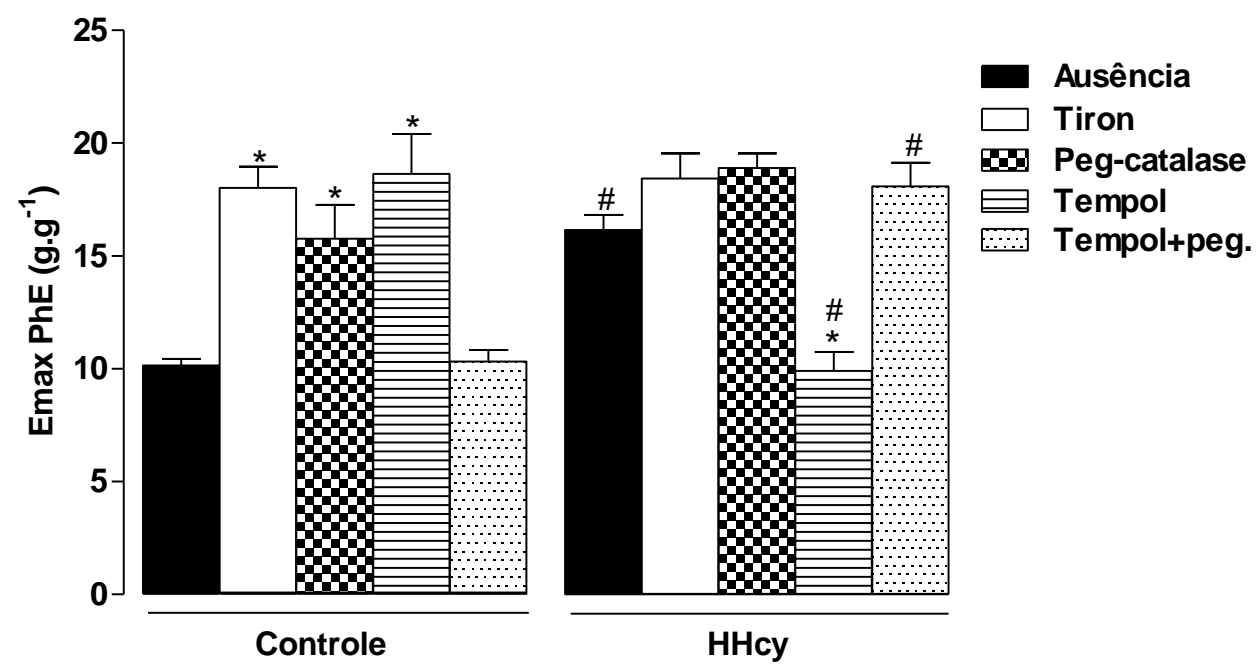

Figura 28: Participação de ERO no Emax da PhE. A figura mostra os valores de Emax da PhE em corpos cavernosos de ratos controle e HHcy, em presença ou ausência de diferentes inibidores. Os dados representam a média \pm E.P.M. ( $n=5$ para cada grupo). $\left({ }^{*}\right)$ significativamente diferente $(p<0,05)$ em relação ao respectivo grupo na ausência de inibidor. (\#) significativamente diferente $(p<0,05)$ em relação ao respectivo controle em presença ou ausência de inibidor. ANOVA de uma via, pós-teste de Bonferroni.

Tabela 9 - Valores de Emax e $\mathrm{pD}_{2}$ de PhE, em presença ou ausência de diferentes inibidores, em corpos cavernosos de ratos controle e HHcy.

\begin{tabular}{|c|c|c|c|c|}
\hline \multirow{2}{*}{ Grupos } & \multicolumn{2}{|c|}{$\operatorname{Emax}\left(g \cdot g^{-1}\right)$} & \multicolumn{2}{|c|}{$\mathrm{pD}_{2}$} \\
\hline & Controle & HHcy & Controle & HHcy \\
\hline Ausência & $10,1 \pm 0,3$ & $16,1 \pm 0,7^{\#}$ & $5,41 \pm 0,02$ & $5,28 \pm 0,02$ \\
\hline Tiron & $18,0 \pm 0,9^{*}$ & $18,3 \pm 1,1$ & $5,35 \pm 0,03$ & $5,32 \pm 0,04$ \\
\hline Peg-cat. & $15,8 \pm 1,5^{\star}$ & $18,9 \pm 0,7$ & $5,35 \pm 0,03$ & $5,32 \pm 0,04$ \\
\hline Tempol & $18,6 \pm 1,5^{\star}$ & $9,9 \pm 0,8^{\star, \#}$ & $5,32 \pm 0,06$ & $5,21 \pm 0,06$ \\
\hline Tempol+peg. & $10,3 \pm 0,5$ & $18,1 \pm 1,0^{\#}$ & $5,42 \pm 0,03$ & $5,41 \pm 0,04^{*}$ \\
\hline
\end{tabular}

Os dados representam a média \pm E.P.M. ( $n=5$ para cada grupo). $\left({ }^{*}\right)$ significativamente diferente $(p<0,05)$ em relação ao respectivo grupo na ausência de inibidor. (\#) significativamente diferente $(p<0,05)$ em relação ao respectivo controle em presença ou ausência de inibidor. ANOVA de uma via, pós-teste de Bonferroni. 


\subsection{Consequência da HHcy nos níveis basais de ERO e nos níveis produzidos por PhE}

Com o objetivo de medir os níveis basais de ERO e os níveis produzidos por PhE, realizou-se a medida de fluorescência por microscopia confocal.

A HHcy aumentou a fluorescência basal em corpos cavernosos destes ratos em relação aos do grupo controle (Figuras 29 e 30).

A adição de PhE não alterou a fluorescência basal em corpos cavernosos de ratos controle ou HHcy (Figuras 29 e 30).

Em presença do sequestrador seletivo para $\mathrm{O}_{2}^{-}$, tiron, observou-se redução da intensidade de fluorescência basal e após estímulo com PhE em corpos cavernosos de ratos controle (Figura 29 e 30).

Em corpos cavernosos de ratos HHcy, o sequestrador tiron reduziu a intensidade de fluorescência basal e após adição de PhE (Figura 29 e 30).

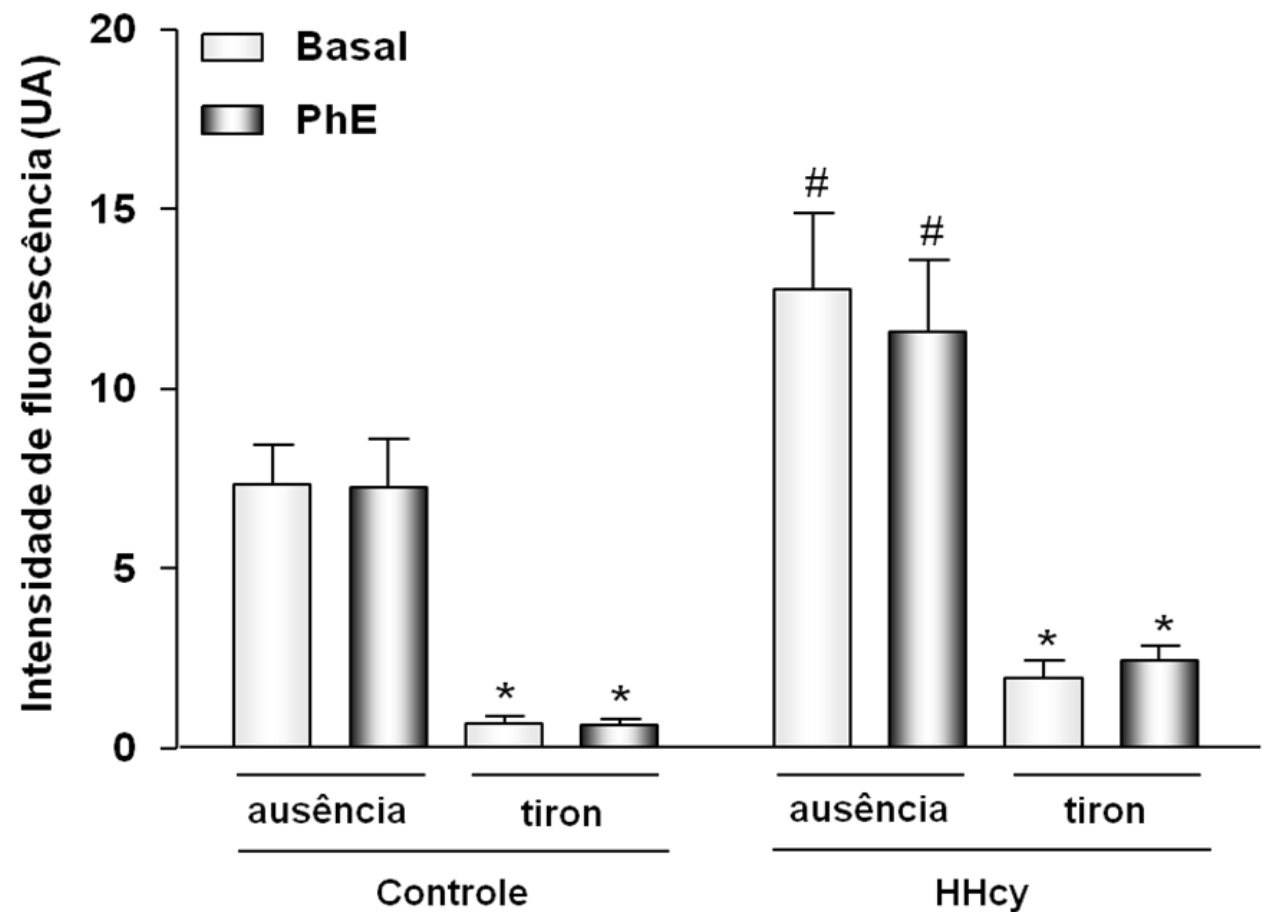

Figura 29: Consequência da HHcy na intensidade de fluorescência basal e após estímulo com PhE, em presença ou ausência de tiron. A figura mostra a intensidade de fluorescência basal emitida por corpos cavernosos de ratos controle e HHcy e a produzida por $\mathrm{PhE}$, em presença ou ausência do pré-tratamento com tiron. Os dados representam a média \pm E.P.M. $\left(n=5\right.$ para cada grupo). $\left({ }^{*}\right)$ significativamente diferente $(p<0,05)$ em relação à fluorescência emitida por corpos cavernosos de ratos dos respectivos grupos em ausência de tiron. (\#) significativamente diferente $(\mathrm{p}<0,05)$ em relação à fluorescência, basal ou após estímulo com PhE, do grupo controle em ausência de tiron. ANOVA de uma via, pós-teste de Bonferroni. 


\section{A. Controle}
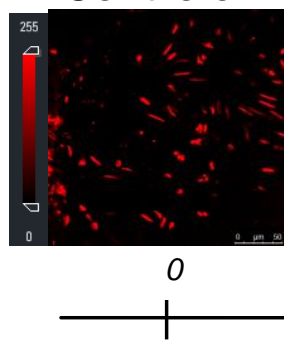

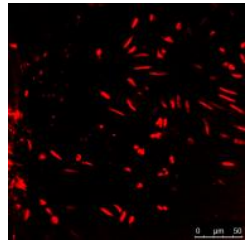

100

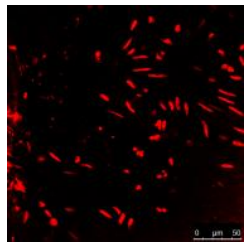

150

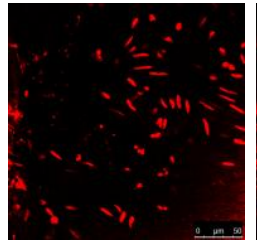

200
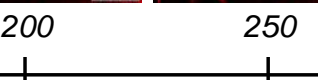

PhE
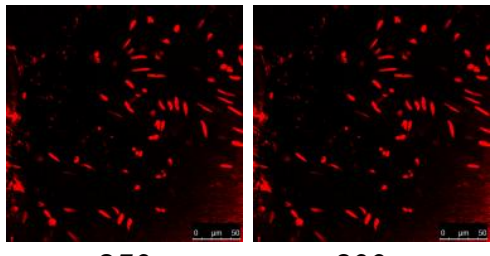

300

Tempo (s)

\section{B. Controle + tiron}
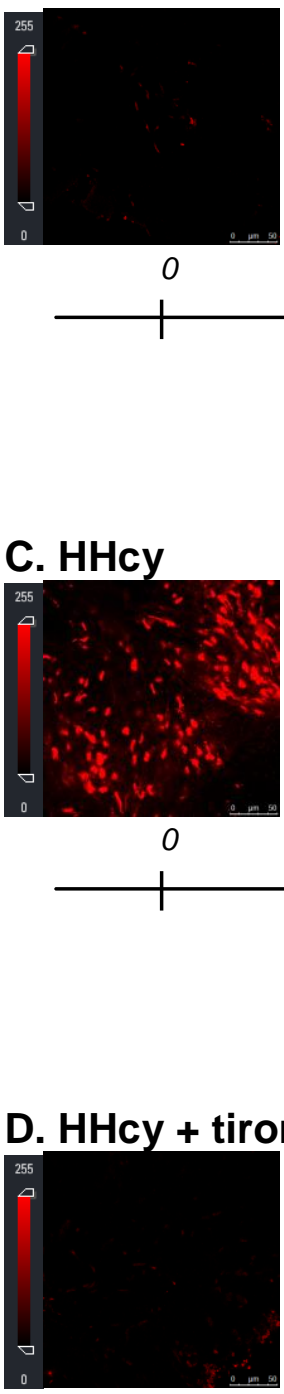

0

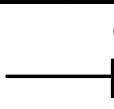

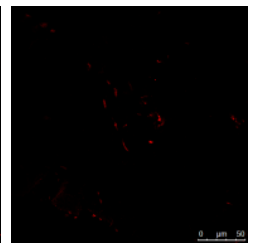

100

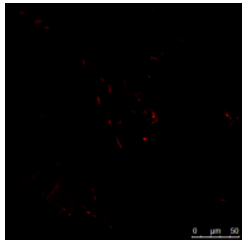

150

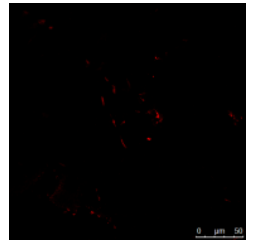

200

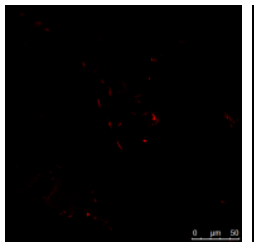

250

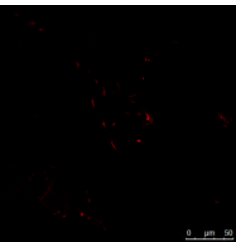

300

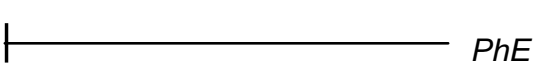

Tempo (s)

PhE

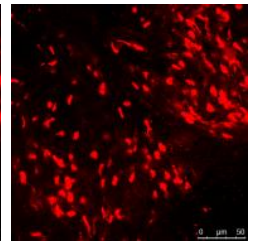

100

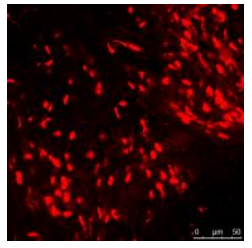

150

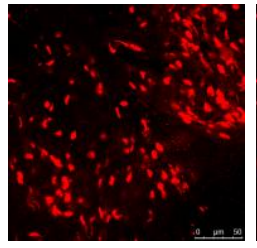

200

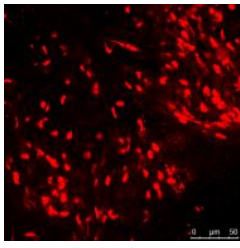

250

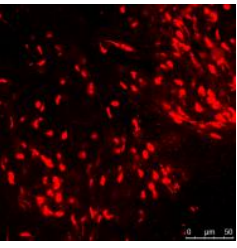

300

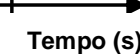

PhE
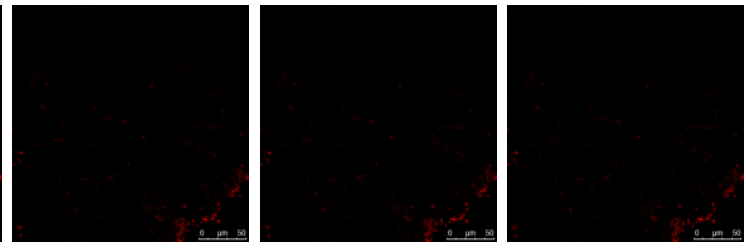

150

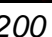

250
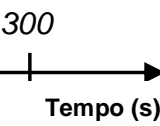

PhE

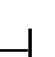

Figura 30: Imagens representativas da fluorescência em corpos cavernosos marcados com brometo de etídio. A figura mostra a marcação com brometo de etídio, antes $(t=0 \mathrm{~s})$ e após $(\mathrm{t}=100 \mathrm{~s})$ a estimulação com $\mathrm{PhE}$ em corpos cavernosos de ratos controle em ausência (A) ou em presença de tiron (B) e em corpos cavernosos de ratos HHcy em ausência (C) ou presença de tiron (D). 


\section{Conclusões Parciais}

\section{Em corpos cavernosos de ratos controle:}

- Os níveis basais de ERO são baixos.

- A adição de tiron mostra que a remoção de $\mathrm{O}_{2}^{-}$aumenta o Emax da PhE, sugerindo que esta espécie modula negativamente este parâmetro.

- Na presença de peg-catalase observou-se aumento no Emax da PhE, sugerindo que $\mathrm{H}_{2} \mathrm{O}_{2}$ tem importante efeito modulador negativo sobre este parâmetro.

- Em presença de tempol, houve aumento no Emax da PhE, sugerindo que:

a. $\mathrm{O}_{2}^{-}$poderia atua como modulador negativo da contração;

b. $\mathrm{H}_{2} \mathrm{O}_{2}$, formado pela dismutação de $\mathrm{O}_{2}{ }^{-}$, catalisada pelo tempol, poderia atuar como fator modulador positivo da contração.

- A adição concomitante da peg-catalase impediu o efeito do tempol, sugerindo que o aumento no Emax da PhE induzido pelo tempol é mediado por $\mathrm{H}_{2} \mathrm{O}_{2}$ derivado da dismutação de $\mathrm{O}_{2}{ }^{-}$, catalisada por este mimético de $S O D$.

\section{Em corpos cavernosos de ratos HHcy:}

- Observa-se aumento dos níveis basais de ERO.

- A presença de tiron não causou alteração no Emax da PhE, sugerindo que o efeito modulador negativo de $\mathrm{O}_{2}^{-}$foi perdido.

- A adição de peg-catalase não acarretou alteração no Emax da PhE, sugerindo que a perda do efeito modulatório negativo pode ser decorrente de prejuízo na formação de $\mathrm{H}_{2} \mathrm{O}_{2}$, via SOD. 
- O pré-tratamento com tempol fez com que o Emax da PhE voltasse aos valores do controle, sugerindo restauração da formação de $\mathrm{H}_{2} \mathrm{O}_{2}$ por dismutação de $\mathrm{O}_{2}^{-}$.

- A adição concomitante de peg-catalase impediu o efeito do tempol, sugerindo que a restauração do Emax da PhE induzido por tempol, é dependente de $\mathrm{H}_{2} \mathrm{O}_{2}$. 


\subsection{Participação de metabólitos da NOS e de suas isoformas específicas na contração induzida por PhE}

Para estudar a participação dos metabólicos derivados da NOS e de suas isoformas específicas na contração induzida por $\mathrm{PhE}$, realizou-se curva concentração-efeito para este agonista em corpos cavernosos de ratos controle e HHcy, em presença ou ausência de inibidor não-seletivo da NOS, L-NAME, ou de inibidor seletivo para eNOS, L-NNA, ou para nNOS, 7-Ni, ou para iNOS, 1400W.

$\mathrm{O}$ Emax da $\mathrm{PhE}$ em corpos cavernosos de ratos controle foi aumentado pela adição de L-NAME, em relação ao respectivo grupo em ausência do inibidor, sem alteração no valor de $\mathrm{pD}_{2}$ (Figuras $31 \mathrm{~A}$ e 32 ; Tabela 10). Em corpos cavernosos de ratos HHcy, a adição de L-NAME não acarretou alteração no Emax da PhE. O valor de $\mathrm{pD}_{2}$ da $\mathrm{PhE}$ não foi modificado, em presença de L-NAME, em relação a este grupo na ausência do inibidor (Figuras 31B e 32; Tabela 10).

A adição de L-NNA, em corpos cavernosos de ratos controle, induziu aumento no Emax da PhE, em relação ao respectivo grupo na ausência do inibidor. $\mathrm{O}$ valor de $\mathrm{pD}_{2}$ da $\mathrm{PhE}$ foi aumentado neste grupo em relação ao respectivo grupo na ausência de L-NNA (Figuras 31C e 32; Tabela 10). Na HHcy, observou-se aumento no Emax da PhE na presença de L-NNA, em relação ao respectivo grupo na ausência do inibidor. $O$ valor de $\mathrm{pD}_{2}$ também apresentou aumento em corpos cavernosos de ratos HHcy na presença de L-NNA, comparado com o respectivo grupo na ausência deste inibidor (Figuras 31D e 32; Tabela 10).

Em corpos cavernosos de ratos controle, o Emax da PhE foi aumentado pela adição de 7-Ni, em relação ao respectivo grupo em ausência do inibidor, sem alteração no valor de $\mathrm{pD}_{2}$ da $\mathrm{PhE}$ (Figuras 31E e 32; Tabela 10). Na HHcy, a adição do inibidor induziu aumento no Emax, bem como no valor de $\mathrm{pD}_{2}$ da $\mathrm{PhE}$, em relação ao respectivo grupo na ausência de 7-Ni (Figuras 31F e 32; Tabela 10).

A adição de 1400W aumentou o Emax da PhE em corpos cavernosos de ratos controle, em relação ao respectivo grupo em ausência do inibidor. Não foi verificada modificação no valor de $\mathrm{pD}_{2}$ da $\mathrm{PhE}$ (Figuras $31 \mathrm{G}$ e 32 ; Tabela 10). Em corpos cavernosos de ratos HHcy, o Emax da $\mathrm{PhE}$ não foi alterado em presença de $1400 \mathrm{~W}$, em relação ao respectivo grupo na ausência deste. $\mathrm{O}$ valor de $\mathrm{pD}_{2}$ da $\mathrm{PhE}$ sofreu aumento em presença deste inibidor (Figuras $31 \mathrm{H}$ e 32 ; Tabela 10). 
A

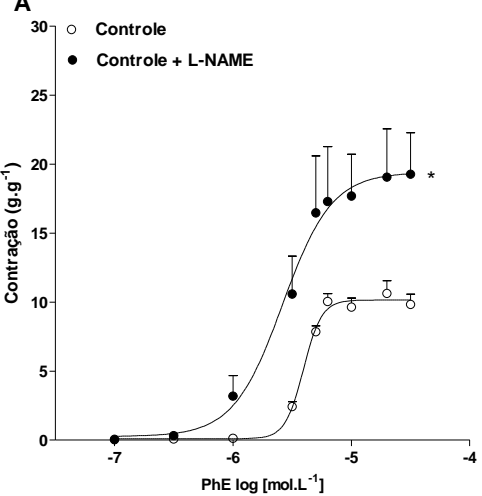

C
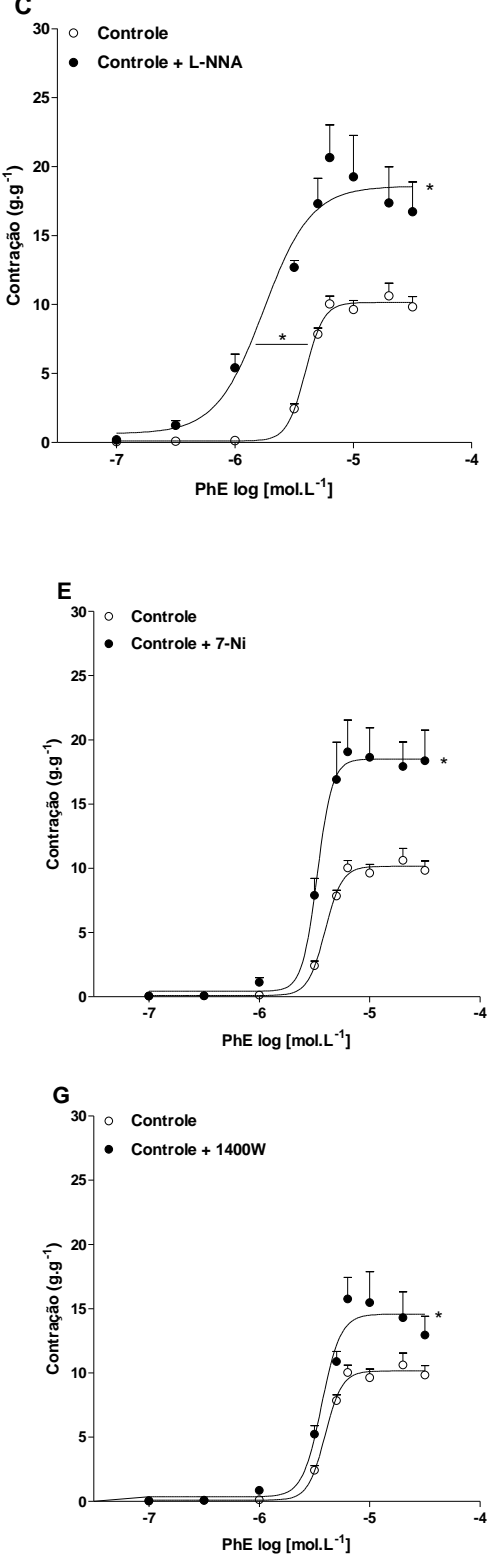

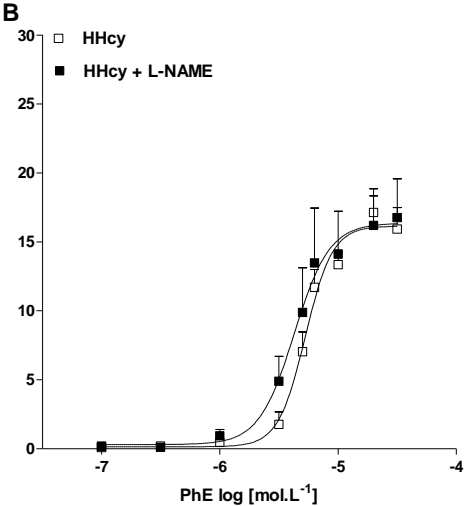

D
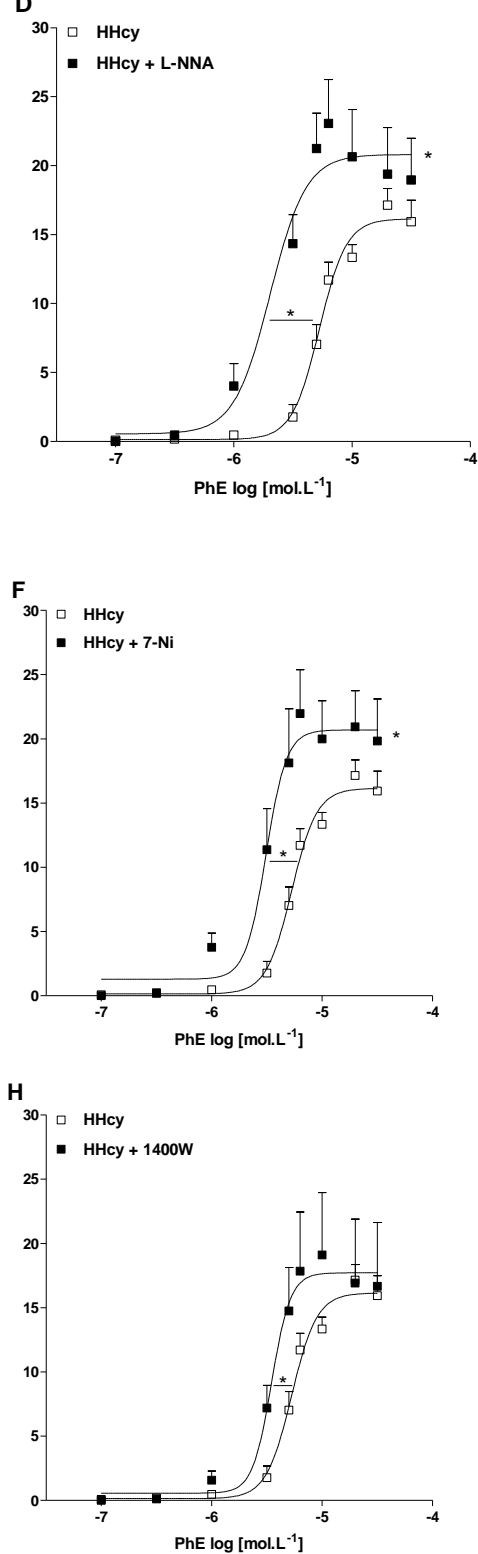

Figura 31: Participação de metabólicos da NOS na contração induzida por PhE. A figura mostra curvas concentração-efeito para $\mathrm{PhE}$ em corpos cavernosos de ratos controle (A,C,E,G) ou HHcy (B,D,F,H) em ausência ou presença de inibidor não-seletivos da NOS ou de inibidores seletivos das isoformas específicas da NOS. Os dados representam a média \pm E.P.M. $\left(n=5\right.$ para cada grupo). $\left(^{*}\right)$ significativamente diferente $(p<0,05)$ em relação ao respectivo grupo em ausência de inibidores. (\#) significativamente diferente $(p<0,05)$ em relação ao respectivo grupo controle em ausência ou presencia de inibidor. ANOVA de uma via, pós-teste de Bonferroni. 


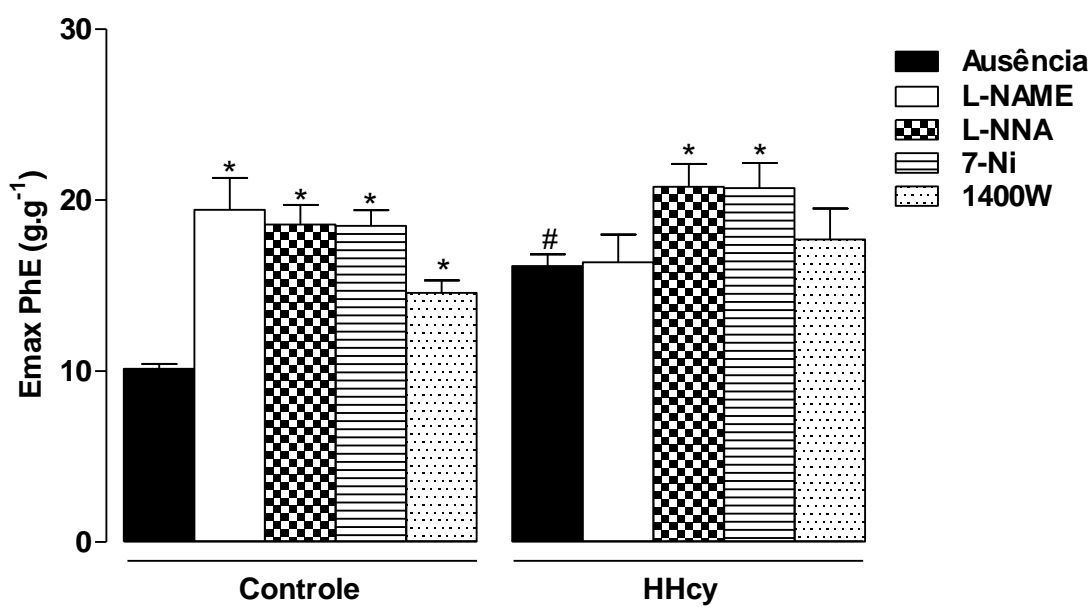

Figura 32: Participação dos metabólicos da NOS no Emax da PhE. A figura mostra os valores de Emax da PhE em corpos cavernosos de ratos controle e HHcy, em ausência ou presença de inibidores específicos e nãoespecíficos na NOS. Os dados representam a média \pm E.P.M. ( $n=5$ para cada grupo). ( $\left.{ }^{*}\right)$ significativamente diferente $(p<0,05)$ em relação ao respectivo grupo em ausência de inibidores. (\#) significativamente diferente $(p$ $<0,05)$ em relação ao respectivo grupo controle em ausência ou presencia de inibidor. ANOVA de uma via, pósteste de Bonferroni.

Tabela 10 - Valores de Emax e $\mathrm{pD}_{2}$ de $\mathrm{PhE}$, em presença ou ausência de inibidores da NOS, em corpos cavernosos de ratos controle e HHcy.

\begin{tabular}{|c|c|c|c|c|}
\hline \multirow{2}{*}{ Grupos } & \multicolumn{2}{|c|}{$\operatorname{Emax}\left(\mathbf{g} \cdot \mathbf{g}^{-1}\right)$} & \multicolumn{2}{|c|}{$\mathrm{pD}_{2}$} \\
\hline & Controle & HHcy & Controle & HHcy \\
\hline Ausência & $10,1 \pm 0,3$ & $16,1 \pm 0,7^{\#}$ & $5,41 \pm 0,02$ & $5,28 \pm 0,02$ \\
\hline L-NAME & $19,4 \pm 1,9^{*}$ & $16,4 \pm 1,6$ & $5,58 \pm 0,12$ & $5,37 \pm 0,07$ \\
\hline L-NNA & $18,6 \pm 1,1^{*}$ & $20,8 \pm 1,3^{*}$ & $5,77 \pm 0,10^{*}$ & $5,70 \pm 0,10^{*}$ \\
\hline $7-\mathrm{Ni}$ & $18,5 \pm 0,9^{*}$ & $20,7 \pm 1,5^{\star}$ & $5,48 \pm 0,03$ & $5,51 \pm 0,05^{*}$ \\
\hline 1400W & $14,6 \pm 0,7^{*}$ & $17,7 \pm 1,8$ & $5,44 \pm 0,03$ & $5,46 \pm 0,07^{*}$ \\
\hline
\end{tabular}

Os dados representam a média \pm E.P.M. ( $n=5$ para cada grupo). $\left({ }^{*}\right)$ significativamente diferente $(p<0,05)$ em relação ao respectivo grupo em ausência de inibidores. (\#) significativamente diferente $(p<0,05)$ em relação ao respectivo grupo controle em ausência ou presencia de inibidor. ANOVA de uma via, pós-teste de Bonferroni. 


\subsection{Efeito da HHcy sobre a expressão do RNAm para eNOS, nNOS e iNOS}

A expressão do RNAm para eNOS, nNOS e iNOS foi analisada pela técnica de Real Time-PCR. A HHcy não acarretou alterações significativas na expressão de RNAm para eNOS, nNOS e iNOS em relação ao grupo controle (Figura 33).
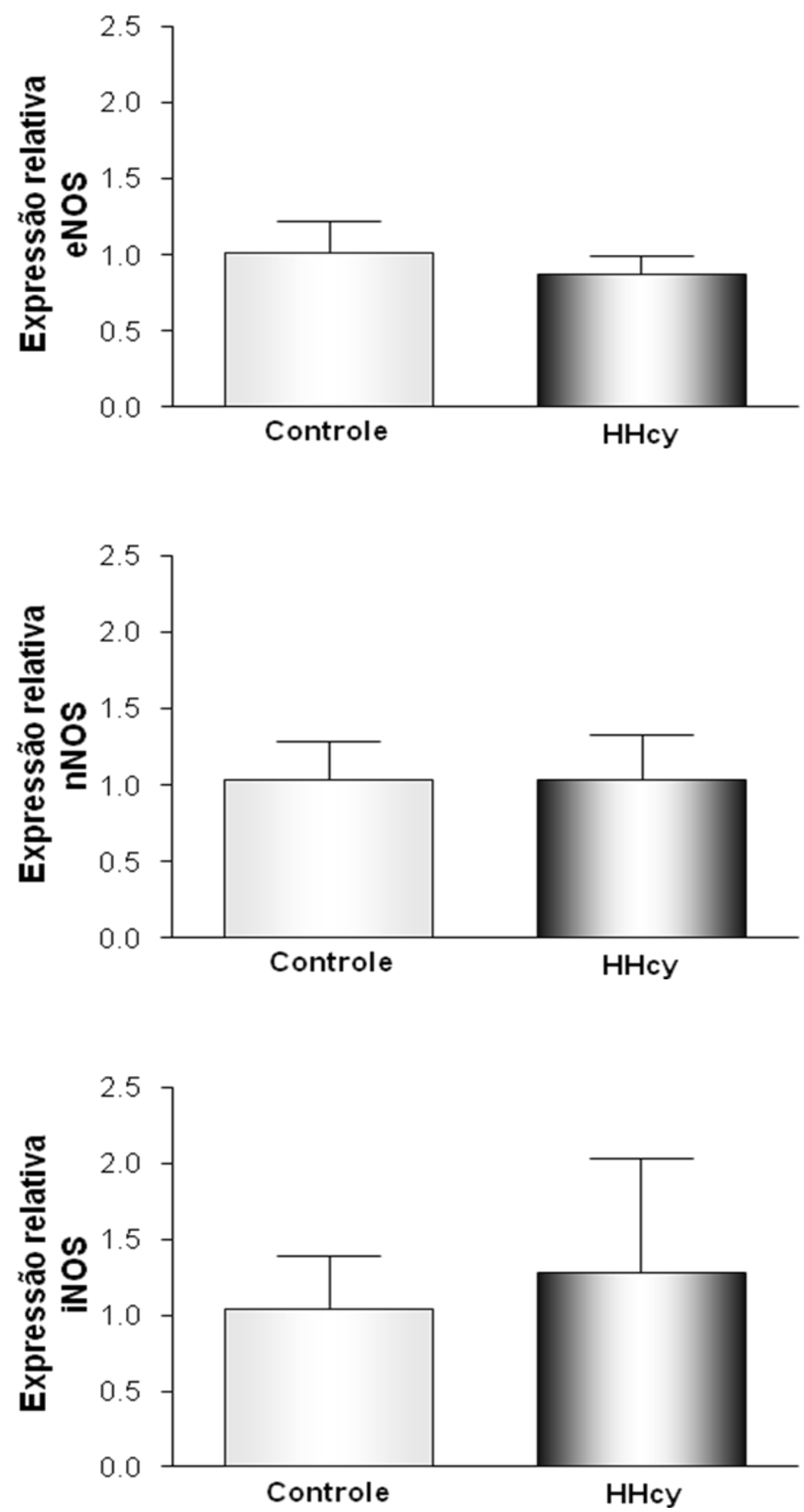

Figura 33: Efeito da HHcy sobre a expressão de RNAm para eNOS, nNOS e iNOS. A figura mostra os valores de $2^{-\Delta \Delta C t}$ para eNOS, nNOS e iNOS em corpos cavernosos de ratos controle e HHcy. Os valores foram normalizados pelo produto correspondente da reação de Real Time-PCR para beta-2-microglobulina. Os dados representam a média \pm E.P.M. ( $n=10$ para cada grupo). Teste $t(p>0,05)$. 


\subsection{Efeito da HHcy sobre a expressão de nitrotirosina}

A expressão de nitrotirosina foi analisada por experimentos de imunohistoquímica.

Foram observadas poucas células imunorreativas para nitrotirosina em corpos cavernosos de ratos controle e HHcy (Figura 34).

A porcentagem de área marcada para nitrotirosina não foi significativamente alterada em decorrência da HHcy em relação ao grupo controle (Figura 35).

CONTROLE
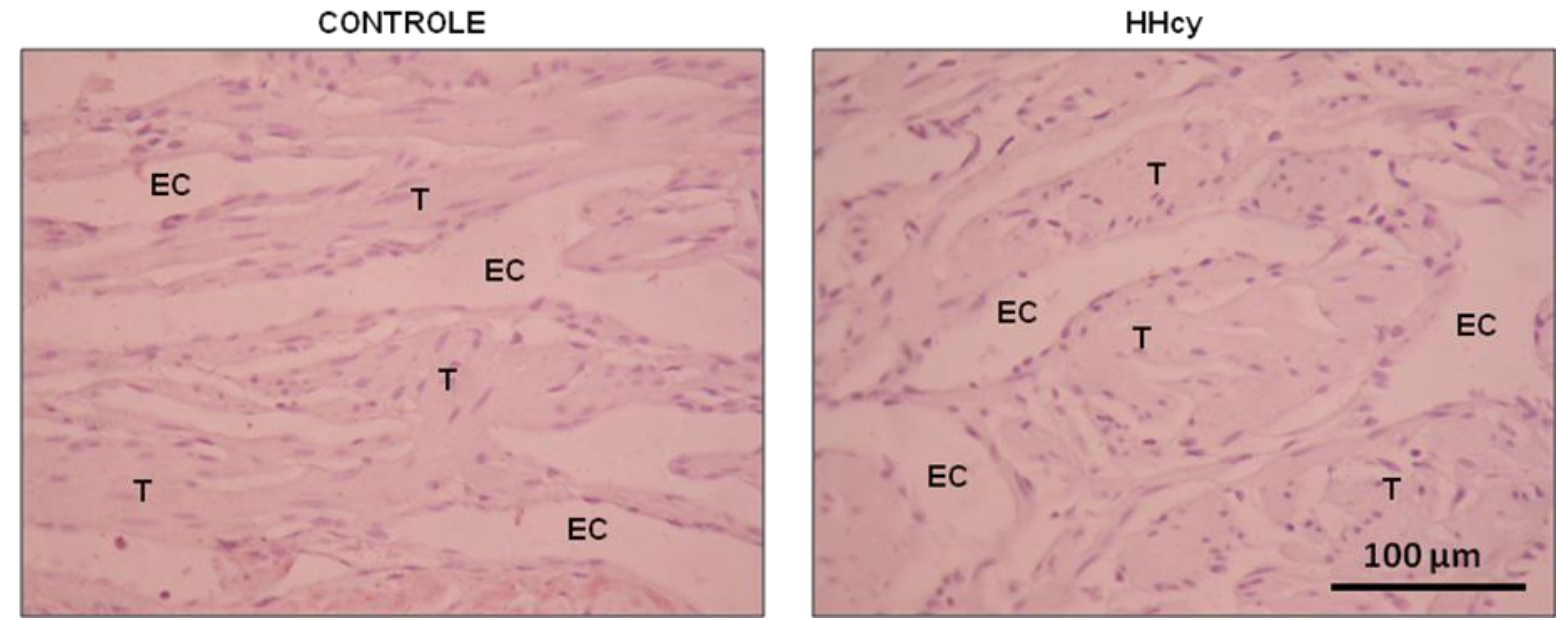

Figura 34: Efeito da HHcy sobre a expressão de nitrotirosina. Imunohistoquímica para expressão de nitrotirosina em corpos cavernosos de ratos controle e HHcy. Trabécula (T), espaço cavernoso (EC). Aumento $40 x$.

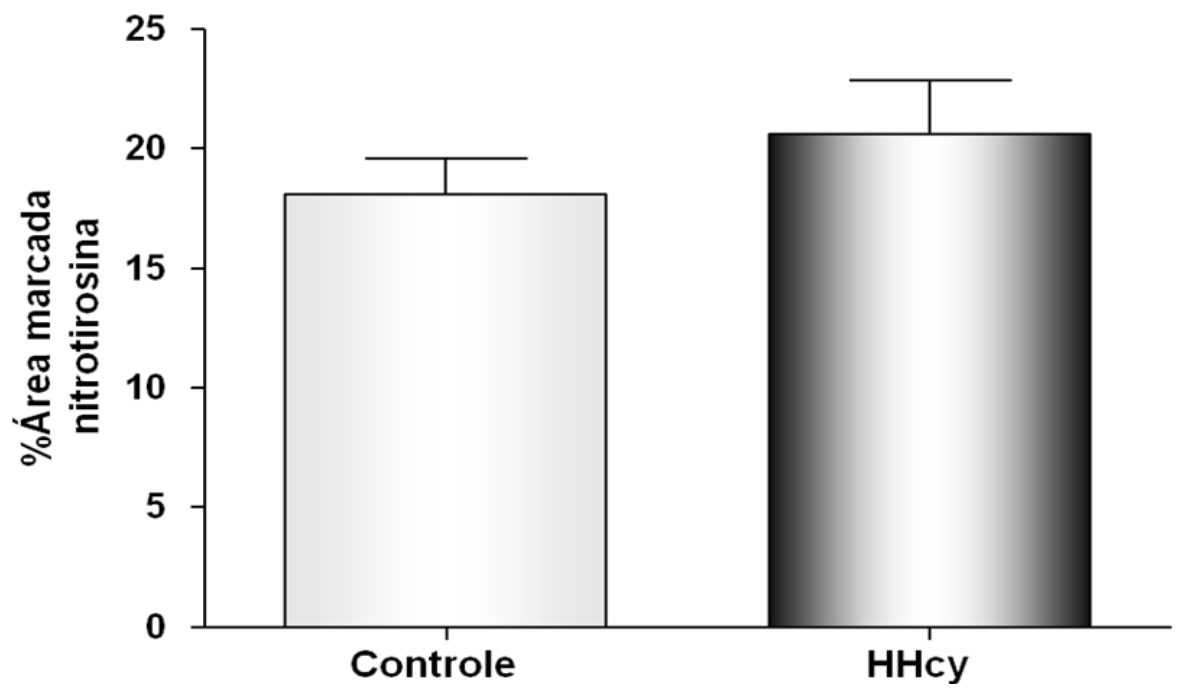

Figura 35: Efeito da HHcy sobre a expressão de nitrotirosina. Os valores em porcentagem de área marcada representam a expressão de nitrotirosina no músculo liso das trabéculas de corpos cavernosos de ratos controle e HHcy. Os dados representam a média \pm E.P.M. ( $n=5$ para cada grupo). Teste $t(p>0,05)$. 


\subsection{Consequência da HHcy na concentração plasmática de nitrato}

A biodisponibilidade de NO foi estudada através das dosagens plasmáticas de nitrato.

A HHcy induziu redução significativa nos níveis plasmáticos de nitrato $(29,35$ $\pm 1,06 \mu \mathrm{mol} / \mathrm{L}, \mathrm{n}=10)$ destes ratos em relação ao grupo controle $(33,69 \pm 1,12$ $\mu \mathrm{mol} / \mathrm{L}, \mathrm{n}=10$ ) (Figura 36).

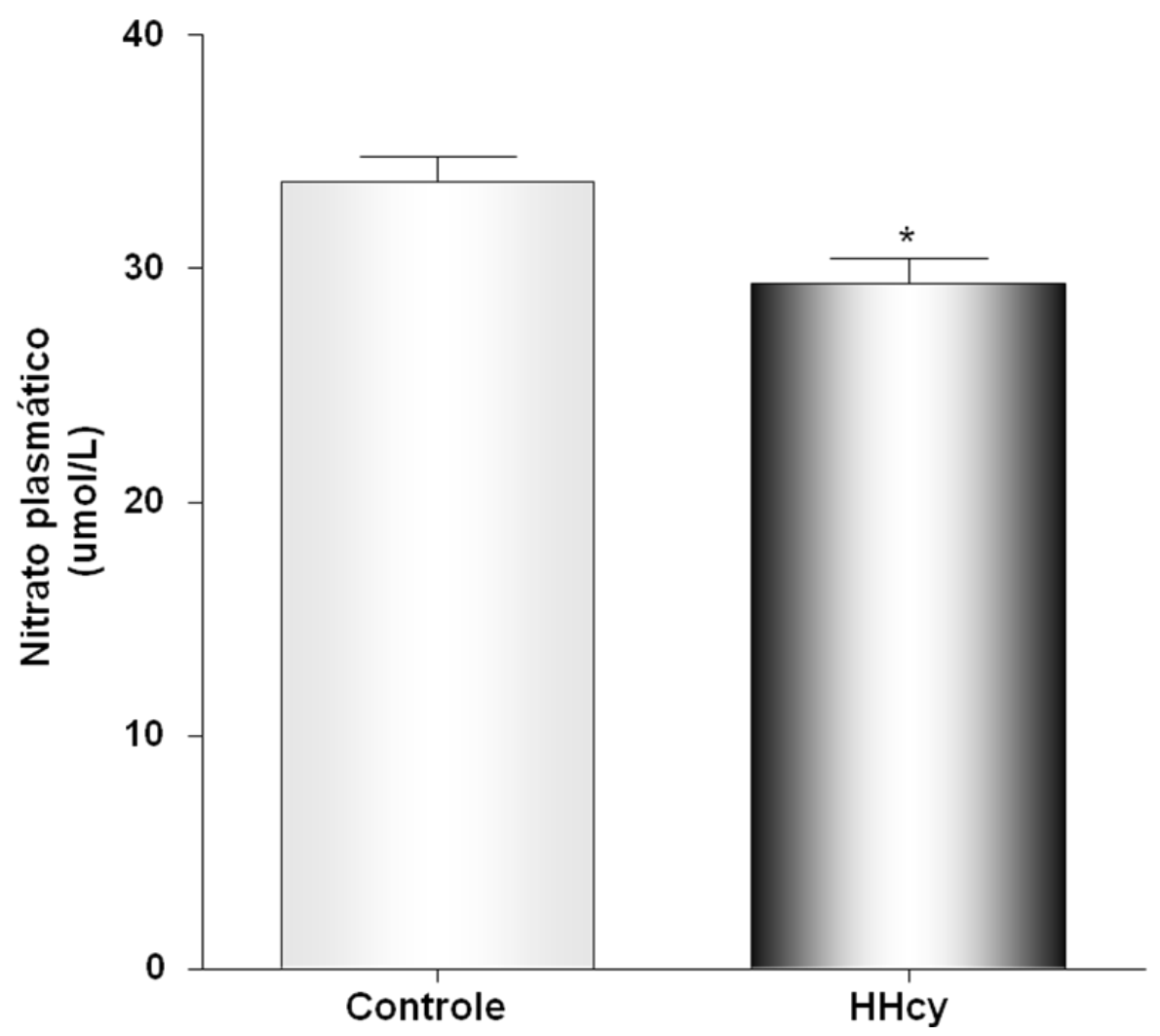

Figura 36: Consequência da HHcy na concentração plasmática de nitrato. A figura mostra os valores de nitrato plasmático em ratos controle e HHcy. Os dados representam a média \pm E.P.M. ( $\mathrm{n}=10$ para cada grupo). $\left(^{*}\right)$ significativamente diferente $(p<0,05)$ em relação ao grupo controle. Teste t. 


\section{Conclusões Parciais}

- Em corpos cavernosos de ratos controle, o aumento no Emax da PhE, em presença de L-NAME, sugere importante participação de metabólitos derivados da NOS, modulando negativamente este parâmetro.

- Nesses ratos, as isoformas eNOS, nNOS e iNOS tem participação na fonte de metabólitos moduladores da contração por PhE.

- Na HHcy, a presença de L-NAME, assim como a do inibidor específico da iNOS, não provocou alteração no Emax da PhE, sugerindo que a HHcy promove prejuízo na produção e/ou biodisponibilidade de metabólitos da NOS, derivados, principalmente da isoforma iNOS. 


\subsection{Participação de metabólitos da COX e de suas isoformas específicas na contração induzida por PhE}

Para estudar a participação de metabólitos derivados da enzima COX e de suas isoformas específicas na contração induzida por $\mathrm{PhE}$, realizou-se curva concentração-efeito para este agonista em corpos cavernosos de ratos controle e HHcy, em presença ou ausência de inibidor não-seletivo da COX, indometacina, ou de inibidor seletivo da COX-1, SC-560, ou da COX-2, SC-236.

O Emax da PhE em corpos cavernosos de ratos controle foi aumentado pela adição de indometacina, em relação ao respectivo controle na ausência do inibidor, sem alteração no valor de $\mathrm{pD}_{2}$ (Figuras $37 \mathrm{~A}$ e 38 ; Tabela 11). Em corpos cavernosos de ratos HHcy, o Emax da PhE também sofreu aumento pela adição de indometacina, em relação ao respectivo grupo na ausência do inibidor. O valor de $\mathrm{pD}_{2}$ da $\mathrm{PhE}$ não foi alterado. (Figuras 37B e 38; Tabela 11).

O Emax da PhE foi aumentado pela adição de SC-560 em corpos cavernosos de ratos controle, em relação ao respectivo grupo em ausência do inibidor. Não foi observado alteração no valor de $\mathrm{pD}_{2}$ da $\mathrm{PhE}$ para este grupo (Figuras 37C e 38; Tabela 11). A adição de SC-560 acarretou aumento no Emax da $\mathrm{PhE}$ em corpos cavernosos de ratos $\mathrm{HHcy}$, em relação ao respectivo grupo na ausência do inibidor. $\mathrm{O}$ valor de $\mathrm{pD}_{2}$ da $\mathrm{PhE}$ apresentou aumento na presença deste inibidor, em corpos cavernosos de ratos HHcy (Figuras 37D e 38; Tabela 11).

Em corpos cavernosos de ratos controle, a adição de SC-236 produziu aumento no Emax da $\mathrm{PhE}$, em relação ao respectivo grupo na ausência do inibidor, sem alteração no valor de $\mathrm{pD}_{2}$ da $\mathrm{PhE}$ (Figuras 37E e 38; Tabela 11). A adição de SC-236 acarretou aumento no Emax da PhE em corpos cavernosos de ratos HHcy, em relação ao respectivo grupo na ausência do inibidor. $O$ valor de $\mathrm{pD}_{2}$ da $\mathrm{PhE}$ não foi alterado pela presença de SC-236 (Figuras 37F e 38; Tabela 11). 

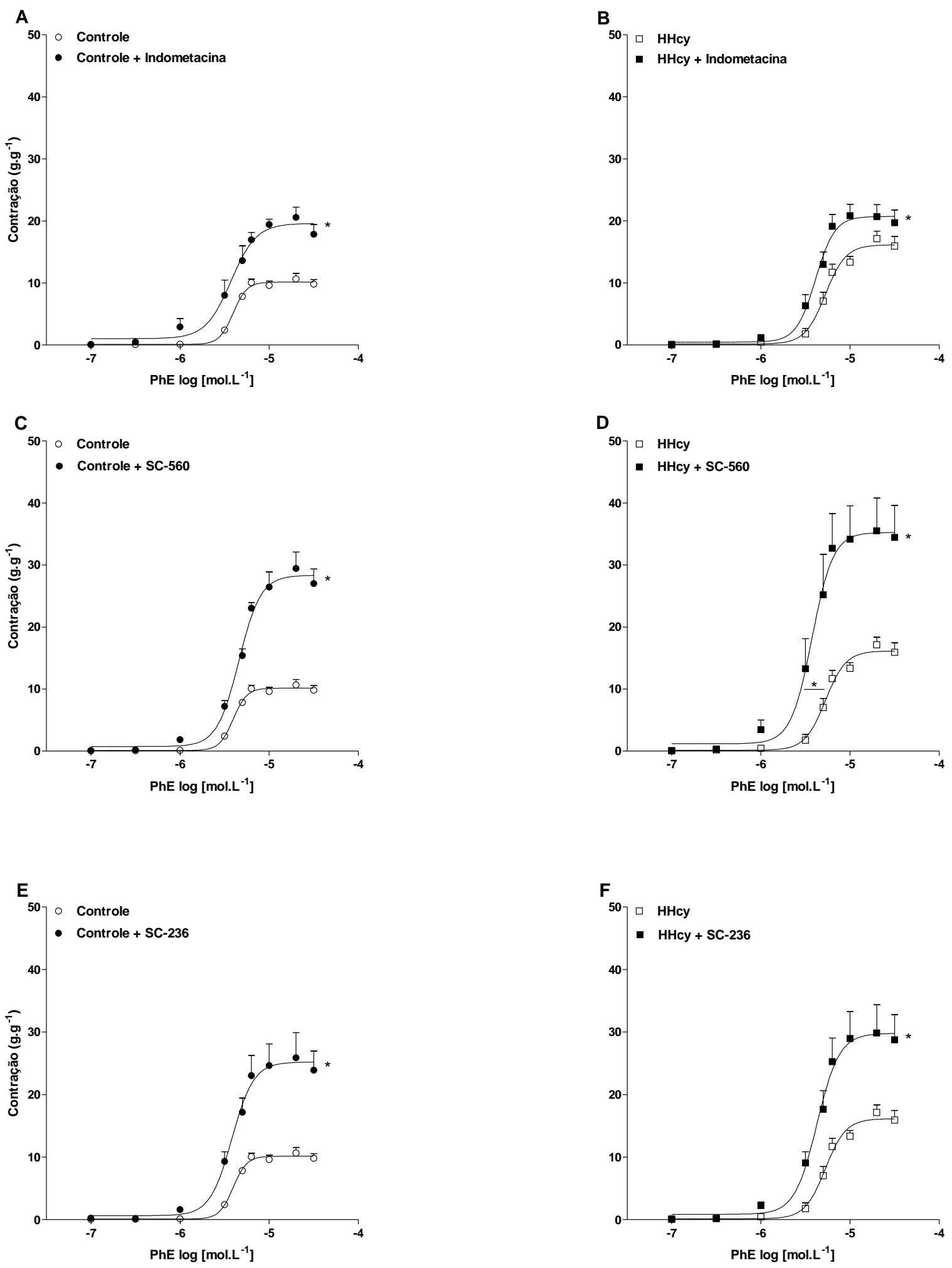

Figura 37: Participação de metabólitos da COX na contração induzida por PhE. A figura mostra curvas concentração-efeito para PhE em corpos cavernosos de ratos controle $(A, C, E)$ ou HHcy $(B, D, F)$ em ausência ou presença de inibidor não-seletivo da COX ou de inibidores seletivos das isoformas específicas da COX. Os dados representam a média \pm E.P.M. $\left(n=5\right.$ para cada grupo). $\left(^{*}\right)$ significativamente diferente $(p<0,05)$ em relação ao respectivo grupo em ausência de inibidor. (") significativamente diferente $(p<0,05)$ em relação ao respectivo controle em presença ou ausência de inibidor. ANOVA de uma via, pós-teste de Bonferroni. 


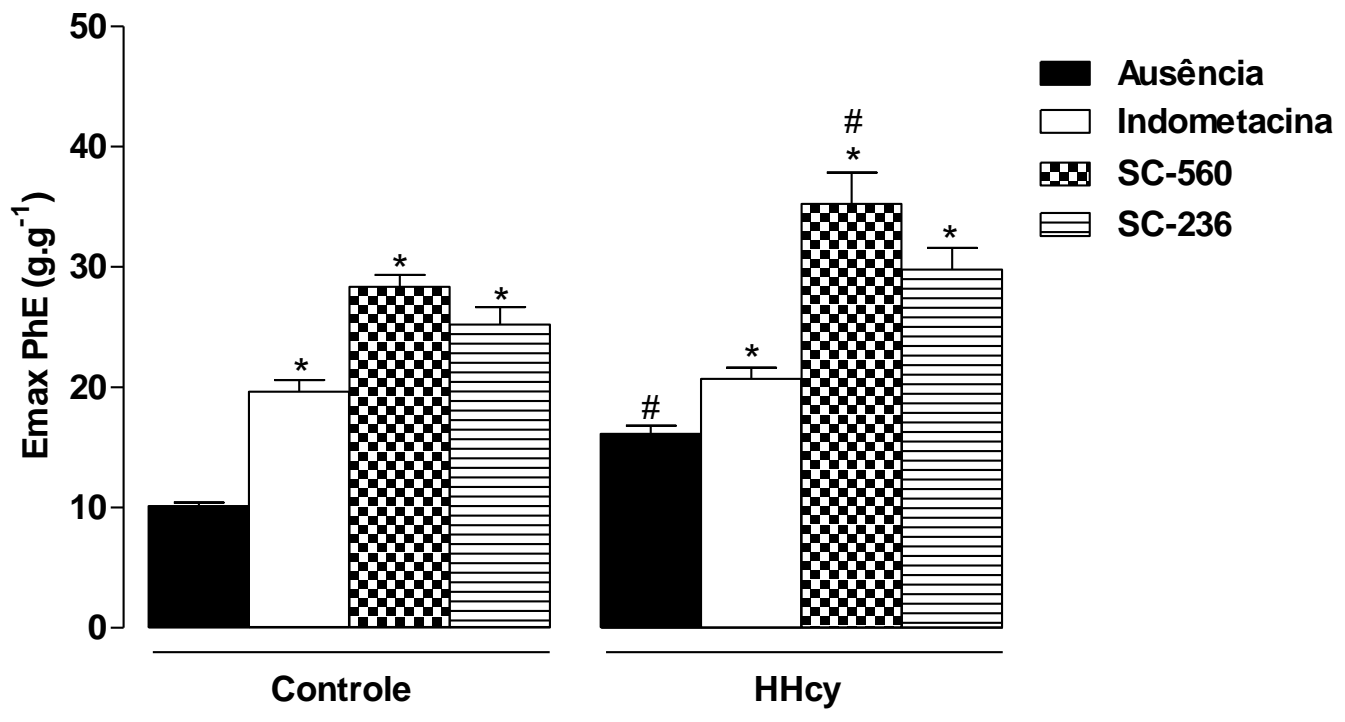

Figura 38: Participação de metabólitos derivados de COX no Emax da PhE. A figura mostra os valores de Emax da PhE em corpos cavernosos de ratos controle e HHcy, em ausência ou presença de inibidor não-seletivo da COX ou de inibidores seletivos das isoformas específicas da COX. Os dados representam a média \pm E.P.M. $\left(n=5\right.$ para cada grupo). $\left(^{*}\right)$ significativamente diferente $(p<0,05)$ em relação ao respectivo grupo em ausência de inibidor. (") significativamente diferente $(p<0,05)$ em relação ao respectivo controle em presença ou ausência de inibidor. ANOVA de uma via, pós-teste de Bonferroni.

Tabela 11 - Valores de Emax e $\mathrm{pD}_{2}$ de $\mathrm{PhE}$, em presença ou ausência de inibidores da COX, em corpos cavernosos de ratos controle e HHcy.

\begin{tabular}{|c|c|c|c|c|}
\hline \multirow{2}{*}{ Grupos } & \multicolumn{2}{|c|}{$\operatorname{Emax}\left(g \cdot g^{-1}\right)$} & \multicolumn{2}{|c|}{$\mathrm{pD} \mathrm{D}_{2}$} \\
\hline & Controle & HHcy & Controle & HHcy \\
\hline Ausência & $10,1 \pm 0,3$ & $16,1 \pm 0,7^{\#}$ & $5,41 \pm 0,02$ & $5,28 \pm 0,02$ \\
\hline Indometacina & $19,6 \pm 1,0^{*}$ & $20,7 \pm 0,9^{*}$ & $5,44 \pm 0,04$ & $5,39 \pm 0,03$ \\
\hline SC-560 & $28,4 \pm 1,0^{*}$ & $35,3 \pm 2,6^{\star, \#}$ & $5,34 \pm 0,02$ & $5,43 \pm 0,03^{*}$ \\
\hline SC-236 & $25,2 \pm 1,5^{\star}$ & $29,8 \pm 1,8^{*}$ & $5,42 \pm 0,04$ & $5,37 \pm 0,04$ \\
\hline
\end{tabular}

Os dados representam a média \pm E.P.M. ( $n=5$ para cada grupo). $\left({ }^{*}\right)$ significativamente diferente $(p<0,05)$ em relação ao respectivo grupo em ausência de inibidor. $\left(^{\#}\right)$ significativamente diferente $(p<0,05)$ em relação ao respectivo controle em presença ou ausência de inibidor. ANOVA de uma via, pós-teste de Bonferroni. 


\section{Conclusões Parciais}

- Em corpos cavernosos de ratos controle, o aumento no Emax da PhE, em presença de indometacina e inibidores seletivos, sugere uma importante participação de metabólitos derivados das isoformas COX-1 e COX-2, modulando negativamente este parâmetro.

- Na HHcy, o Emax da PhE está aumentado em presença de indometacina e dos inibidores seletivos de COX-1 e COX-2, sugerindo que os metabólicos derivados das isoformas específicas da COX não estão prejudicados nesta doença e participam modulando negativamente este parâmetro em corpos cavernosos destes ratos. 
5 Discussão 
Nosso grupo de pesquisa vem estudando as alterações vasculares associadas à HHcy nos últimos dez anos. O tratamento com DL-HcyT de ratos (de ANDRADE et al., 2006, 2009, 2009a) ou ratas ovariectomizadas (CELOTTO et al., 2009), na dose de $1 \mathrm{~g} / \mathrm{Kg} /$ dia, durante 15 dias, acarretou aumento nos níveis plasmáticos de Hcy, em torno de 10 vezes em relação aos níveis basais. Estes estudos mostraram que o tratamento utilizado no presente trabalho causa elevação nos níveis de Hcy plasmática, caracterizando um quadro de HHcy intermediária (KANG et al., 1992).

A HHcy está envolvida no remodelamento vascular em humanos (DEMUTH et al., 2002; LUPATTELLI et al., 1999), bem como participa da proliferação celular in vitro (TSAl et al., 1994) e da proliferação da camada íntima em modelos experimentais (ZULLI et al., 2003). Deste modo, as consequências da HHcy sobre a morfologia de corpos cavernosos de ratos foram avaliadas.

O estudo morfológico foi realizado através de cortes histológicos e coloração específica de Hematoxilina e Eosina, evidenciando estruturas como as trabéculas e os espaços cavernosos revestidos por endotélio. As análises mostraram que o tratamento, durante 15 dias, não acarretou alterações nas estruturas dos corpos cavernosos. Nossos resultados corroboram aqueles previamente descritos por de Andrade et al. (2009a), em carótida de ratos HHcy, nos quais não foram observados alterações na morfologia e morfometria. A HHcy em carótida de ratos foi capaz de induzir alterações morfológicas, tal como aumento na camada média, somente após 30 dias de tratamento (de ANDRADE et al., 2009a).

Foi demonstrado ainda que as alterações na reatividade vascular, tais como prejuízo do relaxamento induzido por ACh e aumento de contração à PhE e ET-1, precedem alterações na estrutura de artérias carótidas, indicando a disfunção endotelial. Tais fatos mostram que a HHcy se caracteriza em seus estágios iniciais por uma disfunção vascular, evidenciada por prejuízo da regulação do tônus vascular com redução de fatores relaxantes derivados do endotélio e/ou exacerbação de fatores relacionados à contração, que evolui para alterações morfológicas somente em estágios avançados da patologia (ANDRADE et al., 2009a).

A disfunção endotelial decorrente do aumento da concentração plasmática de Hcy advém da formação de compostos oxidados o que levaria, mais tardiamente, a proliferação de células musculares e de matriz extracelular (TYAGI et al., 1996). 
Nossos resultados, evidenciaram, através da coloração específica de Tricrômico de Gomori, que a HHcy induziu um discreto aumento nos depósitos de colágenos, no entanto, não se observaram macroalterações que justificassem modificações na reatividade vascular.

No presente estudo, a expressão da proteína a-actina, presente no músculo liso das trabéculas, não foi alterada em consequência da HHcy, sugerindo que o tratamento, no período utilizado, não acarretou hiperplasia muscular. Os resultados observados nos estudos de morfologia, de conteúdo de colágeno e de a-actina indicam que alterações na funcionalidade de corpos cavernosos de ratos HHcy não decorreram de alterações em sua estrutura.

O estudo da reatividade (contração ou relaxamento) foi baseado em processos de interação droga-receptor por análise dos parâmetros farmacológicos de Emax e $\mathrm{pD}_{2}$, obtidos por regressão não-linear das curvas concentração-efeito. Emax é definido como o efeito máximo que um agonista é capaz de produzir em um dado tecido sobre condições experimentais particulares (KENAKIN, 1997). Este parâmetro farmacológico serve como ferramenta para a análise dos efeitos do tratamento sobre a eficácia aparente de diferentes agonistas. Já o valor de $\mathrm{pD}_{2}$ serve como parâmetro para avaliação das variações na potência dos agonistas em virtude do tratamento. É definido como -log $\mathrm{EC}_{50}$, sendo $\mathrm{EC}_{50}$ a concentração molar de um agonista que produz $50 \%$ do efeito máximo dado por esse mesmo agonista (KENAKIN, 1997).

A ação de uma droga sobre um tecido depende da eficácia intrínseca do agonista, da sua afinidade pelos receptores e das características intrínsecas do tecido em estudo (FURCHGOTT \& BURSZYN, 1967). Os efeitos desencadeados pelos agonistas farmacológicos podem ser influenciados por fatores como a geração de substâncias pelos tecidos estudados. Essas substâncias estabelecem interações sinérgicas ou antagônicas com os agonistas, podendo modificar o perfil de curvas concentração-efeito e, consequentemente os parâmetros farmacológicos obtidos (KENAKIN, 1997).

Curvas concentração-efeito para $\mathrm{KCl}$ avaliam a função contrátil da musculatura lisa (BRIZZOLARA et al., 1994; ENGLISH et al., 2000) e possíves alterações na mobilização de cálcio via VOC. Concentrações aumentadas de $\mathrm{KCl}$ no meio extracelular promovem despolarização da membrana plasmática e abertura de canais de cálcio operados por voltagem (VOC), levando ao aumento da 
concentração de cálcio citoplasmático e consequentemente à contração muscular (BERRIDGE et al., 2005). Observou-se, no presente trabalho, que a HHcy não alterou a resposta de contração induzida por $\mathrm{KCl}$ em corpos cavernosos, indicando que não há comprometimento do processo de contração muscular desencadeado por despolarização da membrana celular, bem como na mobilização de cálcio via VOC. Deste modo, as alterações vasculares induzidas por HHcy, observadas neste trabalho, são agonista e receptores específicos.

No presente estudo, a resposta de relaxamento independente do endotélio foi estudada através de curva de relaxamento para NPS, um doador de NO. A HHcy não alterou esta resposta de relaxamento em corpo cavernoso de ratos. O NPS libera NO que promove sua ação de relaxamento via atividade da enzima guanilato ciclase (GC) e, consequentemente, formação de GMPc. Concluiu-se, portanto, que o sistema de transdução de sinal da via NO-GMPc não foi afetado pelo tratamento.

Nossos resultados corroboram aqueles previamente descritos por Jones et al. (2005) que observaram que o relaxamento de corpos cavernosos de coelhos em resposta ao NPS não foi afetado pela HHcy. Os autores concluíram que a HHcy acarretou prejuízo do relaxamento induzido por carbacol em corpos cavernosos de coelho em decorrência da redução da biodisponibilidade de NO endotelial e não por redução da atividade da GC.

No presente trabalho foi também estudada a reatividade à ACh por promover relaxamento dependente do endotélio (UNGVARI et al., 1999). Nossos resultados mostram que o tratamento com Hcy promoveu alteração na resposta induzida pela ACh, indicando que houve prejuízo no mecanismo de relaxamento dependente do endotélio, ou seja, possivelmente houve alteração na síntese e/ou biodisponibilidade de NO endotelial. Estes resultados corroboram os encontrados por de Andrade et al. (2009a) que mostraram que o relaxamento induzido por ACh estava reduzido em artéria carótida de ratos HHcy.

A redução da biodisponibilidade do NO ocorre devido à interação deste com os radicais livres gerados pela auto-oxidação da Hcy, levando à produção de peroxinitrito que é um potente oxidante. Jones et al. (2005) mostraram que o prejuízo da resposta de relaxamento induzida por carbacol em corpo cavernoso de coelhos HHcy foi revertido por incubação com SOD ou catalase, sugerindo que o efeito inibitório no relaxamento dependente de endotélio, induzido por HHcy, é mediado por ERO. 
Nossos dados corroboram as condições de aumento de estresse oxidativo em condição de HHcy narrada por estes autores, uma vez que nossos estudos de microscopia confocal em corpos cavernosos de ratos HHcy revelaram aumento basal expressivo no nível de $\mathrm{ERO}$, com importante participação de $\mathrm{O}_{2}{ }^{-}$, em relação àqueles observados em ratos controles.

O presente trabalho avaliou os efeitos vasomotores, vasoconstritor e vasorelaxante, do peptídeo ET-1 em corpos cavernosos de ratos controle e HHcy. Os resultados obtidos mostraram que a HHcy não causou alteração significativa no Emax do efeito contrátil da ET-1 em corpos cavernosos de ratos. Este fato pode ser decorrente da precocidade da patologia na disfunção vascular ou da consequência da HHcy sobre as subpopulações de receptores de ET-1.

O efeito da ET-1 é mediado pelos receptores $E T_{A}$ e $E T_{B}$. A participação dos receptores $\mathrm{ET}_{\mathrm{A}}$ na contração induzida por $\mathrm{ET}$-1 em corpos cavernosos de coelho apresenta maior relevância que a participação de receptores ET $_{B}$ (MUMTZ et al., 2006). Estes autores observaram que a inibição da contração por antagonista de receptores $\mathrm{ET}_{\mathrm{B}}$ em músculo liso do corpo cavernoso foi menor que aquela com antagonista dos receptores $\mathrm{ET}_{\mathrm{A}}$.

Carneiro et al. (2009a) mostraram que o IRL-1620, agonista dos receptores $\mathrm{ET}_{\mathrm{B}}$, não induziu resposta de contração quando testado em corpos cavernosos de coelho em estado basal, mas produziu relaxamento desta preparação após précontração com PhE, sugerindo o papel de relaxamento para estes receptores.

Considerando que os receptores $\mathrm{ET}_{\mathrm{B}}$ apresentam predominantemente efeito de relaxamento e, de alguma forma, pode contrabalancear o efeito de contração induzido pela ET-1, estudamos o efeito da ET-1 em presença de antagonista de receptores $\mathrm{ET}_{\mathrm{B}}$, com o objetivo de avaliar as consequências da HHcy na contração induzida por este agonista.

A HHcy acarretou aumento no Emax da ET-1, na vigência de bloqueio de receptores $\mathrm{ET}_{\mathrm{B}}$, em corpos cavernosos de ratos. Considerando que HHcy aumentou os níveis basais de ERO, evidenciado pelo aumento da marcação por brometo de etídio, incluindo $\mathrm{O}_{2}^{-}$, estes poderiam estar participando das vias intracelulares decorrentes da ativação de receptores $\mathrm{ET}_{\mathrm{A}}$. Além disso, $\mathrm{O} \mathrm{H}_{2} \mathrm{O}_{2}$, formado pela dismutação de $\mathrm{O}_{2}^{-}$, poderia atuar como fator modulador positivo da contração. Tais fatos favoreceriam a disfunção erétil. 
Corroborando nossa hipótese, Just et al. (2007) forneceram evidências que ERO, provavelmente $\mathrm{O}_{2}^{-}$, contribuem para a vasoconstrição aguda renal induzido por ET-1 em ratos normais. De Andrade et al. (2009) observaram que os receptores $\mathrm{ET}_{\mathrm{A}}$ modulam a resposta contrátil à ET-1 em carótida de rato HHcy, por ativação da Rhoquinase, sugerindo a participação de $\mathrm{O}_{2}^{-}$. Assim, uma possível sugestão para os resultados obtidos seja a ativação da Rho-quinase por $\mathrm{O}_{2}^{-}$, com consequente aumento no Emax da ET-1.

Nossos ensaios de microscopia confocal evidenciaram também que a produção de ERO ocorre principalmente em decorrência da patologia, sendo que a ET-1 não promoveu aumento significativo destes níveis em corpos cavernosos de ratos.

O efeito da HHcy no relaxamento induzido por ET-1 também foi estudado em corpos cavernosos pré-contraídos com PhE. O relaxamento induzido por ET-1 é dado principalmente por ativação de receptores $E_{B}$ em corpos cavernosos (ARI et al., 1996). Observou-se, no presente estudo, que o relaxamento induzido por ET-1 quando ambos os receptores, $\mathrm{ET}_{\mathrm{A}}$ e $\mathrm{ET}_{\mathrm{B}}$, estão disponíveis, ocorre em concentrações entre $10^{-10}$ a $3.10^{-8} \mathrm{~mol} / \mathrm{L}$. Em concentrações maiores, observou-se efeito contrátil, provavelmente por ativação dos receptores $\mathrm{ET}_{\mathrm{A}}$.

Considerando a maior importância dos receptores $E T_{B}$ no efeito de relaxamento desencadeado por ET-1, estudou-se este efeito em presença de antagonista dos receptores $\mathrm{ET}_{\mathrm{A}}, \mathrm{BQ}-123$. Os resultados mostraram que a $\mathrm{HHcy}$ reduziu o efeito vasorelaxante da ET-1 em corpos cavernosos de ratos. Uma possível explicação para esta redução no Emax da ET-1 seria a homocisteinilização de proteínas. Jakubowski (2000) mostrou que a HHcy pode acarretar lesão endotelial pelo mecanismo de homocisteinilização dos resíduos de lisina de proteínas. Considerando esse aspecto, é factível pensar que poderia ocorrer a homocisteinilização de resíduos de lisina dos receptores $\mathrm{ET}_{\mathrm{B}}$, que possuem em sua estrutura, aproximadamente $12 \%$ do total de aminoácidos dessa proteína (MASAKI, 2000). Esse processo acarretaria inativação dos receptores $E_{B}$ e, consequentemente, comprometimento da liberação de fatores de relaxamento desencadeados pela ativação desses receptores, tais como, NO e $\mathrm{PGI}_{2}$ (NOLL et al., 1996).

A utilização do agonista dos receptores $\mathrm{ET}_{\mathrm{B}}, \mathrm{IRL}-1620$, permitiu inferir que estes receptores estão envolvidos no relaxamento desencadeado pela ET-1 em 
corpos cavernosos de ratos. O prejuízo desta resposta em decorrência da HHcy, confirma que a patologia altera mecanismos específicos relacionados aos receptores $\mathrm{ET}_{\mathrm{B}} \mathrm{e}$, que, depois de alterados culminam na redução da resposta de relaxamento.

Ari et al. (1996) sugeriram que a ação vasodilatadora da ET-1, injetada intravenosamente em baixas doses em ratos, era mediada por ativação de receptores $\mathrm{ET}_{\mathrm{B}}$ presentes no endotélio e liberação local de NO, uma vez que estas ações foram inibidas por L-NAME, inibidor não-seletivo da NOS. Deste modo, neste trabalho, foi estudada a participação dos metabólitos da NOS no relaxamento mediado por IRL-1620 e as possíveis alterações em decorrência da HHcy. Em corpos cavernosos de ratos controle, a presença de L-NAME reduziu significativamente a resposta de relaxamento induzida por IRL-1620, sugerindo que metabólicos derivados da enzima NOS, provavelmente NO, estão envolvidos nesta resposta, corroborando os achados de Ari et al (1996)

Em corpos cavernosos de ratos HHcy, observamos que a presença de LNAME não acarretou alteração no parâmetro de Emax do IRL-1620. Isto pode ser decorrente de atividade reduzida da enzima NOS, ou de desacoplamento, conforme descrito por Topal et al (2004). Estes autores mostraram que o estresse oxidativo e a inibição de NO induzida por Hcy são dependentes do desacolpamento da eNOS, em decorrência da redução intracelular de $\mathrm{BH}_{2}$. Outra possibilidade é de que a biodisponibilidade de $\mathrm{NO}$ esteja comprometida em decorrência do estresse oxidativo evidenciado na HHcy (JONES et al., 2005).

A quantificação do RNAm para receptores $E_{A}$ e $E T_{B}$, pré-pró-ET-1 e ECE em corpos cavernosos de ratos HHcy, realizadas neste trabalho, não apresentou alterações em relação aos ratos controle. Entretanto, consequências da HHcy em mecanismos pós transcricionais não devem ser desconsideradas. De Andrade et al. (2009) observaram, em estudos imunohistológicos, aumento na expressão da proteína $\mathrm{ET}_{\mathrm{A}}$ na musculatura lisa de carótidas de ratos $\mathrm{HHcy}$, sugerindo que $\mathrm{o}$ aumento na densidade deste receptor poderia interferir na resposta contrátil observada à ET-1.

Nesta primeira etapa do nosso trabalho, foi possível evidenciar que a HHcy intermediária pode afeta de maneira drástica, mesmo em suas fases mais iniciais, a função vasoativa do peptídeo ET-1 em corpos cavernosos de ratos.

As consequências da HHcy sobre a contração desencadeada por $\mathrm{PhE}$ também foram estudadas em corpos cavernosos de ratos. No presente estudo, a 
HHcy promoveu aumento significativo no Emax da PhE em corpos cavernosos de ratos, após 15 dias de tratamento, corroborando os resultados obtidos por de Andrade et al. (2009).

O efeito da PhE é dado pela interação deste agonista com receptor $\alpha_{1}$ adrenérgico, acoplado à proteína Gq (MINNEMAN, 1989). A contração ocorre devido a mobilização de cálcio intracelular e extracelular, principalmente pela geração de $I_{3}$ e DAG (diacilglicerol), respectivamente, com consequente ativação de fosfoquinase (PK) C (MINNEMAN, 1988; MINNEMAN, 1999). A PhE promove ainda ativação de Rho-quinase, bem como a formação de ácido araquidônico (SEASHOLTZ et al., 1999; GARCÍA-CAZARÍN et al., 2008; ZHONG; MINNEMAN, 1999). No endotélio, a ativação do receptor adrenérgico resulta em produção e liberação de NO, que atua como um controle local da resposta vasoconstritora de aminas simpatomiméticas (BOER et al., 1999; FILIPPI et al., 2001). Os receptores $\alpha_{1}$-adrenérgicos estão envolvidos na ativação da NAD(P)H oxidase na membrana, gerando ERO (XIAO et al., 2002).

O termo estresse oxidativo descreve a condição que envolve aumento nos níveis de ERO, intermediárias de reações de redução-oxidação para a formação de água e oxigênio. As ERO são quimicamente reativas e incluem $\mathrm{O}_{2}^{-}$, radical hidroxil $\left(\mathrm{OH}^{-}\right), \mathrm{H}_{2} \mathrm{O}_{2}$ e peroxinitrito (DROGE, 2002; FRIDOVICH, 1997).

A distinta propriedade entre $\mathrm{O}_{2}^{-}$e $\mathrm{H}_{2} \mathrm{O}_{2}$ e seus diferentes locais de distribuição revelam que diferentes ERO podem ativar diferentes vias de sinalização, o que leva a respostas funcionais divergentes. Níveis de $\mathrm{O}_{2}^{-}$aumentados causam inativação do efeito vasodilatador do NO, causando disfunção endotelial e vasoconstrição (CAI; HARRISON, 2000). Por outro lado, $\mathrm{H}_{2} \mathrm{O}_{2}$ atua como vasodilatador em alguns leitos vasculares, incluindo cerebral, coronária e artérias mesentéricas (PARAVICINI et al., 2004; LIU et al., 2003; MATOBA et al., 2000).

A fonte enzimática responsável pela formação das ERO inclui a xantina oxidase (presente no endotélio vascular) (LACY et al., 1998), NOS desacoplada (ANDREW et al., 1999) e NAD(P)H oxidase. As principais enzimas antioxidantes são a SOD (catalisa a dismutação de $\mathrm{O}_{2}^{-}$em $\mathrm{H}_{2} \mathrm{O}_{2}$ ) (JOHNSON AND GIULIVI, 2005), catalase (catalisa a reação de $\mathrm{H}_{2} \mathrm{O}_{2}$ em água e oxigênio molecular) (CAI, 2005) e a glutationa peroxidase. (GONGORA et al., 2006; SINDHU et al., 2005; SUI et al., 2005). 
A participação de $\mathrm{O}_{2}^{-}$e $\mathrm{H}_{2} \mathrm{O}_{2}$ na contração induzida por $\mathrm{PhE}$ em corpos cavernosos de rato foi estudada pelo pré-tratamento destas preparações com drogas que atuam em diferentes momentos da via de produção de ERO, como indicado na figura seguinte (Figura 39).

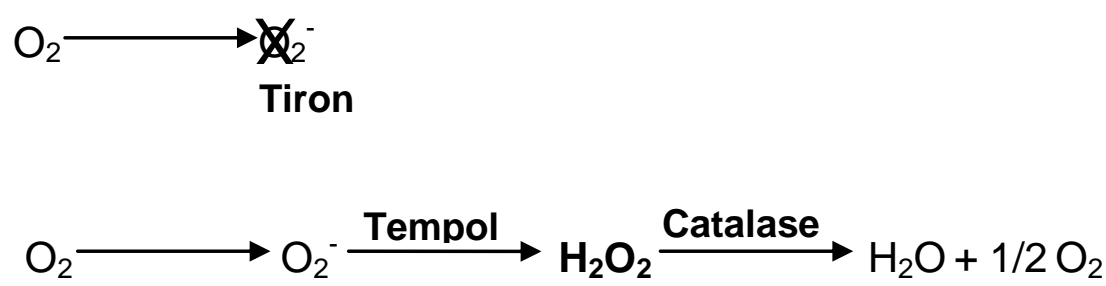

Figura 39: Atuação das diferentes drogas na via de formação de ERO

O Tiron promove o sequestro de $\mathrm{O}_{2}^{-} \mathrm{e}$, consequentemente, poderia impedir a continuação da via, acima mencionada, e formação de $\mathrm{H}_{2} \mathrm{O}_{2}$. Em corpos cavernosos de ratos controle, a presença de tiron acarretou aumento no Emax da PhE, sugerindo a participação de fatores que modulam negativamente este parâmetro. A presença de peg-catalase, que transforma $0 \mathrm{H}_{2} \mathrm{O}_{2}$ em água e oxigênio, também promoveu aumento no Emax da $\mathrm{PhE}$, sugerindo que $\mathrm{O}_{2} \mathrm{H}_{2}$ tem participação no efeito modulador negativo sobre este parâmetro.

Quando a formação do $\mathrm{H}_{2} \mathrm{O}_{2}$ ocorre fisiologicamente, por ação da SOD, este parece ter efeito modulador negativo sobre a contração induzida por PhE. Por outro lado, o tempol, um mimético da SOD, exacerbaria ainda mais a formação de $\mathrm{H}_{2} \mathrm{O}_{2}$. Nesta situação, houve aumento no Emax da $\mathrm{PhE}$, de maneira semelhante à observada em presença de tiron ou peg-catalase isoladamente. Estes resultados são sugestivos de que, em quantidades maiores de $\mathrm{H}_{2} \mathrm{O}_{2}$, este apresenta um efeito modulador positivo da contração induzida por PhE em corpos cavernosos de rato controle.

$\mathrm{O}$ efeito modulador positivo de $\mathrm{H}_{2} \mathrm{O}_{2}$ nestas condições é evidenciado pela adição de tempol em associação à peg-catalase. A adição concomitante destes dois compostos promove a formação de $\mathrm{H}_{2} \mathrm{O}_{2}$ e sua consequente decomposição pela catalase adicionada, inibindo o efeito modulador positivo desta espécie.

Nossos resultados sugerem um efeito bifásico dependente dos níveis de $\mathrm{H}_{2} \mathrm{O}_{2}$, quando baixos promoveriam relaxamento e, relativamente elevados, promoveriam contração. Esta hipótese é fundamentada na existência de efeito 
bifásico para $\circ \mathrm{H}_{2} \mathrm{O}_{2}$ sugerida por Gao et al. (2003). Os autores observaram que, em artéria mesentérica de ratos pré-contraídas com $\mathrm{PhE}$, o efeito vasodilatador do $\mathrm{H}_{2} \mathrm{O}_{2}$ é dependente da concentração utilizada. Concentrações submicromolares causaram contração, enquanto concentrações maiores provocaram contração transitória seguida por resposta de relaxamento sustentada. Gao et al. (2003), neste estudo, sugerem que a resposta de contração do $\mathrm{H}_{2} \mathrm{O}_{2}$ é mediada por $\mathrm{TXA}_{2}$, enquanto a de relaxamento é mediado por ativação de canais para potássio.

Em corpos cavernosos de ratos $\mathrm{HHcy}$, o efeito modulador negativo de $\mathrm{H}_{2} \mathrm{O}_{2}$ está prejudicado, uma vez que a adição de tiron ou peg-catalase, isoladamente, não alterou a resposta de contração induzida pela PhE. O prejuízo deste efeito do $\mathrm{H}_{2} \mathrm{O}_{2}$ poderia ser decorrente de um comprometimento envolvendo a SOD.

Nossos resultados corroboram estudos prévios de Lee et al. (2007) que examinaram o efeito de altas concentrações plasmáticas de Hcy nas células glial retinal de ratos e observaram expressão retinal reduzida da SOD em relação aos animais controle, sugerindo que este sistema antioxidante local está atenuado.

O efeito da Hcy na expressão e secreção da SOD foi estudado por Nonaka et al. (2001) em células do músculo liso de aorta torácica de ratos. Foi observado que, em presença de Hcy, houve diminuição da expressão e secreção de SOD, sugerindo que a Hcy acarreta aumento de estresse oxidativo na parede vascular. Estes dados poderiam também estar relacionados a nossas observações em ratos HHcy.

Foi mostrado que a HHcy reduz significativamente a concentração de cobre e, consequentemente, pode reduzir a atividade da SOD (HUCKS et al., 2004), uma vez que esse metal atua como co-fator para a ação antioxidante desta enzima (BROWN \& STRAIN, 1990), fato este que poderia também explicar os resultados por nós encontrados em corpos cavernosos de ratos HHcy.

A adição do mimético da SOD, tempol, em corpos cavernosos de ratos HHcy acarretou o retorno dos valores de Emax da PhE ao nível dos valores obtidos no grupo controle, sugerindo restauração da formação de $\mathrm{H}_{2} \mathrm{O}_{2}$ por dismutação de $\mathrm{O}_{2}$. A evidência de que este efeito modulador negativo tem a participação de $\mathrm{H}_{2} \mathrm{O}_{2}$ dá-se em presença de tempol associado à peg-catalase, em que ocorre restauração dos valores de Emax em relação ao Emax sem inibidor.

$\mathrm{O}$ efeito modulador negativo do $\mathrm{H}_{2} \mathrm{O}_{2}$ sobre a contração induzida por PhE, observado após adição de tempol em corpos cavernosos de ratos $\mathrm{HHcy}$, pode ser 
decorrente dos níveis basais elevados de $\mathrm{O}_{2}{ }^{-}$. Assim, a dismutação de $\mathrm{O}_{2}{ }^{-}$formariam quantidades muito altas de $\mathrm{H}_{2} \mathrm{O}_{2}$ em relação aos níveis do controle e promoveriam o efeito modulatório negativo observado. Outra possibilidade poderia ser que os níveis de $\mathrm{H}_{2} \mathrm{O}_{2}$ estivessem baixos por atividade aumentada da enzima catalase na HHcy. Há evidência, em modelos de HHcy, de aumento na atividade da enzima catalase hepática. Em camundongos heterozigotos para a deficiência da enzima betacistationina, um modelo de HHcy, observou ativação da $\mathrm{NAD}(\mathrm{P}) \mathrm{H}$ oxidase, porém sem acúmulo de ERO ou de espécies reativas de nitrogênio. A atividade da catalase hepática foi medida e observou-se $50 \%$ de aumento, sugerindo que a deficiência da enzima beta-cistationina inicia um desequilíbrio redox no fígado, porém a ativação da catalase atenua o dano oxidativo (HAMELET et al., 2008). Portanto, possíveis alterações na SOD e/ou catalase poderiam explicar os efeitos observados na HHcy em corpos cavernosos de ratos.

Estudos clínicos mostraram que pacientes HHcy apresentaram disfunção endotelial e elevado estresse oxidativo, ambos in vitro e in vivo (KANANI et al., 1999; LOSCALZO, 1996). O aumento das concentrações plasmáticas de Hcy por ingestão de metionina causou prejuízo da função endotelial e produção de ERO em humanos saudáveis. O aumento do estresse oxidativo parece ser o papel chave no prejuízo da função endotelial pela Hcy, uma vez que a administração de antioxidante preveniu completamente este processo (KANANI et al., 1999).

O NO é formado por ação da enzima NOS e, na camada muscular, promove ativação da enzima GCs, produção de GMPc e ativação da proteína quinase dependente de GMPc (PKG), o que resulta no relaxamento vascular (MONCADA et al., 1991; IGNARRO, 2000; HANAFY et al., 2001). O NO também atua independente de PKG, promovendo a hiperpolarização muscular (BOLOTINA et al., 1994).

A participação dos metabólitos da NOS na resposta de contração induzida por PhE, em corpos cavernosos de ratos controle e HHcy, foi avaliada através da inibição das diferentes isoformas de NOS. Em corpos cavernosos de ratos controle, observamos que metabólitos derivados da NOS participam modulando negativamente a resposta de contração induzida por PhE, uma vez que na presença de L-NAME, inibidor inespecífico da NOS, observou-se um aumento no Emax da PhE. Estes metabólitos, com efeito modulador negativo da contração parecem ser derivados das eNOS, nNOS e iNOS, uma vez que em presença de inibidores seletivos dessas isoformas detectou-se um aumentou deste parâmetro. 
Em corpos cavernosos de ratos HHcy, observamos que em presença de LNAME não ocorreu alteração no parâmetro de Emax da PhE, bem como em presença do inibidor seletivo para iNOS. A não alteração deste parâmetro em presença dos referidos inibidores sugere duas possibilidades. Uma possibilidade é de que a isoforma iNOS apresente atividade reduzida, ou esteja desacoplada. A transferência de elétrons durante a síntese de NO pela enzima NOS é um processo sensível á oxidação. Quando desestabilizado, ocorre a formação de $\mathrm{O}_{2}{ }^{-}$em vez de NO pela enzima, caracterizando o processo de desacoplamento (FORSTERMANN \& MUNZEL, 2006). O desacoplamento ocorre em condições de escassez do substrato L-arginina ou do co-fator $\mathrm{BH}_{4}$, por ação de arginases e estresse oxidativo (FORSTERMANN \& MUNZEL, 2006). Este processo agrava o estresse oxidativo, sendo, portanto, causa e consequência deste processo.

Outra possibilidade é de que haja redução da biodisponibilidade de NO. Corroborando nossa última sugestão, Jones et al. (2005) demonstraram um comprometimento decorrente da menor biodisponibilidade de NO por ação do estresse oxidativo. Jones et al. (2005) mostraram que o prejuízo do relaxamento endotélio-dependente em corpos cavernosos de coelhos HHcy foi revertido pela SOD e pela catalase, sugerindo que a HHcy prejudica o relaxamento do corpo cavernoso por diminuição da biodisponibilidade de NO, um efeito mediado pela ação das $\mathrm{ERO}, \mathrm{O}_{2}^{-}$e $\mathrm{H}_{2} \mathrm{O}_{2}$.

A nitrotirosina é um biomarcador do estresse oxidativo e/ou nitroativo (HIDALGO; DONOSO, 2008; IGNARRO, 2000). Maior acumulação de nitrotirosina pode ser indicativo de presença de peroxinitrito, produto da reação de $\mathrm{O}_{2}{ }^{-}$e $\mathrm{NO}$, com consequente redução na biodisponibilidade deste último (UPCHURCG et al., 1997). No presente estudo, a expressão deste marcador não foi alterada pela HHcy em corpos cavernosos de ratos. Por outro lado, de Andrade et al. (2006) mostraram que, em carótida de ratos HHcy, a expressão de nitrotirosina estava aumentada, sugerindo que a geração de $\mathrm{O}_{2}^{-}$em decorrência da HHcy acarreta formação de peroxinitrito por inativação de NO e consequente redução de sua biodisponibilidade.

Os níveis plasmáticos do metabólito de NO, nitrato, são utilizados como indicativo da biodisponibilidade de $\mathrm{NO}$ no plasma. A HHcy reduziu os níveis de nitrato plasmático nos ratos, sugerindo que o aumento no Emax da PhE pode estar relacionado à redução oxidativa do NO. 
O comprometimento da produção e/ou biodisponibilidade dos metabólitos derivados de NOS não foi decorrente de alterações em mecanismos prétranscricionais, uma vez que a expressão de RNAm das isoformas eNOS, nNOS e iNOS não foram alteradas pela HHcy. No entanto, as consequências da HHcy em mecanismos pós-transcricionais não devem ser desconsideradas, uma vez que estudos prévios de imunohistoquímica aumentaram a expressão de RNAm de eNOS e iNOS em artéria carótida de ratos HHcy (de ANDRADE et al., 2006) ou ratas ovariectomizadas HHcy (CELOTTO et al., 2009). Por outro lado, Chen et al. (2002) observaram redução na expressão de eNOS em artérias coronárias e artérias carótidas de porcos, na HHcy.

O estresse oxidativo também pode resultar na ativação de COX, gerando prostanóides $\mathrm{e} \mathrm{O}_{2}^{-}$(SHI; VANHOUTTE, 2008). Por outro lado, Daley et al. (1996) mostraram um efeito inibitório do estresse oxidativo na produção de PG em corpos cavernosos de coelhos.

Os prostanóides (TXA 2 , PG e prostaciclinas) são derivados de eicosanóides por ação da enzima COX. A ativação da fosfolipase (PL) C, assim como da PLA 2 é responsável pela liberação do ácido araquidônico dos fosfolipídeos de membrana. $A$ enzima COX catalisa a formação de $\mathrm{PGH}_{2}$, subsequentemente convertida em $\mathrm{TXA}_{2}$ pela $\mathrm{TX}$ sintase ou em $\mathrm{PGI}_{2}, \mathrm{PGE}_{2}, \mathrm{PGD}_{2}$ ou $\mathrm{PGF}_{2 \alpha}$ por diferentes enzimas (UBBINK et al., 1993).

A HHcy induzida pela administração de metionina aumentou a contração da angiotensina II em carótida de rato por mecanismos que envolve aumento da produção ou liberação de prostanóides vasoconstritores, uma vez que a adição de indometacina preveniu o aumento no Emax da angiotensina II observado após o tratamento (BONAVENTURA et al, 2004). Em carótida de rato HHcy, prostanóides vasoconstritores derivados do endotélio como $\mathrm{PGF}_{2 \alpha}, \mathrm{PGH}_{2}$ e $\mathrm{TXA}_{2}$ reduziram a ação vasorelaxante derivada da bradicinina (BONAVENTURA et al., 2009).

CHRIST et al. (1990) demonstraram que a atividade contrátil espontânea observada em tecido erétil humano pode ser mediada por geração e liberação de produtos da COX. A síntese de PGs tem sido demonstrada em tecido erétil humano in vitro (ROY et al., 1984) e a adição de $\mathrm{PGF}_{2 \alpha}$ neste tecido induziu atividade contrátil rítmica (ROY et al., 1984; HEDLUND; ANDERSSON, 1985).

Por outro lado, também foi relatada a participação de metabólitos da COX com ação relaxante em corpos cavernosos. Moreland et al. (2001) mostraram que 
$\mathrm{PGE}_{2}$ é o principal prostanóide sintetizado e liberado por células do músculo cavernoso de humanos em resposta ao aumento da tensão de oxigênio, o que caracteriza o estado erétil. Os autores sugeriram que este prostanóide liga-se ao receptor acoplado a proteína $\mathrm{G}, \mathrm{EP}_{2}$, estimulando a adenilato ciclase $(\mathrm{AC})$ do músculo liso, com consequente aumento do AMPc.

Para verificar nossa hipótese da participação de metabólitos derivados da COX na contração induzida pela $\mathrm{PhE}$ em corpos cavernosos de ratos controle e HHcy, foram utilizados inibidores não-específicos e específicos para COX.

Sadeghipour et al. (2006) mostraram que a presença do inibidor não-seletivo para COX, indometacina, atenuou o relaxamento mediado pelo endotélio em corpos cavernosos de ratos controle, sugerindo que a via das COX pode ser importante no relaxamento endotelial neste tecido.

Nossos resultados corroboram os relatos de Sadeghipour et al. (2006). Observamos que em corpos cavernosos de ratos controle, na presença de indometacina, ocorre aumentou no Emax da $\mathrm{PhE}$, sugerindo a participação de metabólitos derivados de COX, modulando negativamente a contração induzida por PhE. Estes metabólicos parecem ser derivados tanto de COX-1 quanto COX-2, uma vez que inibidores específicos destas isoformas aumentaram o Emax da PhE. Assim, sugerimos que ambas as isoformas de COX estão expressas constitutivamente em corpos cavernosos de ratos. Nossos dados são confirmados pelos observados de Sanchez et al. (2010) que demonstraram que as isoformas de COX foram constitutivamente expressas em endotélio de artéria peniana de animais saudáveis.

A HHcy parece não interferir na produção e/ou liberação dos metabólitos derivados de COX-1 e COX-2 que modulam negativamente a contração. Nossos resultados corroboram os de Celotto (2005) que estudou a participação dos metabólitos da COX na contração induzida por PhE em artéria carótida de ratas HHcy ovariectomizadas. A autora relatou que a HHcy não acarretou alterações da produção e/ou liberação de prostanóides derivados da COX.

Em síntese, nosso estudo mostrou que a HHcy causou alterações na reatividade decorrente do estresse oxidativo, com prejuízo do efeito dos metabólitos derivados da NOS, sem interferir na produção e/ou liberação de metabólitos derivados da COX. 
6 Conclusões 
A principal contribuição do presente estudo foi mostrar, experimentalmente in vitro, as consequências da HHcy em corpos cavernosos de ratos. Esta patologia caracteriza-se, principalmente, por aumento do estresse oxidativo com consequente redução da produção e/ou biodisponibilidade de NO, o que acarreta exacerbação de respostas contráteis e prejuízo na capacidade de vasodilatação deste tecido. Fato este, que poderia ser responsável por um processo de disfunção erétil. Deste modo, os resultados do presente estudo possibilitam uma compreensão de alguns dos mecanismos envolvidos na patofisiologia da HHcy que poderiam acarretar esta disfunção. 
Referências 
ANDERSSON, K. E. Erectile physiological and pathophisiological pathway involved in erectile dysfunction. The Journal of Urology, 170, S6-14, 2003.

ANDERSSON, K. E. Pharmacology of penile erection. Pharmacology, v. 53, p. 417-50, 2001.

ANDERSSON, K. E.; STIEF, C. G. Neurotransmission and the contraction and relaxation of penile erectile tissues. World Journal of Urology, v.15, n.1, p.14-20, 1997.

ANDERSSON, K. E.; WAGNER, G. Physiology of penile erection. Physiological Reviews, v. 75, p.191-236, 1995.

ANDREW, P.J.; MAYER, B. Enzymatic function of nitric oxide synthases. Cardiovascular Research, v. 43, p. 521-531, 1999.

ARI, G.; VARDI, Y.; HOFFMAN, A.; FINBERG, J. P. Possible role for endothelins in penile erection. European Journal of Pharmacology, v. 307, p. 69-74, 1996.

AUSTIN, R. C.; LENTZ, S. R.; WERSTUCK, G. H. Role of hyperhomocysteinemia in endothelial dysfunction and atherothrombotic disease. Cell death and differentiation, v. 11, p. S56-64, 2004.

AU-YEUNG, K. K.; WOO, C. W.; SUNG, F. L.; YIP, J. C.; SIOW, Y. L. Hyperhomocysteinemia activates nuclear factor-kappaB in endothelial cells via oxidative stress. Circulation Research, v.94, p. 28-36, 2004.

BELL, C. R.; SULLIVAN, M. E.; DASHWOOD, M. R.; MUDDLE, J. R.; MORGAN, R. J. The density and distribution of endothelin 1 and endothelin receptor subtypes in normal and diabetic rat corpus cavernosum. British Journal of Urology, v. 76, n. 2, p. 203-7, 1995.

BERRIDGE, M. J.; BOOTMAN, M. D.; RODERICK, H. L. Calcium signalling: dynamics, homeostasis and remodeling. Nature, v. 4, p. 517-529, 2005.

BLOM, H. J. Consequences of homocysteine export and oxidation in the vascular system. Seminars in thrombosis and hemostasis, v. 26, p. 227-32, 2000.

BOER, C.; SCHEFFER, G. J.; DE LANGE, J. J.; WESTERHOF, N.; SIPKEMA, P. Alphe1adrenoceptor stimulation induces nitric oxide release in rat pulmonary arteries. Journal of Vascular Research, v. 36, p. 79-81, 1999.

BOLOTINA, V. M.; NAJIBI, S.; PALACINO, J. J.; PAGANO, P. J.; COHEN, R. A. Nitric oxide directly activates calcium-dependent potassium channels in vascular smooth muscle. Nature, v. 368, p. 850-853, 1994. 
BONAVENTURA, D.; TIRAPELLI, C. R.; DE OLIVEIRA, A. M. Chronic methionine loadinduced hyperhomocysteinemia impairs the relaxation induced by bradykinin in the isolated rat carotid. Amino Acids, v. 37, p. 617-627, 2009.

BONAVENTURA, D.; TIRAPELLI, C. R.; HADDAD, R.; HOEHR, N. F.; EBERLIM, M. N.; DE OLIVEIRA, A. M. Chronic methionine load-induced hyperhomocysteinemia enhances rat carotid responsiveness for angiotensin II. Pharmacology, v. 70, p. 91-99, 2004.

BRIZZOLARA, A. L.; STEWART-LEE, A.; BURNSTOCK, G. Responses of rabbit basilar arteries to vasoconstrictor and vasodilator agents: the effects of atherosclerosis, age and sex. Journal Vascular Research, v. 31, p. 106-113, 1994.

BROWN, J. C. W.; STRAIN, J. J. Effect of dietary homocysteine on copper status in rats. The Journal of Nutrition, v. 120, p. 1068-1074, 1990.

BULT, H.; HERMAN, A. G.; MATTHYS, D. E. Antiatherosclerotic activity of drugs in relation to nitric oxide function. European Journal Pharmacology, v. 375, p. 157-176, 1999.

BURK, R. F. Glutathione-dependent protection by rat liver microsomal protein against lipid peroxidation. Biochimica et Biophysica Acta, v. 757, p. 21-28, 1983.

BURNETT, A. L. Role of nitric oxide in the physiology of erection. Biology of Reproduction, v. 53 , n. 3, p. $485-9.1995$

BURNETT, A. L.; LOWENSTEI, C. J.; BREDT, D. S. et al. Nitric oxide: a physiologic mediator of penile erection. Science, v. 257, p. 401-403, 1992.

$\mathrm{CAI}, \mathrm{H}$. Hydrogen peroxide regulation of endothelial function: origins, mechanisms, and consequences. Cardiovascular Research, v. 68, p. 26 -36, 2005.

CAI, H.; HARRISON, D. G. Endothelial dysfunction in cardiovascular diseases: the role of oxidant stress. Circulation Research, v. 87, p. 840-844, 2000.

CARNEIRO, F. S.; CARNEIRO, Z. N.; GIACHINI, F. R. C.; LIMA, V. V.; NOGUEIRA, E. F.; RAINEY, W. E.; TOSTES, R. C.; WEBB, R. C. Murine and rat cavernosal responses to endothelin-1 and urotensin-II Vasoactive Peptide Symposium. Journal of the American Society of Hypertension, v. 2, n. 6, p. 439-447, 2008a.

CARNEIRO, F. S.; NUNES, K. P.; GIACHINI, F. R. C.; LIMA, V. V.; CARNEIRO, Z. N.; NOGUEIRA, E. F.; LEITE, R.; ERGUL, A.; RAINEY, W. E.; WEBB, C.; TOSTES, R. Activation of the ET-1/ET-A pathway contributes to erectile dysfunction associated with mineralocorticoid hypertension. The Journal of Sexual Medicine, v. 5, p. 2793-2807, 2008. 
CELOTTO, A. C. Estudo do efeito vasculoprotetor do fitoestrógeno genisteína em ratas ovariectomizadas hiperhomocisteinêmicas. 2005. 160p. Dissertação (mestrado). Faculdade de Ciências Farmacêuticas de Ribeirão Preto, Ribeirão Preto, 2005.

CELOTTO, A. C.; FUKADA, S. Y.; LAURINDO, F. R. M.; HADDAD, R.; EBERLIN, M. N.; de OLIVEIRA, A. M. Chronic hyperhomocysteinemia impairs vascular function in ovariectomized rat carotid arteries. Amino Acids, 10.1007/s00726-009-0368-y, 2009.

CHAMBERS, J. C.; McGREGOR, A.; JEAN-MARIE, J.; OBEID, O. A.; KOONER, J. S. Demonstration of rapid onset vascular endothelial dysfunction after hyperhomocysteinaemia: an effect reversible with vitamin C therapy. Circulation, v. 99, p. 1156-1160, 1999.

CHAMBERS, J. C.; OBEID, A. O.; KOONER, J. S. Physiological increments in plasma homocysteine induce vascular endothelial dysfunction in normal human subjects. Arteriosclerosis, Thrombosis, and Vascular Biology, v. 19, p. 2922-2927, 1999a.

CHANG, S.; HYPOLITE, J. A.; CHANGOLKAR, A.; WEIN, A. J.; CHACKO, S.; DiSANTO, M. $E$. Increased contractility of diabetic rabbit corpoa smooth muscle in response to endothelin is mediated via Rho-kinase beta. International Journal of Impotence Research, v.15, n.1, p. 53-62. 2003.

CHEN, C.; CONKLIN, B. S.; REN, Z.; ZHONG, D. S. Homocysteine decreases endotheliumdependent vasorelaxation in porcine arteries. The Journal of Surgical Research, v. 102, n. 1, p. 22-30, 2002.

CHEN, C.; HALKOS, M. E.; SUROWIEC, S. M.; CONKLIN, B. S.; LIN, P. H.; LUMSDEN, A. $B$. Effects of homocysteine on smooth muscle cell proliferation in both cell culture and artery perfusion culture models. The Journal of surgical research, v. 88, p. 26-33, 2000.

CHRIST, G. J.; MAAYANI, S.; VALCIC, M.; MELMAN, A. Pharmacological studies of human erectile tissue: characteristics of spontaneous contractions and alterations in a-adrenoceptor responsiveness with age and disease in isolated tissues. British Journal of Pharmacology, v. 101, p. $375-381,1990$.

CLAUDINO, M. A.; PRIVIERO, F. B. M.; TEIXEIRA, C. E.; DE NUCCI, G.; ANTUNES, E.; ZANESCO, A. Improvement in relaxation response in corpus cavernosum from trained rats. Urology, v. 63, p. 1004-1008, 2004.

DAI, Y.; POLLOCK, D. M.; LEWIS, R. L.; WINGARD, C. J.; STOPPER, V. S.; MILLS, T. M. Receptor-specific influence of endothelin-1 in the erectile response of the rat. American Journal of Physiology. Regulatory, Integrative and Comparative Physiology, v. 279, n. 1, p. R25-30, 2000. 
DALEY, J. T.; WATKINS, M.T.; BROWN, M. L.; MARTINEZ, V.; CUEVAS, P.; SAENZ DE TEJADA, I. Prostanoid production in rabbit corpus cavernosum: Inhibition by oxidative stress. The Journal of Urology, v. 156, p. 1169-1173, 1996.

de ANDRADE, C. R.; FUKADA, S. Y.; OLIVON, V. C.; DE GODOY, M. A. F.; HADDAD, R.; EBERLIN, M. N.; CUNHA, F. Q.; DE SOUZA, H. P.; LAURINDO, F. R. M.; de OLIVEIRA, A. M. a1D-adrenoceptor-induced relaxation on rat carotid artery is impaired during the endothelial dysfunction evoked in the early stages of hyperhomocysteinemia. European Journal of Pharmacology, v. 543, p. 83-91, 2006.

de ANDRADE, C. R.; LEITE, P. F.; MONTEZANO, A. C.; CASOLARI, D. A.; YOGI, A.; TOSTES, R. C.; HADDAD, R.; EBERLINS, M. N.; LAURINDO, F. R. M.; DE SOUZA, H. P.; CORREA, F. M. A.; de OLIVEIRA, A. M. Increased endothelin-1 reactivity and endothelial dysfunction in carotid arteries from rats with hyperhomocysteinemia. British Journal of Pharmacology, v. 157, p. 568-580, 2009.

de ANDRADE, C. R.; TIRAPELLI, C. R.; HADDAD, R.; EBERLINS, M. N.; RAMALHO, L. N. Z.; IYOMASA, M. M.; UYEMURA, S. A.; de OLIVEIRA, A. M. Hyperhomocysteinemia induced by feeding rats diets rich in DL-homocysteine thiolactone promotes alterations on carotid reactivity independent of arterial structure. Vascular Pharmacology, v. 51, p. 29129, 2009a.

DEANFIELD, J.; DONALD, A.; FERRI, C.; GIANNATTASIO, C.; HALCOX, J.; HALLIGAN, S.; et al. Endothelial function and dysfunction. A statement by the Working Group on Endothelin and Endotheliual Factors of the European Society of Hypertension. Part I: Methodological issues for assessment in the different vascular beds. Journal of Hypertension, v. 23, p. 7$17,2005$.

DEMUTH, K.; ATGER, V.; BORDERIE, D.; BENOIT, M. O.; SAUVAGET, D.; LOTERSZTAJN, S.; MOATTI, N. Homocysteine decreases endothelin-1 production by cultured human endothelial cells. European Journal of Biochemistry, v. 263, p. 367-376, 1999.

DEMUTH, K.; DRUNAT, S.; GIRERD, X.; MOATTI, N.; PAUL, J.L.; SAFAR, M.; BOUTOUYRIE, P. Homocysteine is the only plasma thiol associated with carotid artery remodeling. Atherosclerosis, v. 165, p. 167-174, 2002.

DE NICOLA L.; BLANTZ, R. C.; GABBAI, F. B. Nitric oxide and angiotensin II. Glomerular and tubular interaction in the rat. The Journal of Clinical Investigation, v. 89, p. 12481256, 1992.

D'ORLÉANS-JUSTE, P.; LABONTE, J.; BKAILY, G.; CHOUFANI, S.; PLANTE, M.; HONORE, J. C. Function of the endothelin B receptor in cardiovascular physiology and pathophysiology. Pharmacology \& Therapeutics, v. 95, p. 221-238, 2002. 
DROGE, W. Free radicals in the physiological control of cell function. Physiological Reviews, v. 82, p. 47-95, 2002.

ENGLISH, K. M.; JONES, R. D.; JONES, T. H.; MORICE, A. H.; CHANNER, K. S. Aging reduces the responsiveness of coronary arteries from male Wistar rats to the vasodilatory action of testosterone. Clinical Science, v. 99, p. 77-82, 2000.

FERMINO, S. L; CLAUDINO, M. A.; TIRAPELLI, C. R.; MORQUETTI, M.; TIRAPELLI, D. P. C.; BATALHÃO, M. E.; CARNIO, E. C.; QUEIROZ, R. H.; EVORA, P. R. B.; TUCCI JR., S.; COLOGNA, A.; MARTINS, A. C.; TIRAPELLI, L. Chronic ethanol consumption induces cavernosal smooth muscle dysfunction in rats. Urology, v. 74, p. 6, 2009.

FILIPPI, S.; PARENTI, A.; DONNINI, S.; GRANGER, H. J.; FAZZINI, A.; LEDDA, F. Alpha (1D)-adrenoceptores cause endothelium-dependent vasodilatation in the rat mesenteric vascular bed. Journal of Pharmacology Experimental Therapy, v. 296, p. 869-875, 2001.

FINKELSTEIN, J. D. Methionine metabolism in mammals. The Journal of Nutritional Biochemistry, v. 1, p. 228-237, 1990.

FORSTERMANN, U.; MUNZEL, T. Endothelial Nitric Oxide Synthase in vascular disease from marvel to menace. Circulation, v. 113, p. 1708-1714, 2006.

FRIDOVICH, I. Superoxide anion radical $\left(\mathrm{O}_{2}{ }^{-}\right)$, superoxide dismutases, and related matters. The Journal of Biological Chemistry, v. 272, p. 18515-18517, 1997.

FURGHGOTT, R. F.; BURSZTYN, P. Comparison of dissociation constants and of relative efficacies of selected agonists acting on parasympathetic receptors. Annals of the New York Academy of Science, v. 139, p. 882-899, 1967.

GAO, Y-J.; HIROTA, S.; ZHANG, D-W.; JANSSEN, L. J.; LEE, R. M. K. W. Mechanisms of hydrogen-peroxide-induced biphasic response in rat mesenteric artery. British Journal of Pharmacology, v. 138, p. 1085-1092, 2003.

GARCÍA-CAZARÍN, M. L.; SMITH, J. L.; OLSZEWSKI, K. A.; MCCUNE, D. E.; SIMMERMAN, L. A.; HADLEY, R. W.; KRANER, S. D.; PIASCIK, M.T. The $\alpha_{1 \mathrm{D}}$-adrenergic receptor is expressed intracellularly and coupled to increases in intracellular calcium and reactive oxygen species in human aortic smooth muscle cells. Journal of Molecular Signaling, v. 3, n. 6, p. 1-9, 2008.

GONGORA, M. C.; QUIN, Z.; LAUDE, K.; KIM, H. W.; McCANN, L.; FOLZ, J. R.; DIKALOV, S.; FUKAI, T.; HARRISON, D. G. Role of extracellular superoxide dismutase in hypertension. Hypertension, v. 48, p. 473-481, 2006 
GRANCHI, S.; VANNELLI, G. B.; VIGNOZZI, L.; CRESCIOLI, C.; FERRUZZI, P.; MANCINA, R.; VINCI, M. C.; FORTI, G.; FILIPPI, S.; LUCONI, M.; LEDDA, F.; MAGGI, M. Expression and regulation of endothelin-1 and its receptors in human penile smooth muscle cells. Molecular Human Reproduction, v. 8, n. 12, p. 1053-64. 2002

HAMELET, J.; SELTZER, V.; PETIT, E.; NOLL, C.; ANDREAU, K.; DELABAR, J. M.; JANEL, $\mathrm{N}$. Cystathionine beta synthase deficiency induces catalase-mediated hydrogen peroxide detoxification in mice liver. Biochimica et Biophysica Acta - Molecular Basis of Disease, v. 1782 , n. $7-8$, p. $482-488,2008$.

HANAFY, K. A.; KRUMENACKER, J. S.; MURAD, F. NO, nitrotyrosine and GMPc in signal transduction. Medical Science Monitor, v. 7, n. 4, p. 801-819, 2001.

HARKER, L. A.; ROSS, R.; SLICHTER, S. J.; SCOTT, C. R. Homocysteine-induced atherosclerosis: the role endothelial cell injury and platelet response in its genesis. The Journal of Clinical Investigation, v. 58, p. 731-741, 1976.

HEDLUND, H.; ANDERSSON, K. E. Contraction and relaxation induced by some prostanoids in isolated human penile erectile tissue and cavernous artery. The Journal of Urology, v. 134, p. 1245-1250, 1985.

HIDALGO, C.; DONOSO, P. Crosstalk Between Calcium and Redox Signaling: From Molecular Mechanisms to Health Implications. Antioxidants \& Redox Signaling, v. 10, p. 138, 2008.

HOLMQUIST, F.; KIRKEBY, H. J.; LARSSON, B.; FORMAN, A.; ALM, P.; ANDERSSON, K. E. Functional effects, binding sites and immunolocalization of endothelin-1 in isolated penile tissues from man and rabbit. The Journal of Pharmacology and Experimental Therapeutics, v. 261, n. 2, p. 795-802, 1992.

HUCKS, D.; THURAISINGHAM, R. C.; RAFTERY, M. J.; YAQOOB, M. M. Homocysteine induced impairment of nitric oxide-dependent vasorelaxation is reversible by the superoxide dismutase mimetic TEMPOL. Nephrology, Dialysis, Transplantation, v. 19, p. 1999-2005, 2004.

IGNARRO, L. J. Nitric oxide - biology and pathobiology. San diego, Califórnia: Academic Press, 2000, 1003p.

INOUE, A.; YANAGISAWA, M.; KIMURA, S.; KASUYA, Y.; MIYAUCHI, T.; GOTO, K.; MASAKI, T. The human endothelin family: three structurally and pharmacology distint isopeptides predicted by three separates genes. Proceedings of the National Academy of Sciences of the United States of America, v. 86, p. 2863-2867, 1989. 
JAKUBOWSKI, H. Calcium-dependent human serum homocysteine thiolactone hydrolase. A protective mechanism against protein $\mathrm{N}$-homocysteinylation. The Journal of Biological Chemistry, v. 275, p. 3957-3962, 2000.

JAKUBOWSKI, H. Homocysteine is a protein amino acid in humans. Implications for homocysteine-linked disease. The Journal of Biology Chemistry, v. 277, p. 30425-30428, 2002.

JEREMY, J. Y.; JONES, R. A.; KOUPPARIS, A. J.; HOTSTON, M.; PERSAD, R.; SHUKLA, N. Oxidative stress and erectile dysfunction: possible role of NADPH oxidase. International Journal of Impotence Research, v. 175, p. 1175-6, 2006.

JOHNSON, F.; GIULIVI, C. Superoxide dismutases and their impact upon human health. Molecular Aspects of Medicine, v. 26, p. $340-352,2005$.

JONES, R. W.; JEREMY, J. Y.; KOUPPARIS, A.; PERSAD, R.; SHUKLA, N. Cavernosal dysfunction in a rabbit model of hyperhomocysteinaemia. BJU International, v. 95, p. 12530, 2005.

JUST, A.; WHITTEN, C. L.; ARENDSHORT W. J. Reactive oxygen species participate in acute renal vasoconstrictor responses induced by ETA and ETB Reactive oxygen species participate in acute renal receptors. American Journal of Physiology. Renal Physiology, v. 294, p. F719-F728, 2008. doi:10.1152/ajprenal.00506.2007

KANANI, P. M.; SINKEY, C. A.; BROWNING, R. L.; ALLAMAN, M.; KNAPP, H. R.; HAYNES, W. G. Role of oxidant stress in endothelial dysfunction produced by experimental hyperhomocysteinemia in humans. Circulation, v. 100, p. 1161-1168, 1999.

KANG, S. S.; WONG, P. W.; MALLINOW, M. R. Hyperhomocysteinemia as a risk factor for occlusive vascular disease. Annual review of nutrition, v. 12, p. 279-284, 1992.

KENAKIN, T. P. Pharmacologic analysis of drug-rececptor interation. Efficacy LippincortRaven, 3. Ed, p. 289-330, 1997.

KIFOR, I.; WILLIAMS, G. H.; VICKERS, M. A.; SULLIVAN, M. P.; JODBERT, P.; DLUHY, R. G. Tissue angiotensin II as a modulator of erectile function. I. Angiotensin peptide content, secretion and effects in the corpus cavernosum. The Journal of Urology, v. 157, p. 19201925, 1997.

LACY, F.; GOUGH, D. A.; SCHMID-SCHONBEIN, G. W. Role of xanthine oxidase in hydrogen peroxide production. Free Radical Biology \& Medicine, v. 25, p. 720 -727, 1998.

LEE, I.; LEE, H.; KIM, J.; CHAE, E. H.; KIM, S. J.; CHANG, N. Short-Term hyperhomocysteinemia-induced oxidative stress activates retinal glial cells and increases 
vascular endothelial growth factor expression in rat retina. Bioscience, Biotechnology, and Biochemistry, v. 71, n. 5, p. 1203-1210, 2007.

LEITE, R.; GIACHINI, F. R.; CARNEIRO, F. S.; NUNES, K.P.; TOSTES, R. C.; WEBB, R.C. Targets for the treatment of erectile dysfunction: is NO/cGMP still the answer? Recent Patents on Cardiovascular Drug Discovery, v. 2, n. 2, p. 119-32, 2007.

LI, N.; YI, F. X.; RUTE, E.; ZHANG, D. X.; SLOCUM, G. R.; ZOU, A. P. Effects of homocysteine on intracellular nitric oxide and superoxide levels in the renal arterial endothelium. American Journal of Physiology. Heart and Circulatory Physiology, v. 283, p. H1237-h243, 2002.

LIU, Z.; ZHAO, H.; LI, H.; KALYANARAMAN, B.; NICOLOSI, A. C.; GUTTERMAN, D. D. Mitochondrial sources of $\mathrm{H} 2 \mathrm{O} 2$ generation play a key role in flow-mediated dilation in human coronary resistance arteries. Circulation Research, v. 93, p. 573- 80, 2003.

LOSCALZO, J. The oxidative stress of hyperhomocysteinemia. The Journal of Clinical Investigation, v. 98, p. 5-7, 1996.

LUE, T. F. Erectile dysfunction. The New England Journal of Medicine, v. 342, p. 1802-13, 2000.

LUE, T. Physiology of penile erection and pathophysiology of erection dysfunction and priapism. In: Wash, P.; RETIK, A.; VAUGHAN, E.; WEIN, A.; editors. Campbell's Urology. $8^{\text {th }}$ ed. Philadelphia: Saunders, p. 1561-618, 2003.

LUPATTELLI, G.; RUFINI, S.; LOCATI, E. H.; LOMBARDINI, R.; CIUFFETTI, G.; SIEPI, D.; MANNARINO, E. Hyperhomocysteinemia is associated with carotid atherosclerosis. Angiology, v. 50, p. 823-830, 1999.

MAAS, R.; SCHWEDHELM, E.; ALBSMEIER, J.; BOGER, R. H. The pathophysiology of erectile dysfunction related to endothelial dysfunction and mediators of vascular function. Vascular Medicine, v. 7, p. 213-225, 2002.

MARNETT, L. J., BUCK, J.; TUTTLE, M. A.; BULL, A. W. Distribution and oxidation of malondialdehyde in mice. Prostaglandins, v.30, p. 241-254, 1985.

MASAKI, T. Possible role of endothelin in endothelial regulation of vascular tone. Annual Review of Pharmacology and Toxicology, v. 35, p. 235-255, 1995.

MASAKI, T. The endothelin family: an overview. Journal of Cardiovascular Pharmacology, v. 35, p. S3-S5, 2000. Suppl. 2. 
MATOBA, T.; SHIMOKAWA, H.; NAKASHIMA, M.; HIRAKAWA, Y.; MUKAI, Y.; HIRANO, K.; KANAIDE, H.; TAKESHITA, A. Hydrogen peroxide is an endothelium-derived hyperpolarizing factor in mice. The Journal of Clinical Investigation, v. 106, p. 1521-1530, 2000.

MILLS, T. M.; CHITALEY, K.; WINGARD, C. J.; LEWIS, R. W.; WEBB, R. C. Effect of RhoKinase inhibition on vasoconstriction in the penile circulation. Journal of Applied Physiology, v. 91, p. 1269-73, 2001.

MILLS, T. M.; LEWIS, R. W.; STOPPER, V.S. Androgenic maintenance of inflow and venoocclusion during erection in the rat. Biology of Reproduction, v. 59, p. 1413-1418, 1998.

MILLS, T. M.; POLLOCK, D. M.; LEWIS, R. W.; BRANAM, H. S.; WINGARD, C. J. Endothelin-1-induced vasoconstriction is inhibited during erection in rats. American Journal of Physiology. Regulatory, Integrative and Comparative Physiology, v. 281, p. R476R483, 2001a.

MINNEMAN, K. P. Alpha ${ }_{1}$-adrenergic receptor subtypes, inositol phosphates and sources of cell calcium. Pharmacology Review, v. 40, p. 87-119, 1988.

MONCADA, S.; PALMER, R. M. J. HIGGS, E. A. Nitric oxide: physiology, pathophysiology, and pharmacology. Pharmacology Review, v. 43, p. 109-142, 1991.

MORELAND, R. B.; ALBADAWI, H.; BRATTON, C.; PATTON, G.; GOLDSTEIN, I.; TRAISH, A.; WATKINS, M. T. $\mathrm{O}_{2}$ dependent prostanoid synthesis activates functional PGE receptors on corpus cavernosum smooth muscle. American Journal of Physiology. Heart and Circulatory Physiology, v. 281, p. H552-H558, 2001.

MORROW, J. D.; HILL, K. E.; BURK, R. F.; NAMMOUR, T. M.; BADR, K. F.; ROBERTS, J. L. A series of prostaglandin F2-like compounds are produced in vivo in humans by a noncycloxygenase, free redical-catalyzed mechanism. Proceedings of the National Academy of Sciences of the United States of America, v. 87, p. 9383-9387, 1990.

MUMTAZ, F. H.; LAW, D. H. W.; SIDDIQUI, E. J.; THOMPSON, C. S.; MORGAN, R. J.; MIKHAILIDIS, D. P. Pharmacological Properties of Endothelin-1 in the Rabbit Corpus Cavernosum. In vivo, v. 20, p. 243-246, 2006.

NIH consensus development panel on impotence. NIH consensus conference: impotence. Jama, v. 270, p. 83-90, 1993.

NOLL, G.; WENZEL, P. R.; LUSCHER, T. F. Endothelins and endothelin antagonists: potencial role in cardiovascular and renal disease. Molecular and Cellular Biochemistry, v. 157, p. 259-267, 1996. 
NONAKA, H.; TSUJINO, T.; WATARI, Y.; EMOTO, N.; YOKOYAMA, M. Taurine Prevents the Decrease in Expression and Secretion of Extracellular Superoxide Dismutase Induced by Homocysteine: Amelioration of Homocysteine-Induced Endoplasmic Reticulum Stress by Taurine. Circulation, v. 104, p.1165-1170, 2001 doi: 10.1161/hc3601.093976.

PARAVICINI, T. M.; CHRISSOBOLIS, S.; DRUMMOND, G. R.; SOBEY, C. G. Increased $\mathrm{NAD}(\mathrm{P}) \mathrm{H}$-oxidase activity and Nox4 expression during chronic hypertension is associated with enhanced cerebral vasodilatation to $\mathrm{NAD}(\mathrm{P}) \mathrm{H}$ in vivo. Stroke, v. 35, p. 584-589, 2004.

PARKKISENNIEMI, U. M.; KLINGE, E. Functional characterization of endothelin receptors in the bovine retractor penis muscle and penile artery. Pharmacology \& Toxicology, v. 79, n. 2, p. 73-9. 1996.

PODDAR, R.; SIVASUBRAMANIAM, N.; DiBELLO, P. M.; ROBINSON, K.; JACOBSEN, D.; DONALD, W. Homocysteine induces expression and secretion of monocyte chemoattractant protein-1 and interleukin-8 in human aortic endothelin cells: implications for vascular diseases. Circulation, v. 103, p. 2717-2723, 2001.

RAJFER, J.; ARONSON, W. J.; BUSH, P. A.; DOREY, F. J.; IGNARRO, L. I. Nitric oxide as a mediator of relaxation of the corpus cavernosum in response to nonadrenergic, noncholinergic neurotransmission. The New England Journal of Medicine, v. 326, n. 2, p. 90-4. 1992.

REDDY, G. S.; WILCKEN, D. E. Experimental homocysteinemia in pigs: comparison with studies in sixteen homocystinuric patients. Metabolism, v. 31, p. 778-783, 1982.

RICHTER, V.; JANKE, C.; PURSCHWITZ, K.; KLOTZER, B.; GEISEL, J.; HERRMANN, W.; RASSOUL, F. Plasma homocysteine and lipoprotein profile in patients with peripheral arterial occlusive disease. Angiology, v. 5, p. 189-96, 2000.

ROY, A. C.; TAN, S. M.; KOTTEGODA, S. R.; RATNAM, S. S. Ability of human corpora cavernosa muscle to generate prostaglandins and thromboxanes in vitro. IRCS Medical Science, v. 12, p. 608-609, 1984.

SADEGHIPOUR, H.; GHASEMI, M.; NOBAKHT, M.; EBRAHIMI, F.; DEHPOUR, A. R. Effect of chronic lithium administration on endothelium-dependent relaxation of rat corpus cavernosum: the role of nitric oxide and cyclooxygenase pathways. BJU International, v. 99, p. 177-182, 2006.

SAENZ DE TEJADA, I.; GOLDSTEIN, I.; KRANE, R. J. Local control of penile erection. Nerves, smooth muscle, and endothelium. The Urologic Clinics of North America, v. 15, p. 9-15, 1988. 
SÁNCHEZ, A.; CONTRERAS, C.; VILLALBA, N.; MARTÍNEZ, P.; MATÍNEZ, A. C.; BRÍONES, A.; SALAÍCES, M.; GARCÍA-SACRISTÁN, A.; HERNÁNDEZ, M.; PRIETO, D. Altered arachidonic acid metabolism via COX-1 and COX-2 contributes to the endothelial dysfunction of penile arteries from obese Zucker rats. British Journal of Pharmacology, v. 159 , p. 604-616, 2010.

SCHNYDER, G.; FLAMMER, Y.; ROFFI, M.; PIN, R.; HESS, O. M. Plasma homocysteine levels and late outcome after coronary angioplasty. Journal of the American College of Cardiology, v. 40, p. 1769-1776, 2002.

SEASHOLTZ, T. M.; MAJUMDAR, M.; BROWN, J. H. Rho as a mediator of G proteincoupled receptor signaling. Molecular Pharmacology, v. 55, n. 6, p. 949-956, 1999.

SELHUB, J. Homocysteine metabolism. Annual Review of Nutrition, v. 19, p. 217-46, 1999.

SELHUB, J.; JACQUES, P. F.; WILSON, P. W. F.; RUSH, D.; ROSENBERG, I. H. Vitamin status and intake as primary determinants of homocysteinemia in an elderly population. The Journal of the American Medical Association, v. 270, p. 2693-8, 1993.

SELHUB, J.; MILLER, J. W. The pathogenesis of homocysteinemia: interruption of the coordinate regulation by S-adenosylmethionine of the remethylation and transulfuration of homocysteine. The American Journal of Clinical Nutrition, v. 55, p. 131-8, 1992.

SHI, Y.; VANHOUTTE, P. M. Oxidative stress and COX cause hyper-responsiveness in vascular smoth muscle of the femoral artery from diabetic rats. British Journal of Pharmacology, 1-13, 2008.

SHUKLA, N.; THOMPSON, C. S.; ANGELINI, G. D.; MIKHAILIDIS, D. P.;JEREMY, J. Y. Homocysteine enhances impairment of endothelium-dependent relaxation and guanosine cyclic monophosphate formation in aortae from diabetic rabbits. Diabetologia, v. 45, n. 9, p. 1325-31, 2002.

SINDHU, R. K.; EHDAIE, A.; FARMAND, F.; DHALIWAL, K. K.; NGUYEN, T. ZHAN, C. D.; ROBERTS, C. K.; VAZIRI, N. D. Expression of catalase and glutathione peroxidase in renal insufficiency. Biochimica et Biophysica Acta, v. 1743, p. 86-92, 2005.

SUI, H.; WANG, W.; WANG, P. H.; LIU, L. S. Effect of glutathione peroxidase mimic ebselen (PZ51) on endothelium and vascular structure of stroke-prone spontaneously hypertensive rats. Blood Pressure, v. 14, p. 366-372, 2005.

TOPAL, G.; BRUNET, A.; MILLANVOYE, E.; BOUCHER, J.; RENDU, F.; DEVYNCK, M.; DAVID-DUFILHO, M. Homocysteine induces oxidative stress by uncoupling of no synthase activity through reduction of tetrahydrobiopterin. Free Radical Biology \& Medicine, v. 36, n. 12, p. 1532-1541, 2004. 
TOQUE, H. A. ; DA SILVA, F. H. ; SCHENKA, A. A. ; SAAD, M. J. ; CALIXTO, M. C. ; LINTOMEN, L. ; ZANESCO, A. ; ANTUNES, E. High-fat diet associated with obesity induces impairment of mouse corpus cavernosum responses. BJU International, doi:10.1111/j.1464410X.2010.09704.x, 2010.

TOUYZ, R. M. ; SCHIFFRIN, E. L. Signal Transduction Mechanisms Mediating the Physiological and Pathophysiological Actions of Angiotensin II in Vascular Smooth Muscle Cells. Pharmacological Reviews, v. 52, n. 4, p. 639-72, 2000.

TSAI, J. C.; PERRELLA, M. A.; YOSHIZUMI, M.; HSIEH, C. M.; HABER, E.; SCHLEGEL, R.; LEE, M. E. Promotion of vascular smooth muscle cell growth by homocysteine: a link to atherosclerosis. Proceedings of the National Academy of Sciences of the United States of America, v. 91, p. 6369-6373, 1994.

TYAGI, S. C. Homocysteine redox receptor and regulation of extracellular matrix components in vascular cells. The American Journal of Physiology, v. 274, p. C306-C405, 1998.

UBBINK J.B.; VERMAAK W.J.H.; VAN DER MERWE A.; BECKER P.J. Vitamin B12, vitamin B6 and folato nutritional status in men with hyperhomocysteinemia. The American Journal of Clinical Nutrition, v. 57, p. 47-53, 1993.

UELAND, P. M.; REFSUM, H.; STABLER, S. P.; MALINOW, M. R.; ANDERSSON, A.; ALLEN, R. H. Total homocysteine in plasma or serum: methods and clinical applications. Clinical Chemistry, v. 39, p. 1764-79, 1993.

UNGVARI, Z.; PACHER, P.; RISCHAK, K.; SZOLLAR, L.; KOLLER, A. Dysfunction of nitric oxide mediation in isolated rat arterioles with methionine diet-induced hyperhomocysteinemia. Arteriosclerosis, Thrombosis, and Vascular Biology, v. 19, p. 1899-1904, 1999.

UNGVARI, Z.; SARKADI-NAGY, E.; BAGI, Z.; SZOLLAR, L.; KOLLER, A. Simultaneously increased $\operatorname{TxA}(2)$ activity in isolated arterioles and platelets of rats with hyperhomocysteinemia. Arteriosclerosis, Thrombosis, and Vascular Biology, v. 20, p. 1203-1208, 2000.

UPCHURCH, G. R. Jr.; WELCH, G. N.; FABIAN, A. J. Homocysteine decreases bioavailable nitric oxide by a mechanism envolving gluthatione peroxidase. The Journal of Biological Chemistry, v. 272, p. 17012-17017, 1997.

VIGNOZZI, L.; FILIPPI, S.; MORELLI, A.; AMBROSINI, S.; LUCONI, M.; VANNELLI, G. B.; DONATI, S., CRESCIOLI, C.; ZHANG, X-H.; MIRONE, V.; FORTI, G.; MAGGI, M. Effect of chronic tadalafil administration on penile hypoxia induced by cavernous neurotomy in the rat. The Journal of Sexual Medicine, v. 3, p. 419-431, 2006. 
WALL, R. T.; HARLAN, J. M.; HARKER, L. A.; STRIKER, G. E. Homocysteine-induced endothelial cell injury in vitro: a model for the study at vascular injury. Thrombosis Research, v. 18, p. 113-121, 1980.

WANG, J.; DUDMAN, N. P.; WILCKEN, D. E. Effects of homocysteine and relates compounds on prostacyclin production by cultures human vascular endothelin cells. Thrombosis and Haemostasis, v. 70, p. 1047-1052, 1993.

WANG, S.; WRIGHT, G.; HARRAH, J.; TOUCHON, R.;McCUMBEE, W.;GENG, W.;FULTZ, M. E.; ABDUL-JALIL, M. N.; WRIGHT, G. L. Short-term exposure to homocysteine depresses rat aortic contractility by an endothelium-dependent mechanism. Canadian Journal of Physiology and Pharmacology, v. 78, n. 6, p. 500-506, 2000.

XIAO, L.; PIMENTEL, D. R.; WANG, J.; SINGH, K.; COLUCCI, W. S.; SAWYER, D. B. Role of reactive oxygen species and $\mathrm{NAD}(\mathrm{P}) \mathrm{H}$ oxidase in alpha1-adrenoceptor signaling in adult rat cardiac myocytes. American Journal of Physiology Cell Physiology, v. 282, p. C926C934, 2002.

YANAGISAWA, W.; KURIHARA, H.; KIMURA, S.; TOMOBE, T. Y.; KOBAYASHI, M.; MITSUI, Y.; YAZAKI, Y.; GOTO, K.; MASAKI, T. A novel potent vasoconstrictor produced by vascular endothelial cells. Nature, v. 332, p. 411-415, 1988.

ZHANG, K.; LI, H.; JIN, H.; EBIN, Z.; BRODSKY, S.; GOLIGORSKY, M. S. Effects of homocysteine on endothelial nitric oxide production. American Journal of Physiology. Renal Physiology, v. 279, n. 4, p. F671-8, 2000.

ZHONG, H.; MINNEMAN, K. P. Alpha-1-adrenoceptor subtypes. European Journal of Pharmacology, v. 375, p. 261-276, 1999.

ZUBKOV, A.; MIAO, L.; ZHANG, J. Signal transduction of ET-1 in contraction of cerebral arteries. Journal of Cardiovascular Pharmacology, v. 44, p. S24-6. 2004. Supplement 1.

ZULLI, A.; BUXTON, B. F.; DOOLAN, L.; LIU, J. J. Augmented effects of methionine and cholesterol in decreasing the elastic lamina while thickening the aortic wall in the rat aorta. Clinical Science, v. 95, p. 589-593, 1998. 
Apêndice 


\section{Apêncice A - Determinação da tensão basal}

A PhE induziu contração dependente da tensão basal aplicada em corpos cavernosos de ratos controle e HHcy. Os resultados mostraram que a contração induzida pela PhE é crescente entre 0,1 e 0,3 g e, após este valor, começa a reduzir.

Os Emax da $\mathrm{PhE}$ não foram significativamente diferentes em corpos cavernosos de ratos controle e HHcy, mostrando que o tratamento não alterou a tensão basal à qual o corpo cavernoso deverá ser submetido. Deste modo, para a realização dos protocolos funcionais, adotou-se a tensão de $0,25 \mathrm{~g}$ que corresponde a aproximadamente $80 \%$ da resposta máxima (Figura 40 ).

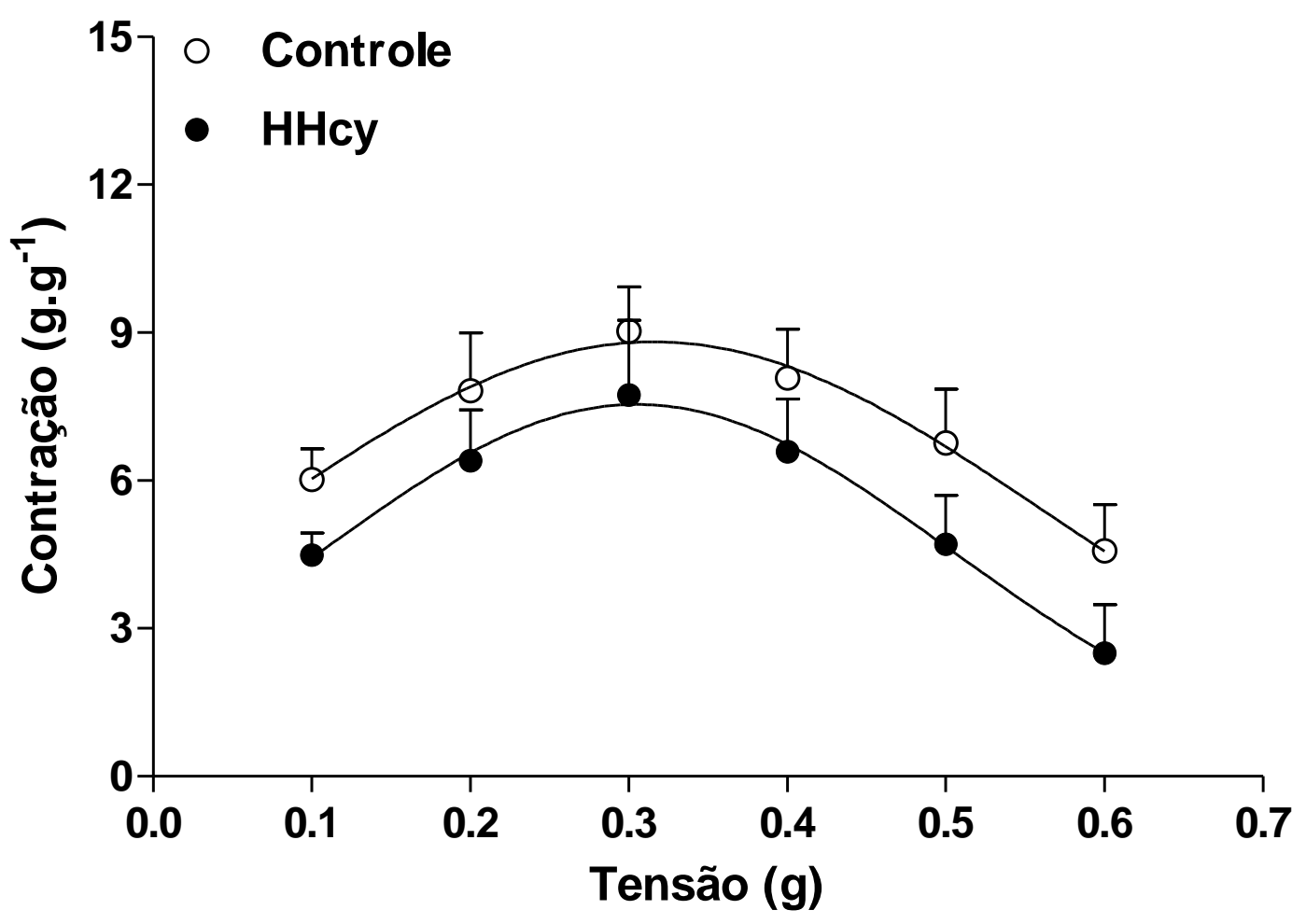

Figura 40: Curvas de tensão realizadas em corpos cavernosos de ratos controle e HHcy. As preparações foram mantidas por 45 minutos em tensões crescentes (indicadas no gráfico) e em seguida, estimuladas com PhE $\left(10^{-5} \mathrm{~mol} / \mathrm{L}\right)$. Os pontos representam a média \pm E.P.M. $(n=5$ para o grupo controle e $n=8$ para 0 grupo H Hcy). 
Anexo 


\author{
UNIVERSIDADE DE SÃO PAULO \\ Campus de Ribeirão Preto \\ Comissão de Ética no Uso de Animais
}

\title{
C E R T I F I C A D O
}

Certificamos que o trabalho (Protocolo $n^{\circ}$ 10.1.364.53.5), intitulado "Consequências da Hiperhomocisteinemia sobre o Sistema Endotelina em Corpo Cavernoso de Ratos", de autoria de Hariane Côco e de Ana Maria de Oliveira por estar de acordo com os Princípios Éticos na Experimentação Animal adotado pela Comissão de Ética no Uso de Animais (CEUA) do Campus de Ribeirão Preto - USP foi aprovado em reunião da CEUA de 09/09/2010.

This is to certify that the work (Protocol number 10.1.364.53.5), entitled: "Consequências da Hiperhomocisteinemia sobre o Sistema Endotelina em Corpo Cavernoso de Ratos", by Hariane Côco and Ana Maria de Oliveira, is in accordance with the Ethic Principles in Animal Experimentation adopted by Ethic Commission for the Use of Animals (CEUA) of the Campus of Ribeirão Preto - USP, and was approved in the meeting, September 09, 2010.

Ribeirão Preto, 10 de setembro de 2010

Eristue Lettianim.

Presidente da CEUA

Profa.Dra. Christie Ramos Andrade Leite Panissi

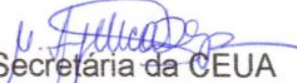

Secretaria da CEUA

Marjal Angélica Depiro

Av. Bandeirantes, 3900 - CEP 14040-900 - Ribeirão Preto - São Paulo Fone: (16) 36024469 - Fax. (16) 36337964 